\title{
Um Método para a Implementação de Regras de Negócio a partir da Semântica SBVR
}

Jandisson Soares de Jesus

DissertaÇÃo Apresentada

$\mathrm{AO}$

Instituto DE MATEMÁtica E EstatísticA

DA

Universidade De SÃo Paulo

PARA

OBTENÇÃO DO TÍTULO

$\mathrm{DE}$

Mestre em CiÊnCIAS

Programa: Ciência da Computação

Orientador: Prof. Dra. Ana C. V. de Melo 


\section{Um Método para a Implementação de Regras de Negócio a partir da Semântica SBVR}

Esta versão da dissertação contém as correções e alterações sugeridas pela Comissão Julgadora durante a defesa da versão original do trabalho, realizada em 04/11/2013. Uma cópia da versão original está disponível no

Instituto de Matemática e Estatística da Universidade de São Paulo.

Comissão Julgadora:

- Prof ${ }^{\mathrm{a}}$. Dr ${ }^{\mathrm{a}}$. Ana Cristina Vieira de Melo (Presidente) - IME-USP

- Prof. Dr. Paulo Sérgio Muniz Silva - EP-USP

- Prof. Dr. Hermano Perreli de Moura - UFPE 


\section{Agradecimentos}

Primeiramente agradeço a Deus por cumprir suas promessas ao me ajudar a finalizar esta etapa tão importante da minha formação.

A toda a minha família por todo o suporte que me foi dado durante os anos dedicados a conclusão deste trabalho como também durante toda a minha vida.

Como representante de tantas pessoas que acreditaram em mim, agradeço a minha querida e eterna professora de matemática Marta Argolo. Especialmente por exercer, com seu exemplo de pessoa, a forma mais eficaz de ensino.

Agradeço a minha orientadora Dra. Ana Cristina Vieira de Melo pela dedicação e paciência. Sem suas observações e direcionamentos, esse trabalho não teria sido finalizado.

Por fim, agradeço aos meus amigos Helio, Diogo, Wesley, Edmar, Pedro, Edson, Silas, Samuel, Alexandre e Fábia por me ajudarem direta ou indiretamente durante a realização deste trabalho.

Muito Obrigado!

Eis que o temor do Senhor é a sabedoria, e apartar-se do mal é a inteligência. Jó 28:28 



\section{Resumo}

Jesus, J. Um Método para a Implementação de Regras de Negócio a partir da Semântica SBVR. 2013. 105 f. Dissertação (Mestrado) - Instituto de Matemática e Estatística, Universidade de São Paulo, São Paulo, 2013.

A implementação das regras de negócio em sistemas de informação não é uma atividade trivial. Isso acontece porque os modelos utilizados para representá-las não determinam como elas podem ser efetivamente implementadas em situações reais. Neste trabalho é proposta um método para a transformação das regras de negócio descritas em SBVR para um modelo de implementação. Essa tradução é feita mapeando todos os elementos relevantes do modelo em SBVR em um modelo em $\pi$-calculus baseado em eventos. Neste modelo, existe uma representação explícita de todos os eventos que precisam ser monitorados a fim de identificar quando a regra pode ter sido violada. O objetivo é facilitar o gerenciamento das regras de negócio ao permitir que elas permaneçam separadas dos outros elementos da arquitetura e com isso possam ser gerenciadas de forma independente.

Palavras-chave: Regras de negócio, SBVR, $\pi$-calculus. 



\section{Abstract}

Jesus, J. A method to business rule implementation from SBVR semantic. 2013.

105 f. Dissertação (Mestrado) - Instituto de Matemática e Estatística, Universidade de São Paulo, São Paulo, 2013.

The implementation of business rules in an information system is not an easy task. This happens because most of the models used to represent them capture only the meaning of the rules and do not provide means to make them to be effectively implemented. In this work we provide an approach for the translation from a SBVR semantic description of business rules into a implementation model. This was done by mapping all relevant elements of the SBVR semantic representation into a $\pi$-calculus event-driven model. On this model will be described explicitly all the events that must be monitored in order to identify when some rule may have been violated. This makes the business rule implementation easier because there is a explicit indication of the moment when make sense to do a verification in order to see if any rule was violated. Besides that, it easier the business rule management since the rules stay separate from the others elements of the system architecture and in this way can be managed independently.

Keywords: Business Rules, SBVR, $\pi$-calculus. 



\section{Sumário}

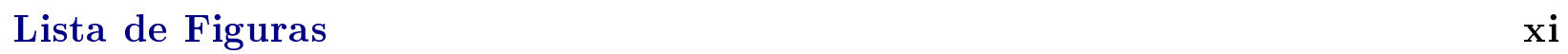

Lista de Tabelas $\quad$ xiii

1 Introdução $\quad 1$

1.1 Desenvolvimento de software com Regras de Negócio . . . . . . . . . . 5

1.1.1 Sistema exemplo - Comércio Eletrônico . . . . . . . . . . . . 5

1.1.2 Da especificação à implementação . . . . . . . . . . . . . . 7

1.2 Objetivos deste trabalho . . . . . . . . . . . . . . . . 9

1.3 Trabalhos relacionados . . . . . . . . . . . . . . . . 11

1.4 Organização da Dissertação . . . . . . . . . . . . . . . . . 13

2 Regras de Negócio $\quad 15$

2.0 .1 Características . . . . . . . . . . . . . . 17

2.0.2 Exemplos de Regras de Negócio . . . . . . . . . . . . . . . . 18

2.0.3 Tipos de Regras de Negócio . . . . . . . . . . . . . . . . 19

2.0.4 Origem das regras de negócio . . . . . . . . . . . . 20

2.1 Linguagens e modelos de representação . . . . . . . . . . . . . . . . 20

2.1.1 Rule Interchange Format - RIF . . . . . . . . . . . . . . 21

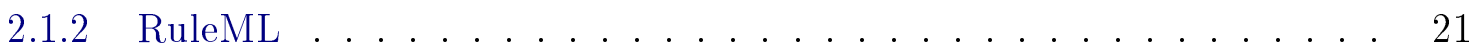

2.1.3 Semantics Of Business Vocabulary and Business Rules . . . . . . . 24

2.2 Tecnologias de Regras de Negócio . . . . . . . . . . . . . . . . . 24

2.2.1 Formas tradicionais de implementação . . . . . . . . . . . . . . . 24

2.2.2 Formas modernas de implementação . . . . . . . . . . . . 27 
3 Semantic of Business Vocabulary and Business Rules

3.1 Organização . . . . . . . . . . . . . . . . . . 36

3.1 .1 Comunidade Semântica . . . . . . . . . . . . . 36

3.1.2 Corpo de significado compartilhado . . . . . . . . . . . . . . 37

3.1 .3 Formulação . . . . . . . . . . . . . . . . . . 38

3.1 .4 Expressão . . . . . . . . . . . . . . . 38

3.2 Representação de regras de negócio em SBVR . . . . . . . . . . . . 38

3.3 Formulação semântica das regras de negócio . . . . . . . . . . . . . . . 40

3.3.1 Exemplos de formulação semântica . . . . . . . . . . . . . . . 41

4 Transformação de regras em SBVR para $\pi$-calculus $\quad 47$

4.0.2 As variáveis da formulação semântica SBVR e os eventos de violação. 50

4.1 Protocolo de comunicação . . . . . . . . . . . . . . . . 53

4.1.1 Representação de eventos em $\pi$-calculus . . . . . . . . . . . 53

4.1 .2 O protocolo de comunicação . . . . . . . . . . . . 55

4.2 Transformação de regras em SBVR para o protocolo de comunicação em $\pi$ -

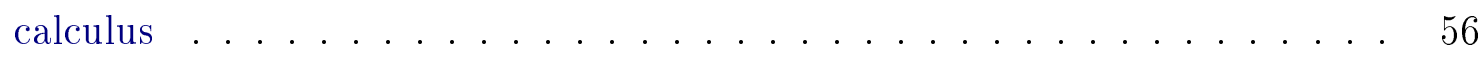

4.2.1 Método de Transformação de SBVR para $\pi$-calculus . . . . . . . . . . 57

4.3 Exemplos de transformação . . . . . . . . . . . . . . 58

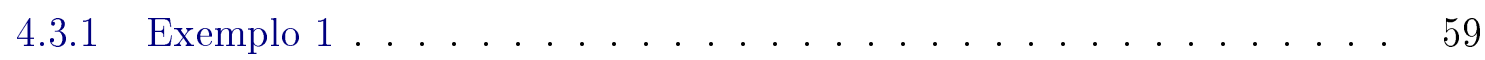

4.3 .2 Exemplo $2 \ldots \ldots \ldots \ldots \ldots \ldots$

5 Sistema exemplo $\quad 63$

5.1 Vocabulário de Negócio . . . . . . . . . . . . . . . . . . . 64

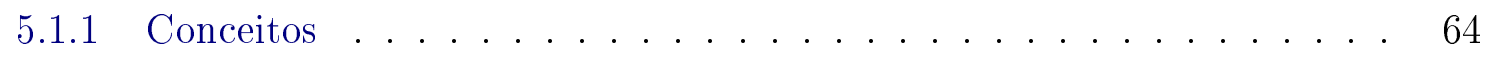

5.1 .2 Tipos de Fatos . . . . . . . . . . . . . . 65

5.2 Regras de negócio e a formulação semântica . . . . . . . . . . . . . 66

5.2 .1 Arquiteturas sugeridas . . . . . . . . . . . . . 72

5.3 Arquitetura sugerida para a solução do problema exemplo . . . . . . . . . 74

5.3.1 Papel dos modelos em $\pi$-calculus na Arquitetura da solução . . . . . 78 
6.1 Contribuições . . . . . . . . . . . . . . . . . . . 82

6.1.1 Protocolo de comunicação . . . . . . . . . . . . 82

6.1.2 Método de transformação . . . . . . . . . . . . . . . 83

6.2 Relação da proposta com a literatura . . . . . . . . . . . . . 83

6.3 Limitações . . . . . . . . . . . . . . . . . . . . 84

6.4 Trabalhos futuros . . . . . . . . . . . . . . . . 84

$\begin{array}{ll}\text { Referências Bibliográficas } & 87\end{array}$ 



\section{Lista de Figuras}

2.1 Visão geral da arquitetura do Drools Expert [Bal09] . . . . . . . . . . . . 30

3.1 Visão geral da especificação SBVR [Tea06] . . . . . . . . . . . . . . 37

3.2 Os elementos de direcionamento formam o corpo de elementos de direcionamentos compartilhados que por sua vez faz parte do corpo de significados compartilhados de uma organização. Esses elementos são utilizados para representar as regras e os avisos de uma comunidade semântica. Adaptado de

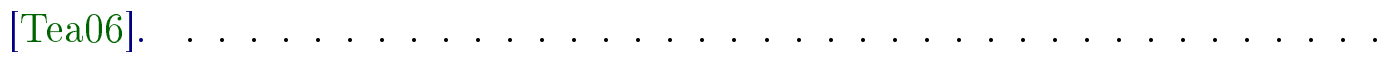

3.3 A formulação lógica, viabilizada pela SBVR, permite que as organizações definam formalmente o significado das expressões que elas utilizam. Adaptado

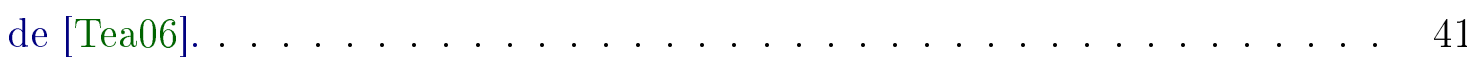

3.4 Os principais elementos do padrão SBVR para a formulação semântica. . . . 42

4.1 Estrutura das quantificações em SBVR. Imagem adaptada de [Tea06]. . . . 51

5.1 Diagrama conceitual dos elementos da aplicação utilizados no sistema exem-

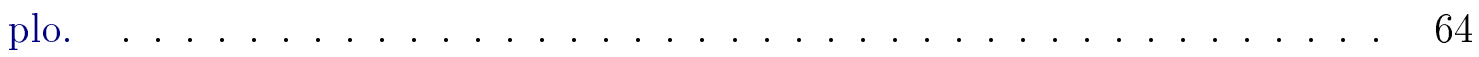

5.2 Arquitetura da proposta. . . . . . . . . . . . 76

5.3 Cada motor de regra utilizado nas aplicações que seguirem essa arquitetura de referência deverão ter um elemento que faça a adaptação entre a interface desse motor e o restante da arquitetura. Esse elemento será chamado de

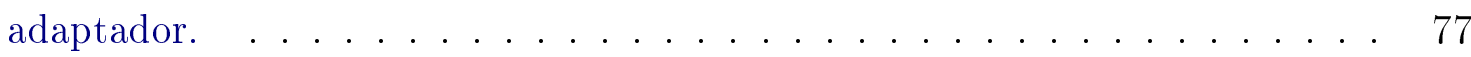





\section{Lista de Tabelas}

4.1 Principais construções sintáticas do $\pi$-calculus . . . . . . . . . . . . 54 



\section{Capítulo 1}

\section{Introdução}

Atualmente, é comum que uma grande parte das atividades realizadas por uma empresa seja feita com a ajuda de algum sistema informatizado [LP04]. Tal sistema automatiza processos, realiza cálculos, armazena e transforma informações. Para que um sistema, que supra as necessidades de uma organização, seja construído é, normalmente, necessário que algum processo de desenvolvimento de software seja empregado. Esse processo geralmente inclui atividades de análise, onde o objetivo é entender o que se espera do software e documentar esse entendimento por meio de diagramas, documentos, gravações, modelos e qualquer outro meio no qual o resultado dessa análise possa ser registrado.

Em grande parte dos processos de desenvolvimento, essas necessidades são divididas em requisitos que podem ser vistos como unidades que exprimem uma expectativa em relação a alguma característica do software a ser construído. Dessa forma, o conjunto dos requisitos identificados descreve o que se espera do software a ser construído, para que ele possa ser utilizado de forma satisfatória. Esses requisitos são classificados de várias formas. Alguns indicam quais funcionalidades o software deve disponibilizar aos usuários, outros estão relacionados às restrições de desempenho e ambiente enquanto outros estão relacionados às necessidades de negócio da organização. A essa última categoria de requisitos dá-se o nome de regras de negócio.

Regras de negócio são asserções que restringem ou dirigem a forma na qual uma organização opera [HH00]. Uma característica importante dessas regras é que elas surgem das estratégias e táticas da organização. São leis de alto nível criadas com o objetivo de 
efetivar as políticas adotadas pela organização ou são imposições feitas por organizações externas. Devido a essa proximidade com o contexto e os aspectos do negócio no qual as organizações estão inseridas, as regras de negócio desempenham um papel importante no desenvolvimento de um software empresarial $\left[\mathrm{N}^{+} 10\right]$. Entender esse papel ajuda analistas, engenheiros de softwares, programadores e todos os envolvidos a terem uma compreensão mais ampla a respeito do que deve construir e por que isso está sendo construído. Isso facilita a comunicação entre os interessados na construção do software e os responsáveis por essa construção.

\section{A necessidade de adaptação ao mercado}

Devido a um notável crescimento na importância dos sistemas de informação na rotina das empresas [LP04, FUR02], o nível de flexibilidade dos mesmos se tornou algo extremamente importante. Não é incomum encontrar situações onde a impossibilidade de alteração de um sistema no tempo necessário seja o maior impedimento para a adoção de mudanças nas organizações. Dessa forma, os sistemas de informação algumas vezes acabam sendo vistos como um dos principais empecilhos para que uma organização consiga implantar alterações agilmente. São vários os fatores internos e externos que podem exigir modificações nas regras de negócio de uma organização. A capacidade em se adaptar agilmente a essas modificações é essencial para que respostas rápidas sejam dadas ao mercado. A seguir são apresentadas algumas das situações que podem axigir mudanças nas regras de negócio de uma organização e consequentemente nos sistemas de informação que implementam essas regras.

- Novas leis podem ser motivo para mudanças nas regras de engócio. A influência da legislação vigente, e consequentemente as mudanças nessas leis, podem levar à necessidade de alteração em aspectos dos sistemas de informação. Caso não haja um gerenciamento adequado dessas características, uma mudança pode obrigar uma reestruturação de partes significativas do sistema e consequentemente a alocação de recursos para a realização dessas alterações juntamente com os testes necessários para a implantação da nova versão.

- A inclusão de um novo negócio ou produto em uma organização pode levar a altera- 
ções e adições no conjunto de regras de negócio existentes. No momento em que uma empresa decide incluir um novo produto em seu portfólio, é necessária a elaboração de um plano de negócio (business plan) que consiste em uma descrição textual que especifica, dentre outras coisas, como o produto será oferecido, quais as estratégias de preço e quais as restrições serão aplicadas no oferecimento desse produto. Essa descrição agrega uma série de regras e direcionamentos que precisa ser, de alguma forma, implementada nos sistemas de informação da empresa.

- A necessidade de resposta rápida ao mercado em situações onde ocorre alguma ação por parte da concorrência pode ocasionar mudanças em aspectos dos sistemas de informações. Em qualquer mercado competitivo algumas das mudanças que uma organização realiza em suas políticas são reações a alguma ação realizada por seus concorrentes. Uma nova oferta agressiva de um concorrente pode fazer com que as regras de negócio de um produto sejam alteradas visando manter ou aumentar a competitividade de um produto.

\section{As regras de negócio nos sistemas de informação}

Regras de negócio podem ser vistas como uma categoria dentro do conjunto de requisitos de um sistema de informação. Os requisitos pertencentes a esta categoria apresentam a característica de serem fortemente influenciados pelas mudanças no contexto do ambiente de negócio na qual as organizações estão inseridas. Isso faz com que seja desejável que os sistemas de informação que os implementam sejam desenvolvidos de tal forma que permitam as alterações necessárias nessas regras a fim de acompanhar essas mudanças.

Entretanto, em grande parte dos sistemas de informações atuais é encontrada uma dificuldade quando se faz necessário alterar algum aspecto do mesmo em decorrência de alguma mudança nos requisitos de negócio. Uma boa parte da dificuldade na realização dessas alterações é dada pela necessidade do envolvimento de pessoas com conhecimentos técnicos em desenvolvimento de software. Quando ocorre alguma mudança na estratégia de uma organização e esta mudança acarreta na necessidade de alteração de uma característica de um ou mais sistemas de informação é necessário que uma equipe técnica, composta por pro- 
gramadores, analistas e engenheiros de software, seja envolvida para que essa alteração seja efetivada.

Essa equipe tem o desafio de compreender essa alteração e traçar uma estratégia para realizá-la minimizando o impacto no sistema. Muitas vezes essa equipe tem pouco ou nenhum conhecimento a respeito do domínio desse sistema e, dessa forma, é necessária uma atividade de análise onde a alteração terá de ser compreendida e documentada. Todo esse processo requer além de um custo, um período de tempo para ser realizado. Caso essa alteração pudesse ser feita pelos especialistas no domínio, com pouco ou nenhum auxílio dessa equipe técnica, esse tempo seria minimizado, os custos seriam diminuídos e a organização poderia responder mais rapidamente a essas mudanças.

Tendo em vista todos esses fatores é preciso que a necessidade de alteração nas regras de negócio seja um evento previsto durante o processo de desenvolvimento de software e com isso sejam fornecidos meios para que essas alterações possam ser realizadas de uma forma rápida. Isso é alcançado quando são empregadas ferramentas, metodologias, arquiteturas e tecnologias onde as regras de negócio são tratadas como elementos altamente voláteis. Com isso, é possível que os sistemas de informação desenvolvidos possam acompanhar, em tempo hábil, as mudanças ocorridas no ambiente na qual eles operam.

De uma forma geral, em uma aplicação onde não existe uma separação entre as características que tendem a sofrer alterações com o tempo e as características onde alterações são menos prováveis, são enfrentadas dificuldades no processo de evolução de software. Para evitar esse problema é necessário que as regras de negócio sejam consideradas explicitamente no processo de desenvolvimento.

Apesar da necessidade de um gerenciamento explícito das regras de negócio, grande parte das metodologias e ferramentas de desenvolvimento de software não fornece suporte suficiente para o gerenciamento e documentação dessas necessidades de negócio da organização e consequentemente a utilização desse conhecimento no desenvolvimento dos requisitos [BJW93] e no restante do processo de desenvolvimento e evolução [WKL04], [VHR02]. 


\subsection{Desenvolvimento de software com Regras de Negócio}

O Business Rules Approach [Ros03b] é um arcabouço conceitual que fornece um conjunto de princípios com o objetivo de tornar as regras de negócio um elemento explícito nos processos de desenvolvimento de software. A ideia principal desse arcabouço é que as regras de negócio sejam logicamente separadas das funcionalidades e dos dados [BKR00]. Com isso, as mudanças nas regras poderiam ser feitas independentemente de outros aspectos dos sistemas de informação e consequentemente os custos para que essas mudanças fossem realizadas seriam reduzidos. Os benefícios trazidos por essa separação são decorrentes do fato de que as regras de negócio apresentam uma probabilidade maior de serem alteradas com o passar do tempo. Sendo assim, essa separação facilita a localização e alteração dessas regras.

\subsubsection{Sistema exemplo - Comércio Eletrônico}

Para ilustrar como um correto gerenciamento das regras de negócio em um sistema de informação pode trazer benefícios arquiteturais utilizaremos como exemplo o domínio de sistemas de comércio eletrônico de alta demanda. Será descrito um sistema hipotético para a revenda de produtos eletrônicos por meio de um website acessado por milhares de usuários ao redor do mundo. A empresa detentora desse negócio não utilizará um estoque próprio, ao invés disso, ela irá realizar os pedidos com os fornecedores de vários países de acordo com a demanda causada por seus usuários. Esses pedidos serão realizados por meio dos serviços disponibilizados por esses fornecedores. Quando um novo pedido for requisitado pelo usuário, o sistema deverá realizar buscas nesses fornecedores visando encontrar o melhor preço juntamente com os melhores prazos de entrega. É possível que para atender um pedido com mais de um produto seja necessário realizar pedidos em diferentes fornecedores e empregar regras para a escolha da melhor opção.

Existem algumas particularidades a respeito da interação com os fornecedores. É possível que sejam feitos acordos onde uma grande quantidade de um produto seja comprada por um preço menor. Esses produtos permanecem no estoque do fornecedor, porém, são despachados para os clientes à medida que os mesmos forem comprados por meio do website. Haverá 
um prazo para que esses produtos comprados fiquem no estoque. Dessa forma, a escolha do fornecedor para um determinado pedido deverá considerar a necessidade de vender os produtos relacionados a esses acordos antes que o prazo seja finalizado. Além disso, deverá ser possível incentivar a compra de um determinado produto visando cumprir com os prazos estabelecidos nesses acordos. Esses incentivos serão feitos por meio de promoções oferecidas aos usuários do website.

Tendo em vista que em negócios de venda online existem necessidades especiais em relação à fraude, deverá existir um mecanismo que identifique e bloqueie pedidos onde seja identificado um nível elevado de risco. Esse risco será calculado observando-se diversas informações a respeito do usuário tais como quais os produtos ele usualmente compra, o valor acumulado dos pedidos que ele realizou recentemente dentre outras. Todas essas informações serão analisadas com base em um modelo de cálculo de risco onde será definido um valor numérico que representará o risco de fraude para cada um dos pedidos realizados. Todos os pedidos que recebam um valor de risco maior que um limite máximo pré-estabelecido deverão ser encaminhados para um departamento de verificação manual ou automaticamente não autorizados.

Com base nessas informações podemos criar algumas regras de negócio relacionados a essa organização. Uma característica pertinente a essas regras é a grande possibilidade das mesmas serem alteradas durante a vida útil desse sistema. É possível também que novas regras de negócio sejam acrescentadas. Em seguida, algumas dessas regras serão descritas.

Fornecedores

- RN 1 - Fornecedores do mesmo país do usuário devem ter prioridade sobre fornecedores de outros países.

- RN 2 - Fornecedores antigos devem ter prioridade maior em relação aos novos fornecedores.

- RN 3 - Fornecedores com acordos devem ter prioridade sobre fornecedores sem acordos.

- RN 4 - Fornecedores da América do norte devem ter prioridade sobre fornecedores da América do sul. 
- RN 5 - O fornecedor de número 50 deve ter prioridade máxima sobre todos os outros fornecedores.

Promoções

- RN 6 - Pedidos com valor total maior do que $\mathrm{R} \$ 5.000,00$ devem ter desconto de $10 \%$.

- RN 7 - Usuários com valor acumulado de $\mathrm{R} \$ 10.000,00$ em pedidos em um período de 60 dias devem receber sem custo um produto na faixa de $\mathrm{R} \$ 10,00$ a $\mathrm{R} \$ 15,00$.

- RN 8 - Um usuário deve receber um desconto de 5\% no próximo pedido caso a entrega do pedido anterior atrase mais do que 5 dias.

- RN 9 - Deve ser dado um desconto de 5\% no mês de janeiro para todos os produtos do setor de livros.

Fraude

- RN 10 - Pedidos com índice de fraude entre 30\% e 50\% devem ser encaminhados para a provação manual.

- RN 11 - Pedidos com índice de fraude maior do que 50\% devem ser automaticamente cancelados.

\subsubsection{Da especificação à implementação}

Devido à natureza tendenciosamente informal da linguagem natural, é possível que existam interpretações ambíguas sobre as regras de negócio definidas no sistema exemplo. Para evitar este problema é necessário que seja utilizada uma linguagem formal para defini-las. Devido a isso, foram criadas algumas iniciativas com o objetivo de formalizar a representação das regras de negócio e com isso evitar essa ambiguidade. Dentre essas iniciativas, destaca-se o meta-modelo Semantic of Business Rule and Business Vocabulary (SBVR) [Tea06] que é um padrão da OMG para a descrição formal das regras de negócio. Esse padrão fornece uma linguagem abstrata baseada em lógica de primeira ordem com uma extensão de lógica modal que pode ser utilizada pelas organizações para a definição da semântica de vocabulários de negócios e regras de negócio [Cha08]. 
Com esse modelo é possível que as organizações definam formalmente o significado de suas regras de negócio de uma forma independente da linguagem utilizada para representálas. Uma característica importante deste padrão é o fato de ter sua estruturação baseada em vocabulários de conceitos, termos e fatos ao invés de alguma estrutura computacional. Essa abordagem linguística oriunda dos padrões internacionais ISO 704:2000 e ISO 1087:2000 facilitam o acesso e a transferência de informação[Lar04]. Essas características permitem, por um lado, a criação de modelos para a definição precisa da semântica das regras de negócio e, por outro, que esses modelos possam ser manipulados por pessoas relacionadas ao negócios utilizando ferramentas compatíveis com o meta-modelo SBVR.

Esse padrão permite que as organizações definam e compartilhem suas regras de negócio de uma forma padronizada e independente da linguagem concreta utilizada para representálas. Apesar disso, são encontradas dificuldades para que a implementação das regras de negócio possa ser corretamente realizada nos sistemas de informação. Isso acontece porque o SBVR, bem como uma parte das iniciativas para a especificação das regras de negócio, não indica como elas podem ser efetivamente implementadas. Um dos aspectos relacionados a essa implementação é a identificação dos eventos que, ao ocorrerem, indicam a necessidade de que a regra de negócio precisa ser verificada. Esses eventos podem ser a alteração, criação ou remoção de algum dado relacionado a regra de negócio.

Podemos utilizar como exemplo a regra de negócio RN 6 descrita anteriormente. A conformidade do sistema em relação a essa regra deverá obrigatoriamente ser verificada apenas quando um novo pedido for feito ou quando um pedido for alterado. Sempre que um desses eventos ocorrer é necessário que o desconto de 10\% seja concedido. Contudo, não há uma especificação explícita dentro do meta-modelo SBVR que associe a verificação de conformidade de regras de negócio mediante a ocorrência de determinados eventos. Uma das alternativas de implementação seria verificar a conformidade com todas as regras do sistema sempre que uma operação fosse realizada. Mas isso degradaria o desempenho do sistema uma vez que uma dada operação poderia não estar relacionada com a maioria das regras de negócio definidas para o sistema.

Uma outra alternativa de implementação é considerar que cada regra de negócio terá um conjunto de eventos associados que indicarão o momento no qual é necessário que a regra 
seja verificada. Esses eventos são a ocorrência de alguma mudança, durante a execução do sistema, nas instâncias dos elementos que estejam relacionados a regra de negócio. Isso permite que essas regras possam ser independentes dos outros elementos de uma arquitetura de um sistema de informação, sendo necessária apenas uma comunicação entre os elementos que implementam essas regras e os outros elementos da arquitetura do sistema. Assim, esses elementos, que efetivamente manipulam a população dos conceitos relacionados as regras de negócio, serão responsáveis por sinalizar quando ocorrer um evento de mudança em alguma das instâncias dessa população. Para isso, o desenvolvedor deverá "extrair"( ad hoc), a partir de um conjunto de regras SBVR, quem são esses eventos e como eles influenciam as regras de negócio. Além disso, a comunicação com os outros elementos do sistema e uma forma de implementar tais verificações também devem ser definidas.

\subsection{Objetivos deste trabalho}

O objetivo deste trabalho é viabilizar a implementação das regras de negócio em sistemas de informação. Para isso, será feito o mapeamento de um modelo de representação semântica das regras de negócio para um modelo de implementação baseado em eventos formalmente definidos em $\pi$-calculus. O objetivo dessa transformação é tornar explícito o momento no qual uma regra de negócio deve ser verificada. Para tanto, nesse modelo, cada uma das regras a serem implementadas terá um conjunto de eventos associados. Esses eventos indicarão em quais situações é necessário que a regra de negócio seja verificada a fim de identificar possíveis violações. Por exemplo, uma regra de negócio que determina que um pedido só poderá ser realizado se o valor total do mesmo for maior do que $R \$ 5,00$, deverá ser verificada sempre que um novo pedido for realizado ou quando um pedido já criado for alterado. Dessa forma, existiriam obrigatoriamente dois eventos associados a essa regra de negócio: o evento "pedido criado"e o evento "pedido alterado". Assim poderá existir um mecanismo padrão que monitore e identifique a ocorrência desses eventos e então acione todas as regras que devem ser verificadas.

As regras de negócio serão especificadas utilizando o meta-modelo Semantics Of Business Vocabulary and Business Rules - SBVR [Tea06] que apesar dos seus benefícios [Cha08], não 
especifica como as regras de negócio podem ser implementadas em um sistema real, pois, não determina quando cada regra deve ser verificada. Sob o ponto-de-vista prático, consideramos como subfases do desenvolvimento de sistemas com regras de negócio:

1. especificação das regras de negócio utilizando o meta-modelo SBVR;

2. extração (da especificação SBVR) dos eventos que influenciam cada regra de negócio;

3. definição da relação entre os eventos e as regras de negócio;

4. definição de um protocolo de comunicação padrão que determina quais regras de negócio devem ser verificadas mediante a ocorrência de eventos do sistema;

5. implementação do mecanismo de verificação de cada regra de negócio.

Este trabalho tem como objetivo contribuir com os itens 2, 3 e 4 acima descritos. Ele se faz necessário já que as regras em SBVR, apesar de estarem formalmente definidas, não são diretamente executáveis. Dessa forma, é necessária uma transformação para que as mesmas possam ser implementadas.

Para os itens 2 e 3, uma especificação prévia das regras de negócio utilizando o metamodelo SBVR se faz necessário. Com isso, um método para a extração dos eventos que requerem a verificação de cada regra de negócio especificada é definido.

No item 4, para a realização da composição das regras de negócio e o restante do sistema de informação, pode-se considerar esses dois elementos como processos paralelos que necessitam se comunicar para formar o comportamento geral do sistema sendo construído. Sendo assim, é necessário que exista um protocolo de comunicação entre esses dois processos independentes. Uma maneira formal de modelar esse protocolo de comunicação é por meio de álgebras de processo, as quais consistem em estruturas matemáticas para análise e especificação de sistemas concorrentes. Por meio dessas estruturas, podemos especificar sistemas concorrentes e realizar análises com base em um conjunto de axiomas e teoremas já provados na literatura. Como exemplos dos benefícios trazidos por essa teoria, podemos citar a possibilidade de verificação da equivalência entre dois sistemas por meio do conceito da bissimulação [Ber86], provar a correção de um sistema com base em sua especificação, 
realizar simulação por meio de ferramentas como o Concurrency Workbench [CPS93] e verificar propriedades que devem ser respeitadas durante a execução do sistema sendo analisado. No trabalho atual, $\pi$-calculus [Mil99] será utilizado pela facilidade de descrever sistemas concorrentes com reconfiguração dinâmica, o que se mostrou apropriado à implementação de sistemas com regras de negócio.

\subsection{Trabalhos relacionados}

Foram encontrados na literatura alguns trabalhos com o objetivo de implementar as regras de negócio nos sistemas de informação. A seguir são apresentadas algumas características desses trabalhos.

Em [RD05] Rosenberg e Dustdar propõem uma arquitetura onde motores de regras de negócio possam ser acionados como serviços. Isso é alcançado por meio de um Rule Interceptor Service e um Business Rule Broker que são responsáveis, respectivamente, por interceptar a comunicação entre os serviços e por permitir a comunicação entre os motores de regras de negócio e o restante dos elementos da arquitetura. Esses dois elementos são acoplados e um barramento padrão de comunicação utilizado pelos serviços. À medida que as mensagens são enviadas e recebidas, por meio desse barramento, elas são interceptadas e enviadas para serem analisadas pelos motores de regras. Com isso, determinadas ações poderão ser proibidas por estarem em desacordo com alguma regra ou ações sejam executadas em resposta a algum evento detectado. Uma desvantagem dessa proposta é a de exigir uma representação semântica de todo o banco de dados de regras de negócio a fim de que o WSDL[CLS ${ }^{+}$05] do Business Rule Broker seja gerado e a comunicação com os motores de regras possa ser estabelecida. Além disso, essa abordagem cobre um subconjunto limitado de tipos de regras de negócio.

Outra proposta para a inserção das regras de negócio em arquiteturas SOA é o FARAO - FrAmewoRk for Adapative Orchestration [WvdHH08] o qual consiste em um arcabouço para a composição declarativa de serviços por meio de regras de negócio. Nesse trabalho é sugerido que a ordem, parcial ou total, de execução de um conjunto de serviços pode ser determinada com base nas regras de negócio sem a necessidade de uma linguagem impe- 
rativa de composição como o BPEL [ $\left.\mathrm{JEA}^{+} 07\right]$. Isso é feito primeiramente identificando as dependências entre as entradas e as saídas de cada serviço. Essas dependências são então utilizadas para determinar se um serviço deve ser executado antes ou depois de outro serviço. Depois disso, todas as regras de negócio são analisadas a fim de que novas restrições de ordem sejam encontradas. Além disso, é possível que restrições sejam definidas manualmente pelo usuário. Por fim, todas essas restrições são reunidas e a ordem de execução dos serviços é definida. O objetivo dessa abordagem é fornecer um alto nível de adaptabilidade já que a composição dos serviços será dinamicamente obtida por meio das regras de negócio ao invés de ser estaticamente definida.

Essa abordagem possui algumas limitações. A primeira delas é a ausência de detalhes sobre a forma como as ordenações serão obtidas das dependências entre as entradas e as saídas dos serviços. Outra limitação é a falta de mecanismos que permitam verificar a consistências das regras de negócio sendo consideradas para a geração da composição. É possível que uma regra defina que o serviço A deva ser executado após o serviço B e outra regra que diga o contrário. Uma forma de resolver essas limitações seria a utilização de um arcabouço formal onde essas inconsistências pudessem ser apontadas.

Em [DRV10] Roover e Vanthienen propõem um modelo para a transformação de regras de negócio especificadas em SBVR em um mecanismo de eventos uniforme. Também é fornecido um modelo para a transformação de regras especificadas em Em-BrA CE [GHV07] que consiste em uma extensão do modelo SBVR que permite a definição de conceitos de processos. O objetivo dessa transformação é permitir que as regras possam ser aplicadas nos sistemas de informação por meio de um modelo de execução padrão. Dessa forma, poderiam ser criadas soluções integradas e independentes do sistema para o gerenciamento dos processos, auditorias, checagem de dados e assim por diante. Os autores afirmam que as regras de negócio precisam ser, por um lado compreensíveis de tal forma que as pessoas de negócio possam entendê-las e, por outro lado devem ser formais de tal forma que possam ser aplicadas por um sistema de informação. Dessa forma, o mecanismo de representação de regras escolhido foi o SBVR [Tea06] que, juntamente com ferramentas de modelagem tal como SBeaVer [DTC06], permite que essas propriedades sejam alcançadas. Apesar dessas características, o SBVR não foi desenvolvida para ser executada e, por esse motivo é necessário 
que algum modelo seja utilizado para que os sistemas de informação possam aplicá-las. Uma opção seria modelar essas regras utilizando modelos procedurais tais como BPMN [Whi04] ou os diagramas de atividade da UML. O problema dessa abordagem é que ela não permite separar as regras dos processos e isso viola o princípio de que esses dois conceitos precisam ser modelados e implementados independentemente.

Nesse contexto é proposto um conjunto de padrões para transformar as regras de negócio especificadas em SBVR em regras no formato de eventos. Com isso, as regras podem continuar sendo manuseadas em SBVR por pessoas do negócio e depois traduzidas, por meio de ferramentas, em eventos que serão executados por um subsistema padrão de execução de eventos.

Nesse trabalho, são fornecidos diversos padrões de transformações de regras de integridade como também regras de reação e regras de derivação. Foi mostrado que diversos tipos de regras modeladas em SBVR podem ser transformadas de tal forma que um mecanismo padrão de execução de eventos possa ser utilizado. O próximo passo será a construção de uma ferramenta que utilize esses padrões e a criação de um modelo de execução compatível com essas regras.

\subsection{Organização da Dissertação}

No Capítulo 2 serão fornecidos mais detalhes a respeito das regras de negócios. Será fornecido um estudo sobre suas principais características e classificações juntamente com um conjunto de exemplos. Nesse capítulo também serão discutidas as várias definições para esse conceito e a relação delas com o trabalho a ser apresentado. Serão fornecidas também informações a respeito dos principais modelos e linguagens para especificação de regras de negócio. Por fim, será fornecido um panorama com as formas tradicionais de implementação das regras de negócio e as tecnologias mais modernas. O meta-modelo SBVR será descrito no Capítulo 3. Serão fornecidos alguns detalhes a respeito da fundamentação dessa especificação da OMG e quais os principais benefícios obtidos ao utilizar esse padrão. Também serão dadas algumas informações a respeito da sintaxe para a definição de modelos de regras de negócio. No Capítulo 4 será descrito um método para a transformação das regras de negócio em 
SBVR para um modelo de evento baseado em pi-calculus. Serão fornecidos detalhes sobre os elementos do SBVR que deverão ser observados e quais os elementos correspondentes no modelo em $\pi$-calculus. No Capítulo 5 haverá a descrição de um sistema exemplo baseado na proposta deste trabalho. No Capítulo 6 serão apresentadas as conclusões e trabalhos futuros. 


\section{Capítulo 2}

\section{Regras de Negócio}

Em uma organização, normalmente, as pessoas envolvidas com cada departamento sabem qual o seu papel dentro dos processos. Elas sabem quando devem agir durante o processo e quais os procedimento que devem ser realizado em determinado momento. Apesar disso, existe uma série de regras válidas para toda a organização que restringem ou influenciam a interação entre esses departamentos. Algumas dessas regras são impostas pela legislação do país na qual essas organizações operam. Outras podem ser originadas de políticas e estratégias internas. Apesar dessas diferentes origens, essas regras possuem papéis importantes na organização e operação dessas organizações. Dois desses papéis são:

- Restrições. Um dos papeis das regras de negócio é definir quais atividades podem ou não podem ser realizadas em um determinado contexto. Isso quer dizer que em algumas situações certas atividades não poderão ser realizadas ou serão realizadas sob certas restrições. Como exemplo podemos citar uma empresa bancária que pode definir uma regra que proíba a realização de empréstimos nos períodos pós-festas onde o risco seja considerado alto. Essas regras restringem o comportamento da organização e impedem que uma atividade seja realizada caso isso possa trazer algum impacto negativo para essa empresa ou esteja em desacordo com algum critério ético adotado pela organização em questão.

- Direcionamentos.

Uma regra pode mudar o fluxo de atividades habitual de um processo. É possível que 
o fluxo normal de um processo seja alterado caso exista uma regra de negócio que especifique que isso deva ocorrer quando determinadas condições forem satisfeitas. Por exemplo, em um processo de locação de veículos é possível que exista uma atividade que verifique o histórico de multas da pessoa que está realizando a locação. O gerente dessa locadora pode então definir uma regra que determine que caso essa pessoa tenha mais do que três multas nos últimos seis meses, a locação deve ser redirecionada para o departamento de análise de riscos e somente será feita a locação com a aprovação desse departamento. Essa mudança no fluxo normal de vendas é um exemplo onde uma regra influencia um processo.

Uma das práticas defendidas pelo Business Rule Aproach [Ros03b] e explicitadas no manifesto das regras de negócio [Ros03a] é a de separar regras dos processos tornandoas parte fundamental, explícita e individual na modelagem e desenvolvimento de sistemas de informação. Isso quer dizer que as regras não devem ser associadas a um processo ou conjunto de processos específico. Ao invés disso, elas devem ser consideradas como parte da organização e do negócio sendo desempenhado por essa organização e a sua aplicação realizada quando o contexto do processo estiver de acordo com a definição da regra. Uma vantagem direta obtida por meio dessa separação é a de que esses dois conceitos podem evoluir independentemente durante o ciclo de vida da organização e dos sistemas de informação relacionados a ela.

Não existe um consenso absoluto a respeito do que são regras de negócio. Existem diversos grupos utilizando esse termo, entretanto, cada um com um significado diferente [KB03]. No contexto empresarial, regras de negócio são declarações que restringem ou dirigem algum aspecto do negócio [HH00]. As regras tratam de práticas e orientações do negócio. Portanto, as regras são motivadas pelas metas e objetivos de negócio [Ros03a].

Nesse trabalho consideraremos regras de negócio como políticas organizacionais indivisíveis. São átomos de orientações que de alguma forma restringem ou influenciam o modo como uma organização age. É um conjunto de regras derivado das metas, visões e estratégias que regem de forma global o funcionamento de uma organização. Na perspectiva de sistemas de informação, as regras de negócio são requisitos motivados diretamente pelo negócio, sendo 
realizado pela organização e pelo ambiente na qual esse negócio é realizado.

\subsubsection{Características}

Um importante fato a respeito das regras de negócio é que elas são declarativas e não procedurais. Elas descrevem possíveis estados que são permitidos ou proibidos. Entretanto, elas não descrevem os passos necessários para realizar a transição de um estado para outro, ou os passos para proibir uma transição [BKR00]. Uma regra descreve o que deve ser feito, mas, não como deve ser feito. Essa característica diminui consideravelmente a dificuldade na definição de regras já que isso é feito utilizando uma linguagem muito próxima à linguagem natural. A vantagem é que pessoas não técnicas e que não possuem familiaridade com linguagens de programação podem definir e modificar regras de negócio com facilidade.

Algumas das características essenciais às regras de negócio foram definidas [Mor02]:

- Atomicidade: Regras de negócio não podem ser compostas por outras regras de negócio. Isso significa que elas não podem ser divididas sem que haja perda de informação. Por exemplo, a sentença "Um aluno será desligado do curso caso tenha sido reprovado duas vezes e seja um aluno especial" não pode ser dividida sem que o significado seja alterado. Enquanto que a sentença "O cliente será bloqueado se estiver com saldo negativo a pelo menos um mês. Um cliente bloqueado só poderá ser reativado após dois meses" poderia ser dividida em duas regras de negócio: uma definindo em qual circunstância um cliente deve ser bloqueado; e a outra em qual circunstância ele pode ser reativado. Portanto, esse segundo exemplo não se trata de "uma"regra de negócio já que essa declaração não é atômica.

- Não ambiguidade: As regras de negócio precisam ter um e somente um significado no contexto na qual elas serão utilizadas. Isso implica que a definição de uma regra precisa ser feita por meio de alguma linguagem formal. Dessa forma, o significado de cada uma das regras em uma organização será único e poderá ser compartilhado com outras organizações como também internamente sem que haja possibilidade de múltiplas interpretações já que a semântica da linguagem utilizada para especificá-las está formalmente definida. 
- Minimalismo: Um dos objetivos do estudo de regras de negócio é permitir que as mesmas sejam definidas pelas próprias pessoas envolvidas com o negócio. Dessa forma, elas precisar ser simples para que possam ser manipuladas por pessoas sem conhecimentos de desenvolvimento de software.

- Consistência: Uma regra não pode entrar em conflito com outra regra. Essa característica é importante já que a execução das regras não obedece a nenhuma definição de ordem. Dessa forma, caso existam duas regras conflitantes em um mesmo instante, não será determinado qual dessas regras será priorizada.

- Compatibilidade: Todas as regras devem ser definidas por meio de conceitos conhecidos pela organização. Devido ao fato de que as regras de negócios são originadas e direcionadas ao negócio, é importante que a linguagem utilizada para defini-las seja inteligível pelas pessoas de negócio. Não seria proveitoso exigir que essas pessoas tenham que aprender alguma linguagem computacional para poderem especificar as regras de negócio.

\subsubsection{Exemplos de Regras de Negócio}

Vejamos alguns exemplos de regras de negócio.

"Um aluno não pode estar matriculado em mais do que 6 disciplinas em um determinado semestre."

"O valor máximo de um saque em terminal ATM deve ser de R\$1.000,00."

"Um projeto não deve ser aceito caso a estimativa de conclusão seja maior do que 3 anos."

"Caso a temperatura interna da caldeira seja maior do que 30 graus, o sistema de aquecimento deve ser desligado"

"Caso um cliente compre um produto com valor maior do que $\mathrm{R} \$ 1.000,00$ deve ser fornecido um desconto de $5 \% . "$

"O departamento de segurança deve ser acionado caso existam mais de 3 tentativas de acesso com usuário e senha inválidos.” 


\subsubsection{Tipos de Regras de Negócio}

Na literatura são encontradas diversas formas de categorização das regras de negócio. Não existe um consenso em relação a essas categorias, entretanto, as mais comumente citadas são:

Restrições: Toda organização restringe seu comportamento de alguma forma [HH00]. As regras nessa categoria são compostas por restrições que devem ser respeitadas pela organização em seus processos. Um exemplo nessa categoria seria uma regra que define que um departamento deve ser gerenciado por pelo menos uma diretoria.

Regras de Derivação:

As regras de derivação são aquelas que permitem que novo conhecimento seja obtido por meio de um conhecimento já consolidado. Um exemplo é a seguinte regra "Se pessoa é juiz pessoa é advogado". Essa regra determina que tudo que se aplica a um advogado também se aplica a um juiz. Se tivermos uma regra que diga que "Tiago é um juiz", por derivação, também teremos que Tiago é um advogado. Esse tipo de regra é amplamente utilizado para definição dos vocabulários de negócio no padrão SBVR[Tea06] que veremos mais a frente. As regras de derivação são compostas por dois elementos: um conjunto de condições ou premissas e uma ou mais implicações. No exemplo acima, a premissa é "Ser juiz"e a implicação é "É advogado".

Regras de Produção: As regras de negócio nesta categoria baseiam-se nos sistemas de produção criados por Post em 1943. Esse tipo de regra foi amplamente utilizado na década de 80 como base dos sistemas especialistas [Wal91]. Essas regras são formadas por pares de condições e ações. Todas as ações de uma regra desse tipo serão executadas quando todas as condições forem satisfeitas. Enquanto as regras de derivação estão relacionadas à inferência de novo conhecimento, as regras de produção estão relacionadas a ações ou intervenções que deverão ser realizadas quando as premissas da regra forem avaliadas como verdadeiro em um determinado momento. 


\subsubsection{Origem das regras de negócio}

As regras de negócio são criadas com o objetivo de garantir que uma organização atinja seus objetivos e que cumpra suas responsabilidades em relação ao ambiente em que opera. Elas são reflexos da forma como uma organização opera ou pretende operar no futuro [Mor02] juntamente com as restrições impostas pelo ambiente. Por ambiente entendemos como o lugar físico onde essa organização opera, as restrições impostas pela legislação juntamente com os aspectos culturais e econômicos desse lugar. Com isso, vemos que a origem dessas regras podem ser divididas em dois grupos. Um grupo de regras com origens internas e outro de regras com origens externas.

Quando não existe um modelo de negócio que separe as regras dos processos, é necessário que alguma técnica seja empregada para isolar esses dois itens e com isso seja alcançado o objetivo de permitir que eles sejam independentes dentro dos sistemas de informação. Uma parte dessas técnicas faz uso de descrições de processos em conjunto com o levantamento e documentação do conhecimento das pessoas envolvidas no dia-a-dia da organização para identificar as regras de negócio [Mor02]. Outra parte utiliza técnicas de engenharia reversa para identificar e extrair as regras de negócio do código-fonte com objetivo de ajudar analistas de negócio a compreender os sistemas de informações atuais [SE96].

\subsection{Linguagens e modelos de representação}

Existem diversas linguagens e modelos de representação de regras de negócio. Alguns deles utilizam adaptações de modelos já consolidados e utilizados na modelagem de sistemas de informação tais como redes de petri, diagramas de fluxos de dados [HKMS94] e diagramas de entidade e relacionamento [TNCK91] enquanto outros foram criados exclusivamente para a representação de regras de negócio. Apesar dessa diversidade de opções para modelagem de regras, não existe um consenso em relação a qual metodologia é a mais apropriada [LRP06]. Cada organização escolhe uma linguagem de acordo com suas necessidades. Neste capítulo, nos concentraremos nas representações criadas exclusivamente para regras de negócio. 


\subsubsection{Rule Interchange Format - RIF}

Com o surgimento de diversos sistemas de regras [ $\mathrm{FH}^{+}$05], [Bro09] e [NRD06], percebeu-se a necessidade da criação de padrões para viabilizar a interoperabilidade entre estes sistemas. O objetivo destes padrões é permitir que regras definidas em um sistema possam ser utilizadas por outro sem que as mesmas tenham que ser reescritas manualmente observando a sintaxe e a semântica utilizada neste novo sistema. Isso é alcançado mapeando os elementos descritos no sistema base em elementos descritos no sistema alvo. Essa tarefa não é trivial devido ao fato de que estes diferentes sistemas possuem características e funcionalidades próprias e em alguns casos essas características não possuem um correspondente no outro sistema.

Neste contexto foi desenvolvido pela w3c o Rule Interchange Format - RIF. Um arcabouço conceitual para o intercâmbio de regras de negócios entre sistemas de regras. Este framework baseia-se na lógica formal e disponibiliza um conjunto de dialetos de regras com uma precisa definição sintática e semântica. Sistemas de regras podem mapear os elementos de sua linguagem de, ou para, um destes dialetos permitindo a interoperabilidade entre todos os sistemas de regras que suportem este dialeto [Kif08]. Dessa forma, uma mesma regras escrita no dialeto RIF X poderá ser executada no sistema $\mathrm{Y}$ e Z deste que estes dois sistemas suportem este dialeto.

Os dialetos desenvolvidos neste arcabouço são divididos em dois tipos: baseados em lógica e baseados em regras de ações. Os dialetos baseados em lógica são voltados à sistemas que suportem regras do tipo derivação e restrição enquanto que os dialetos baseadas em regras de ação serão voltados a sistemas que suportem regras de produção e regras do tipo evento, condição e ação -ECA.

\subsubsection{RuleML}

RuleML[BTW01] é uma família de linguagens baseada em XML para o intercâmbio de regras de negócio. Foi desenvolvida pela RuleML initiative com o intuito de permitir a interoperabilidade de regras na web por meio de uma linguagem padrão de definição. O objetivo deste iniciativa é permitir a instalação, execução, publicação e disseminação de regras de 
negócios entre diferentes tecnologias, plataformas e ambientes. A fundamentação do design de RuleML está na criação de uma sintaxe abstrata que é utilizada como base para o desenvolvimento de sub-linguagens concretas cada qual com características próprias servindo a objetivos específicos [BTW01]. Foram criadas sub-linguagens baseadas em Datalog [CGT89], HornLog [GR87], FOL [Smu95], CEP[BK09] entre outras. Por ser fundamentada em XML, RuleML permite a criação de uma hierarquia onde cada uma das sub-linguagens é definida por meio de um schema [FW04] que por sua vez é baseado no schema da linguagem abstrata.

A versão atual 1.0 da especificação da RuleML apresenta mudanças significativas em relação aos princípios de design das versões anteriores. As sub-linguagens foram dividas em dois grandes tipos: derivação e reação. As linguagens do tipo derivação são utilizadas para expressar regras dedutivas enquanto que as regras do tipo reação estão relacionadas a ação que deve ser realizada em determinadas situações. Estes dois tipos de regras são representadas respectivamente pelos elementos Implies e Reaction.

Abaixo são fornecidos dois exemplos de regras definidas em RuleML. A primeira trata-se de uma regra do tipo derivação especificada utilizando a sub-linguagem RuleML-datalog. Neste exemplo, é mostrado como um novo conhecimento é obtido com base na combinação de outros conhecimentos. O segundo exemplo especifica uma regra de reação utilizando a sub-linguagem FOL RuleML.

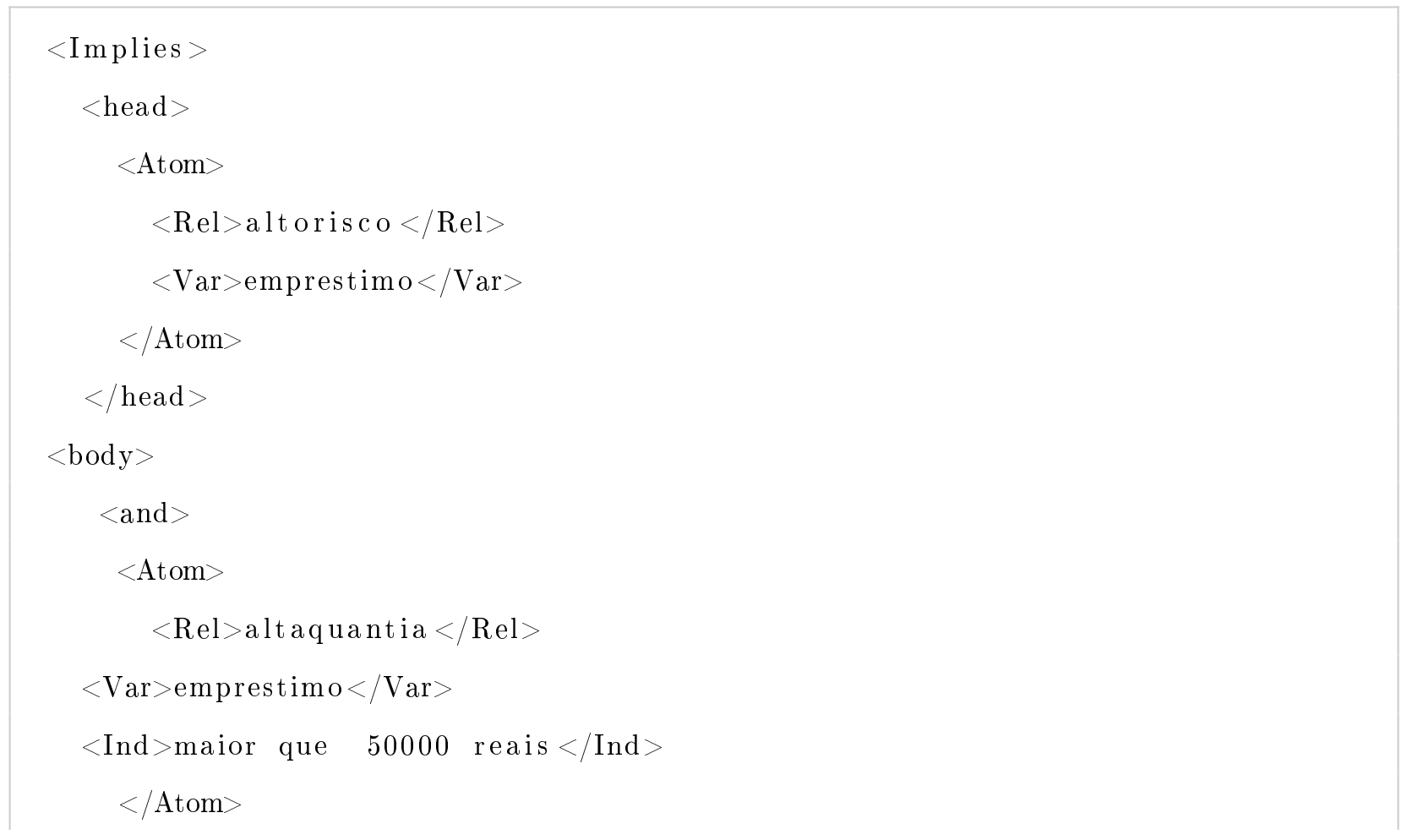




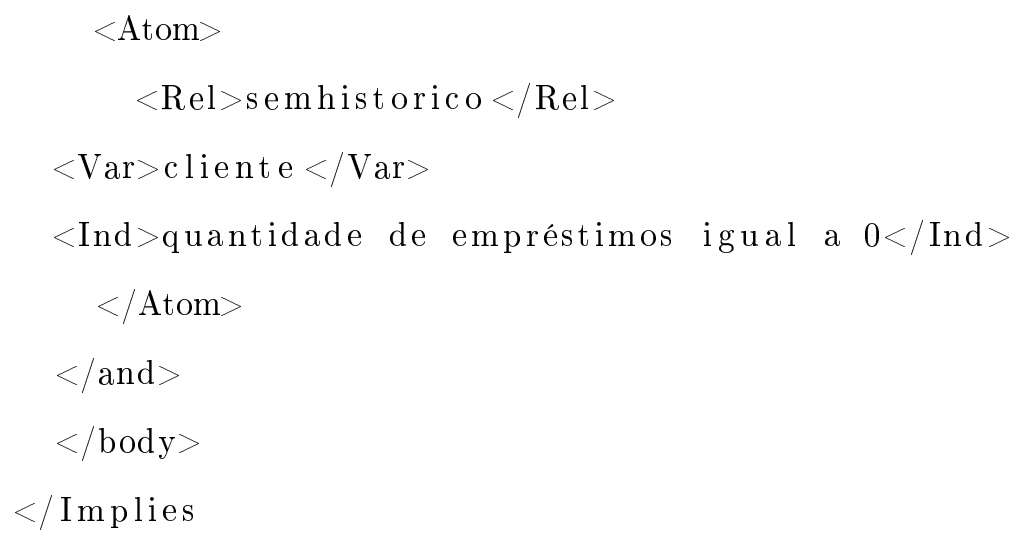

Esta regra define que um empréstimo será considerado como de alto risco se o valor for maior que 50000 reais e o cliente não tiver realizado nenhum empréstimo anterior. A parte head da regra define a relação altorisco como um join entre as relações altaquantia e semhistorico.

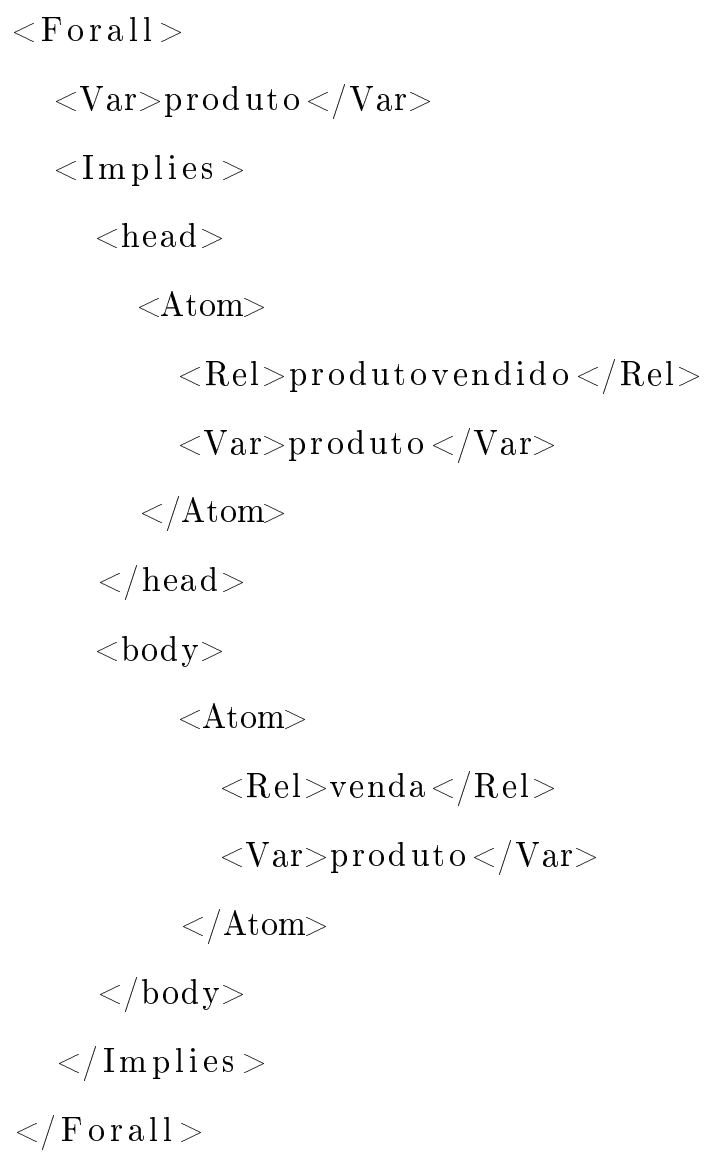

Esta regra descrita na sub-linguagem FOL-RuleML (First Order Logic RuleML) define que todos os produtos que forem vendidos precisam ter uma venda associada. Esta sublinguagem utiliza uma notação explícita para o quantificador universal. 


\subsubsection{Semantics Of Business Vocabulary and Business Rules}

Semantics Of Business Vocabulary and Business Rules - SBVR é um padrão criado pela OMG para especificação de modelos de negócio baseados em vocabulários e regras de negócio [Tea06]. Por meio desse padrão é possível que organizações definam formalmente o significado dos conceitos que elas utilizam no negócio na qual operam e as regras de negócios que restringem ou dirigem esse negócio. A SBVR é situada na camada CIM da arquitetura MDA[KWB03]. Dessa forma, trata-se de um metamodelo que define a linguagem que é utilizada para a especificação nos modelos instanciados. No capítulo 3 serão dadas mais informações a respeito desse meta-modelo.

\subsection{Tecnologias de Regras de Negócio}

Apesar das contribuições teóricas serem de extrema importância para o assunto, sem o fornecimento de tecnologia que permita que as ideias discutidas sejam devidamente implementadas torna-se impossível um aproveitamento satisfatório das vantagens que a conscientização da importância das regras de negócio pode trazer a engenharia de sistemas e ao processo de desenvolvimento de software. A seguir será apresentado um conjunto de tecnologias que permitem efetivar os conceitos desenvolvidos relacionados ao assunto de regras de negócio em aplicações reais. É importante notar que uma atenção especial as regras de negócio deve ser feita em todos os estágios do desenvolvimento de software e não apenas na implementação. Ou seja, desde a análise de requisitos até a manutenção e testes, devem ser usadas técnicas para que as regras de negócio sejam devidamente tratadas e inseridas de uma forma satisfatória na arquitetura do sistema.

\subsubsection{Formas tradicionais de implementação}

A seguir serão apresentadas algumas das formas tradicionais de implementação de regras de negócio em sistemas de informação segundo [BKR00]. É importante notar que estas técnicas foram desenvolvidas e aprimoradas com o passar do tempo e que não são exclusivamente utilizadas para isolar as regras de negócio. 


\section{Código-Fonte}

As regras de negócio estão presentes em sistemas de informação desde que eles começaram a surgir na década de setenta. Apesar de não haver uma preocupação explícita em relação a elas, esses sistemas já incluíam diversas regras de negócio dentro do código fontes dos módulos dessas aplicações. Estas regras normalmente eram inseridas por meio de blocos do tipo "se" e "então".

Apesar dessa ser a forma mais simples de implementação, ela apresenta grandes desvantagens. A primeira delas é que é difícil alterar estas regras já que elas estão misturadas com outras porções do software que não tendem a mudar com a mesma frequência. Em programas escritos em $\mathrm{c}$ ou $\mathrm{c}++$, um programa inteiro teria de ser recompilado para que alguma alteração pudesse ser realizada. Outro desafio é encontrar qual ou quais partes do código devem ser alteradas para que uma determinada regra seja modificada e garantir qual será o impacto da alteração desse código no restante da aplicação. [VHR02] fazem uma declaração interessante a respeito disso: "It is no longer acceptable to bury that knowledge deep in code where no one knows what it is". Com isso, a implementação de regras diretamente no código-fonte das aplicações não se mostra uma alternativa plausível devido às desvantagens apresentadas.

\section{Parametrização}

A parametrização de sistemas tem sido utilizada como uma das opções para permitir flexibilidade nos sistemas de informação. Neste modelo, são criados arquivos de configuração com diversos parâmetros relacionados à aplicação. Dessa forma, é possível que o comportamento de um sistema seja alterado por meio da alteração de parâmetros nesses arquivos. Com a popularização do padrão XML é comum encontrar sistemas que permitem que boa parte de seu comportamento seja alterado por meio de um ou mais arquivos de configuração baseados em XML. Além disso, normalmente são fornecidas ferramentas gráficas para a manipulação desses arquivos. Com isso, até mesmo pessoas que não tenham grandes conhecimentos em linguagens de programação podem alterar aspectos das funcionalidades desses sistemas [BKR00].

O projeto de um sistema de informação pode permitir que algumas características das 
regras de negócio sejam alteradas por meio desses arquivos de configuração. Um exemplo poderia ser um sistema de controle de caixa com a regra "Uma transação de venda com pagamento por meio de cheque não pode ser superior a $R \$ 10.000,00 ”$. Poderia existir um arquivo de configuração nesse sistema onde existiria um campo chamado "limite_cheque" com o valor 10000. Esse campo poderia ser alterado pelo gerente da loja onde esta aplicação estivesse sendo utilizada de acordo com a política adotada para vendas com pagamento por cheque.

A desvantagem desse modelo está em suas limitações em relação ao que pode ser parametrizado. Ele pode ser utilizado com sucesso para permitir a manutenção dos valores quantitativos de regras restritivas como a dada no exemplo acima onde o usuário poderia apenas alterar o valor do limite de vendas por cheque. Entretanto, não é possível utilizar esses modelos para a criação de novas regras. Dessa forma, esse modelo pressupõe que a equipe de análise desse sistema tenha identificado todas as possíveis regras durante a análise e construção do software [BKR00].

\section{Gatilhos e procedimentos de banco de dados.}

As tecnologias de banco de dados são uma outra forma de implementar regras de negócio em sistemas de informação. Gatilhos e procedimentos são utilizados com sucesso em muitos sistemas de informação para gerenciar regras de negócios. As vantagens desse modelo estão no fato de que ele isola estas regras do software da aplicação e permite um tratamento explícito das mesmas. Outra vantagem é que tanto regras de reação quanto regras restritivas podem ser criadas.

A grande desvantagem desse modelo está na necessidade de pessoas com conhecimento em linguagens de banco de dados como o SQL para a realização da manutenção destas regras [BKR00]. De acordo com o princípio de que as regras precisam ser gerenciadas por pessoas do negócio, devido a esta limitação, gatilhos e procedimentos não podem ser utilizados corretamente a não ser que sejam criadas interfaces amigáveis que traduzam as regras de negócios para a linguagem do banco de dados. Apesar dessa ser uma abordagem viável [KHS94], os motores de regras se mostram como uma alternativa mais atrativa como será mostrado, mais à frente, neste texto. 


\subsubsection{Formas modernas de implementação}

Aqui serão apresentados alguns exemplos de tecnologias e padrões modernos de implementação de regras de negócios. Foi possível perceber uma predominância de tecnologias baseadas no ambiente Java.

\section{JSR-94}

A Java Community Process - JCP é uma comunidade java internacional que propõe, aprova e mantém especificações de novas tecnologias baseadas em Java. Estas especificações são criadas por meio de uma Java Especification Request - JSR que consiste em um documento onde esta comunidade publica a necessidade de alguma especificação e espera que empresas ou grupos acadêmicos enviem propostas que são então votadas pelos membros do grupo. Após uma especificação ser aprovada ela é divulgada pela comunidade e torna-se oficial. Em 2004 foi aprovada a JSR-94 que se trata de uma especificação de um modelo de desenvolvimento de motores de regras de negócio baseada em Java. Nesse documento é descrita uma série de requisitos e recomendações que uma implementação compatível deve observar. Alguns dos itens no escopo desse padrão são:

- Restrições e Limites das implementações compatíveis.

- Definição das interfaces pelo qual o clientes executarão as regras.

- Mecanismos para adquirir a interface para uma implementação compatível.

- Definição das interfaces pelo qual as regras poderão ser obtidas de sistemas externos e registradas para uso.

O escopo desse padrão foi limitado à aspectos relacionados à interface desses sistemas de regras com o intuito de garantir a interoperabilidade semântica entre as implementações. Dessa forma, características relacionadas a semântica das regras processadas por esses sistemas e como as regras devem ser representadas e executadas estão fora do escopo dessa especificação. Existe a expectativa de que novas versões desses padrão imponham algumas restrições semânticas às implementações compatíveis e com isso possam ser mais abrangentes. 
As implementações desses padrão deverão suportar o ciclo básico de execução de regras que consiste em carregar as regras, adicionar objetos na engine, executar as regras e obter os resultados. O primeiro passo consiste em obter as regras de uma fonte externa tais como um arquivo XML, um arquivo de texto, uma URL, arquivo de som ou uma imagem e converter essa representação no formato de regras do sistema. A partir disso, o sistema estará pronto para receber os dados que devem ser confrontados com estas regras e executar as regras na qual as condições sejam satisfeitas. Após as regras serem executadas o sistema deve permitir que o cliente obtenha os resultados dessa execução. Todas as classes e interfaces da especificação JSR 94 estão contidas em dois pacotes, o pacote javax.rules e o pacote javax.rules.admin. No pacote javax.rules estão as classes e interfaces que permitem que os clientes das motores de regras criem uma sessão para interagir com um conjunto de execução de regras previamente criado enquanto que por meio do pacote javax.admin pacote javax.rules.admin será possível registrar ou remover na engine um conjunto de regras.

No exemplo [Mah05] abaixo é mostrado o código onde um cliente instancia uma sessão de um conjunto de regras, insere alguns dados nesta sessão, executa todas as regras desses conjunto sobre esses dados e obtém os resultados.

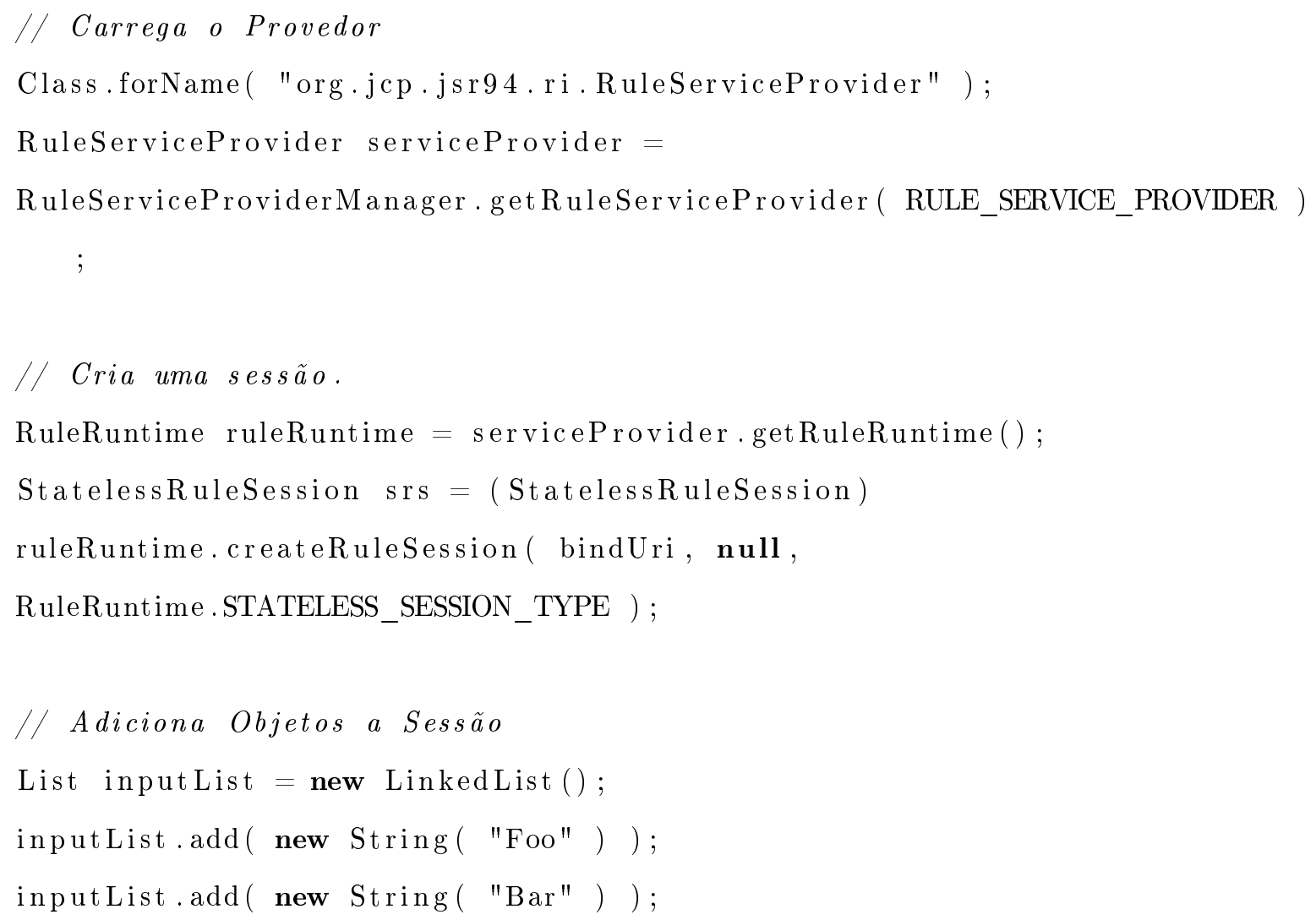




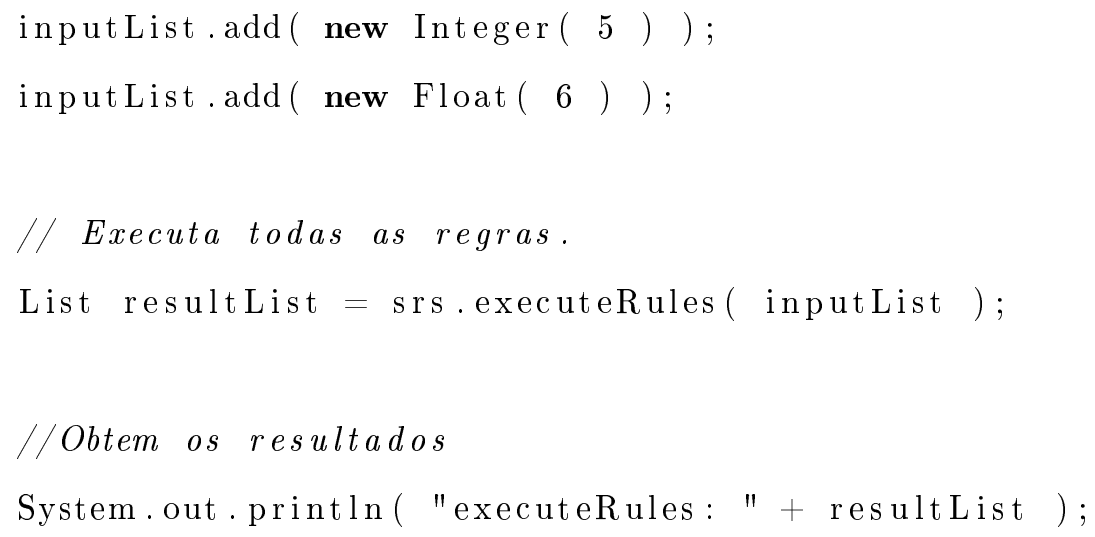

\section{Drools}

Drools consiste em uma iniciativa da comunidade jboss para a criação de uma plataforma baseada em Java para integração de lógica de negócios que provê um conjunto de tecnologias unificadas e integradas para o gerenciamento de regras, workflows e processamento de eventos [PNLF08]. Atualmente o projeto conta ao todo com cinco subprojetos dentre os quais o projeto Guvnor e Expert são os que diretamente se relacionam com as regras de negócio.

\section{Drools Expert}

Este projeto trata dos aspectos da linguagem utilizada para a definição das regras e do ambiente de execução das mesmas. Trata-se de um sistema de regras de produção que utiliza uma versão orientada a objetos do algoritmo RETE para o escalonamento e execução das regras. Detalhes sobre o algoritmo RETE podem ser encontrados em [For82]. O conceito de sistemas baseados em regras de produção foi desenvolvido por Post em 1943. A ideia básica de Post era de que um sistema matemático ou lógico é simplesmente um conjunto de regras especificando como fazer uma dada mudança de string de símbolos em outro conjunto de símbolos, ou seja, dado um conjunto de símbolos de entrada, ou antecedentes, uma regra de produção poderia produzir uma nova string, ou consequente [JJ13]. Quando um determinado padrão de string fosse encontrado, uma nova string era gerada e esse padrão era então substituído por um novo de acordo com a regra estabelecida. Dessa forma, uma regra consistia em dois elementos: um conjunto de condições e um conjunto de ações que devem ser executadas caso estas condições sejam atendidas. Durante os anos seguintes, o modelo proposto por Post foi melhorado e generalizado para permitir o processamento de 


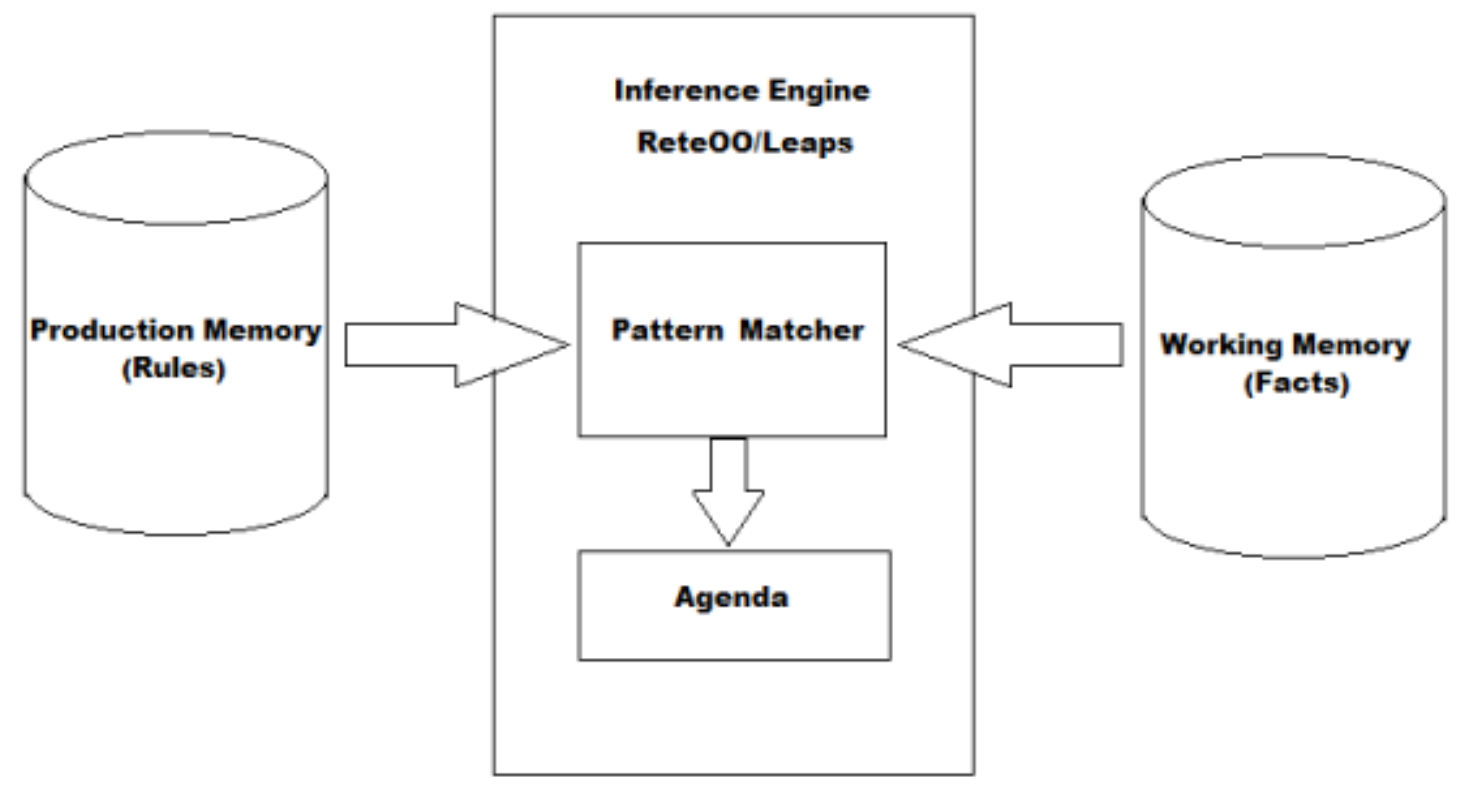

Figura 2.1: Visão geral da arquitetura do Drools Expert [Bal09]

outros dados além de apenas strings. Esses dados foram então denominados fatos. Um fato é uma afirmação de verdade que deve ser analisada pelo sistema a fim de identificar regras que devem ser executadas devido à existência dessas verdades. Um exemplo pode ser uma regra como Quando houver uma pessoa na sala, ascenda a luz. Quando uma nova pessoa (fato) for disponibilizada ao sistema de regras, a luz deverá ser ascendida. Nesses caso as condições para que a regra seja executada é a existência de ao menos um fato pessoa e a ação a ser executada é ascender a luz.

A arquitetura geral do Drools Expert pode ser vista na Figura 2.1. A memória de produção armazena as regras definidas e a memória de trabalho armazena todos os fatos na qual as regras serão aplicadas. A engine de inferência é composta por dois elementos, o Pattern Matcher que é o responsável por identificar, de acordo com as condições especificadas na regras, quais delas devem ser executadas e agenda. A tarefa da Agenda é escalonar as regras de acordo com as prioridades e resolver conflitos de execução.

O Drools Expert fornece uma linguagem própria para a definição das regras de negócio chamada de DRL - Drools Rule Language. A sintaxe básica dessa linguagem é a seguinte:

when

Lista de condições 
then

Lista de ações

A lista de condições é um conjunto de pré-requisitos para que as ações da regra sejam executadas. Estas condições podem indicar a necessidade de que existam fatos com determinados valores ou faixa de valores em seus atributos como também podem requerer a existência ou não existência de um determinado fato. A lista de ações são as ações que deverão ser executadas caso todas as condições da regra sejam satisfeitas. As ações podem incluir a alteração de dados dos fatos, o acionamento de algum método ou a inclusão e exclusão de fatos da memória de trabalho.

Serão fornecidos alguns exemplos de regras especificadas em DRL.

\section{Exemplo 1}

Regra especificada em linguagem natural:

"Caso uma pessoa seja do sexo masculino e tenha 18 anos, ela deverá se apresentar para a solenidade de jurar a bandeira nacional."

Regra especificada na linguagem DRL:

when

\$person : Person( $\mathrm{idade}=18$, sexo $=$ masculino)

then

\$person.jurarBandeira ()

\section{Exemplo 2}

Regra especificada em linguagem natural:

"Se um cliente comprar um sofá ganhará 30\% de desconto caso compre no mesmo pedido uma cama."

Regra especificada na linguagem DRL:

when

\$pedido : Pedido(); 


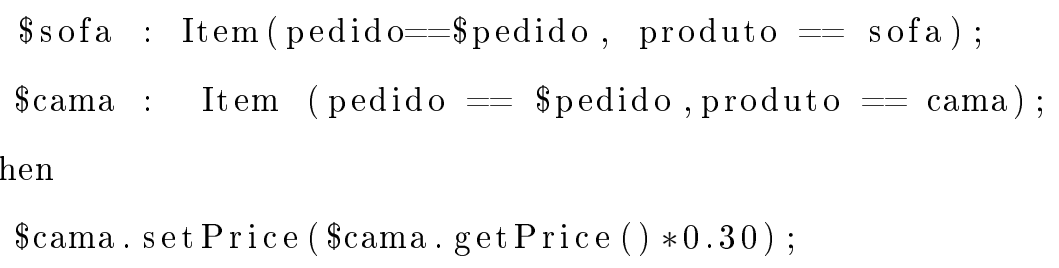

\section{DSL - Domain Specific Languages}

Uma DSL pode ser definida como uma linguagem simples, geralmente declarativa que oferece poder de expressão focado em um domínio particular de problemas [VDKV00]. Em muitos casos programas escritos em uma DSL são traduzidos para uma linguagem mais geral. O objetivo é esconder os detalhes da linguagem geral e fornecer uma interface especifica para o domínio. Linguagens DSL normalmente são linguagens de alto nível e consequentemente mais simples de serem compreendidas dos que as linguagens de uso geral. O Drools Expert fornece a possibilidade de definição e utilização de linguagens específicas ao domínio na qual as regras serão utilizadas. A vantagem oferecida é de simplificar a definição de regras permitindo que elas sejam feita por meio de uma linguagem facilmente entendida para as pessoas envolvidas com o domino em questão.

A definição das regras é feita utilizando a seguinte sintaxe:

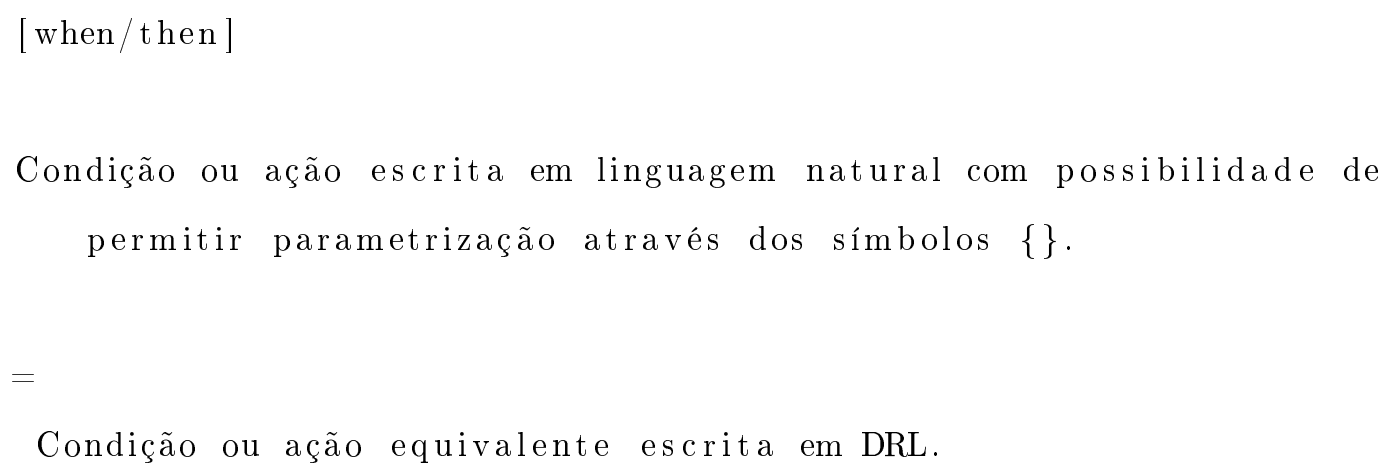

Utilizando este recurso podemos criar uma linguagem DSL para ajudar na definição do exemplo 2 .

\section{Exemplo 3}

[when]

Um pedido incluir o item $\{$ item $\}$ 


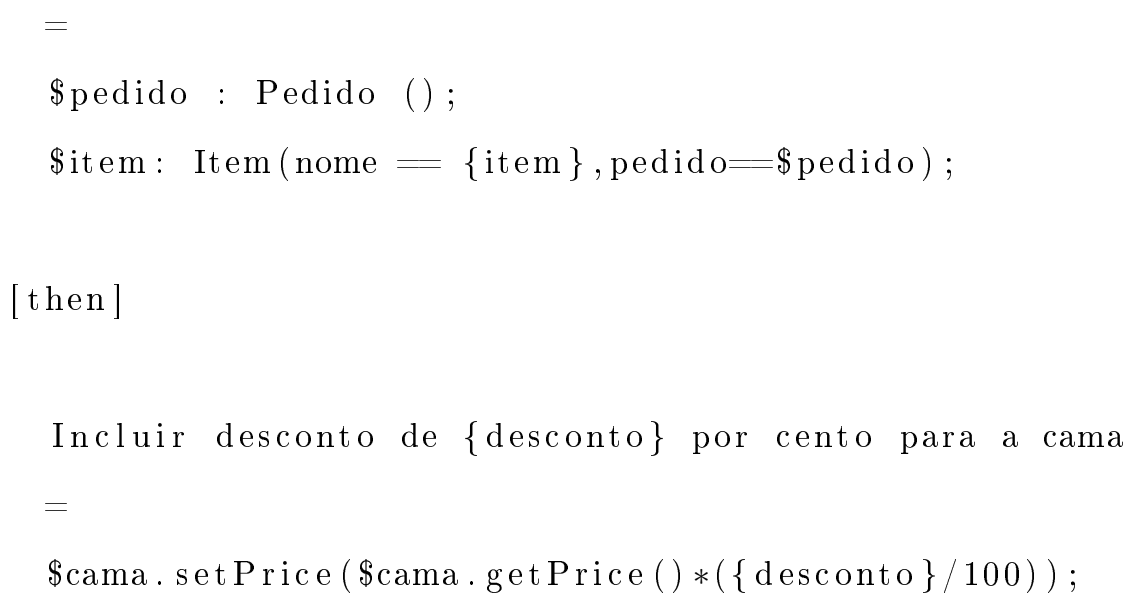

Utilizando a linguagem definida, a regra do exemplo 2 poderia ser reescrita da seguinte forma:

when

Um pedido incluir cama

Um pedido incluir sofá

then

Incluir desconto de 30 por cento para a cama. 


\section{Capítulo 3}

\section{Semantic of Business Vocabulary and}

\section{Business Rules}

O Semantic of Business Vocabulary and Business Rules (SBVR) é um metamodelo mantido pela OMG para a especificação da semântica de modelos de negócios. Com o SBVR, as organizações podem descrever o significado dos seus vocabulários e regras de negócio em uma linguagem formal baseada em lógica de primeira ordem com uma pequena extensão de lógica modal. O objetivo, ao disponibilizar essa linguagem para descrição formal, é permitir que essas organizações possam comunicar informações sobre suas atividades formalmente e independente da forma de representação utilizada. Ao invés de manter o significado das informações na própria linguagem utilizada para representá-las, o SBVR permite que esse significado seja descrito em uma linguagem independente e que pode ser transmitida internamente ou externamente entre setores e empresas que conheçam o padrão. O resultado dessa separação é permitir que o vocabulário e as regras de negócios possam ser expressos por meio de diferentes representações com a possibilidade de perda no significado diminuida. Os engenheiros deste metamodelo optaram por alcançar este objetivo criando uma linguagem abstrata para representar o significado dos conceitos e regras de negócio. Assim estes conceitos e regras podem ser representados em qualquer linguagem que seja inteligível pelas pessoas envolvidas no negócio e transformados em SBVR apenas quando for necessário transmiti-los para outra organização que utilize uma forma diferente de representação. Com isso, estes modelos poderão ser manipulados por pessoas sem habilidades em TI [Bol08], já 
que essa transformação poderá ser feita automaticamente por ferramentas compatíveis com o padrão SBVR.

A semântica dos modelos de negócio é descrita por meio de um conjunto de estruturas . Por meio dessas estruturas é possível que essas comunidades definam formalmente a semântica de dois aspectos dos seus modelos: os vocabulários de negócios e as características dinâmicas do negócio. Essas características dinâmicas são divididas em dois tipos. O primeiro consiste nas regras de negócios que devem ser garantidas pelos sistemas de informação enquanto que o segundo consiste nas políticas ou normas internas da organização. Essas políticas, normalmente, não podem ser diretamente controladas por um sistema de informação porque geralmente estão relacionadas ao comportamento dos indivíduos dessa organização.

A especificação SBVR fornece ainda um metamodelo baseado em MOF [KWB03] permitindo que essas comunidades escrevam o significado dos elementos dos seus vocabulários em documentos XML por meio da tecnologia XMI. Dessa forma, estes documento podem ser manipulados por ferramentas compatíveis com o SBVR/MOF. Além disso, estes documentos podem ser compartilhados com outras organizações permitindo a interoperabilidade da semântica destes elementos. Os princípios deste padrão estão baseados no Model Driven Architecture - MDA $\left[\mathrm{S}^{+} 00\right]$. Dentro da arquitetura de modelos MDA, SBVR se situa na camada CIM - Computer Independent Model.

\subsection{Organização}

A Figura 3.1 apresenta informalmente uma visão geral do modelo SBVR. Os elementos presentes nessa visão são descritos a seguir.

\subsubsection{Comunidade Semântica}

No modelo SBVR, uma comunidade consiste em um grupo de organizações que são relacionadas pelas atividades que exercem. Um exemplo de comunidade seria a de telecomunicações. Um aspecto importante a respeito de comunidades é que elas podem ser formadas por sub-comunidades. Uma sub-comunidade em telecomunicações poderia ser empresas de

telecomunicação móvel. É natural que organizações com atividades semelhantes utilizem 


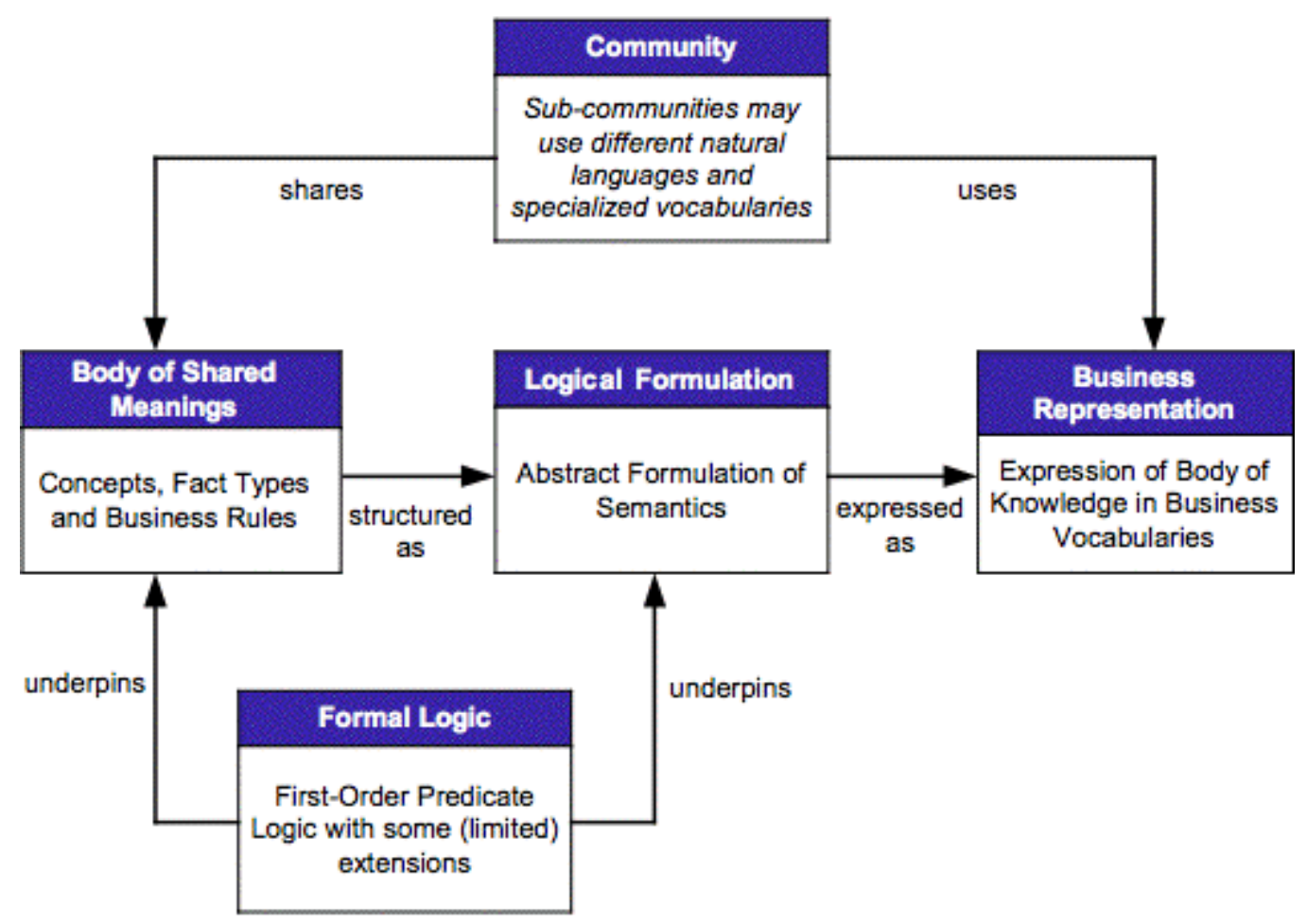

Figura 3.1: Visão geral da especificação SBVR [Tea06]

vocabulários semelhantes para descrever suas atividades. Apesar da existência dessa semelhança, existem ambiguidades nos significados dos conceitos utilizados por essas comunidades. Como exemplo, podemos utilizar o conceito "conta". Este conceito pode ter diferentes significados para organizações diferentes. Em uma empresa de cobrança pode significar uma fatura vencida enquanto que em uma entidade bancária pode significar a associação entre um cliente e o banco. Essas organizações poderão descrever formalmente, por meio da SBVR, o que o conceito "conta" significa. Assim é possível eliminar as ambiguidades na definição deste termo e com isso permitir que ele seja traduzido de um sistema para outro sem que a semântica do mesmo seja perdida.

\subsubsection{Corpo de significado compartilhado}

De acordo com o dicionário Michaelis da língua portuguesa a definição de significar é 1) Ser sinal de; ter a significação ou o sentido de; 2) Dar a entender, exprimir, mostrar, 3) Manifestar-se como; ser; traduzir-se; 4) Ser a representação ou o símbolo de;5) Comunicar, declarar, fazer saber. Um corpo de significado compartilhado consiste em um conjunto de conceitos e regras com um significado compartilhado por uma comunidade semântica. 


\subsubsection{Formulação}

O SBVR fornece uma linguagem abstrata baseada em lógica para a descrição da semântica das regras de negócio. Essa linguagem é formada por um conjunto de estruturas e relacionamentos que são compostos para descrever o significado das regras de negócio. As formulações semânticas são o elemento base para a geração do modelo baseado em eventos apresentado neste trabalho. Por isso, serão descritas com mais detalhes no decorrer deste texto.

\subsubsection{Expressão}

No metamodelo SBVR, a expressão é correspondente à linguagem utilizada para representar o conhecimento, as quais podem ser gráfica, sonora, textual e assim por diante. Apesar dos exemplos na especificação serem dados em uma linguagem chamada Inglês Estruturado, é possível, e fortemente incentivado, o desenvolvimento e utilização de outras linguagens.

\subsection{Representação de regras de negócio em SBVR}

Em SBVR os elementos de vocabulário utilizados para definir as regras de negócio são chamados de direcionamentos (guidances). Esses elementos são divididos em dois tipos: as regras e os avisos. As regras removem de alguma forma a liberdade que uma organização tem em se organizar ou realizar seus procedimentos. Por outro lado, os avisos são espécies de lembretes de que uma liberdade existe. A figura 3.2 apresenta a estrutura macro desses elementos dentro da SBVR.

As regras são divididas em estruturais e operacionais. As regras estruturais definem direcionamentos que são considerados logicamente impossíveis de serem violados. Um exemplo seria a regra "É necessário que um carro possua uma cor". Essa regra estrutural garante que no contexto da comunidade na qual ela foi definida não existem carros que não tenham cor. O significado desta regra poderia ser definido igualmente como "É impossível que um carro não tenha uma cor". Enquanto isso, as regras operacionais são aquelas que apesar de estarem definidas podem ser violadas pela comunidade. Um exemplo seria a regra "É obrigatório que um contrato de aluguel tenha vigência menor ou igual há 10 anos" e sua forma negativa "É 


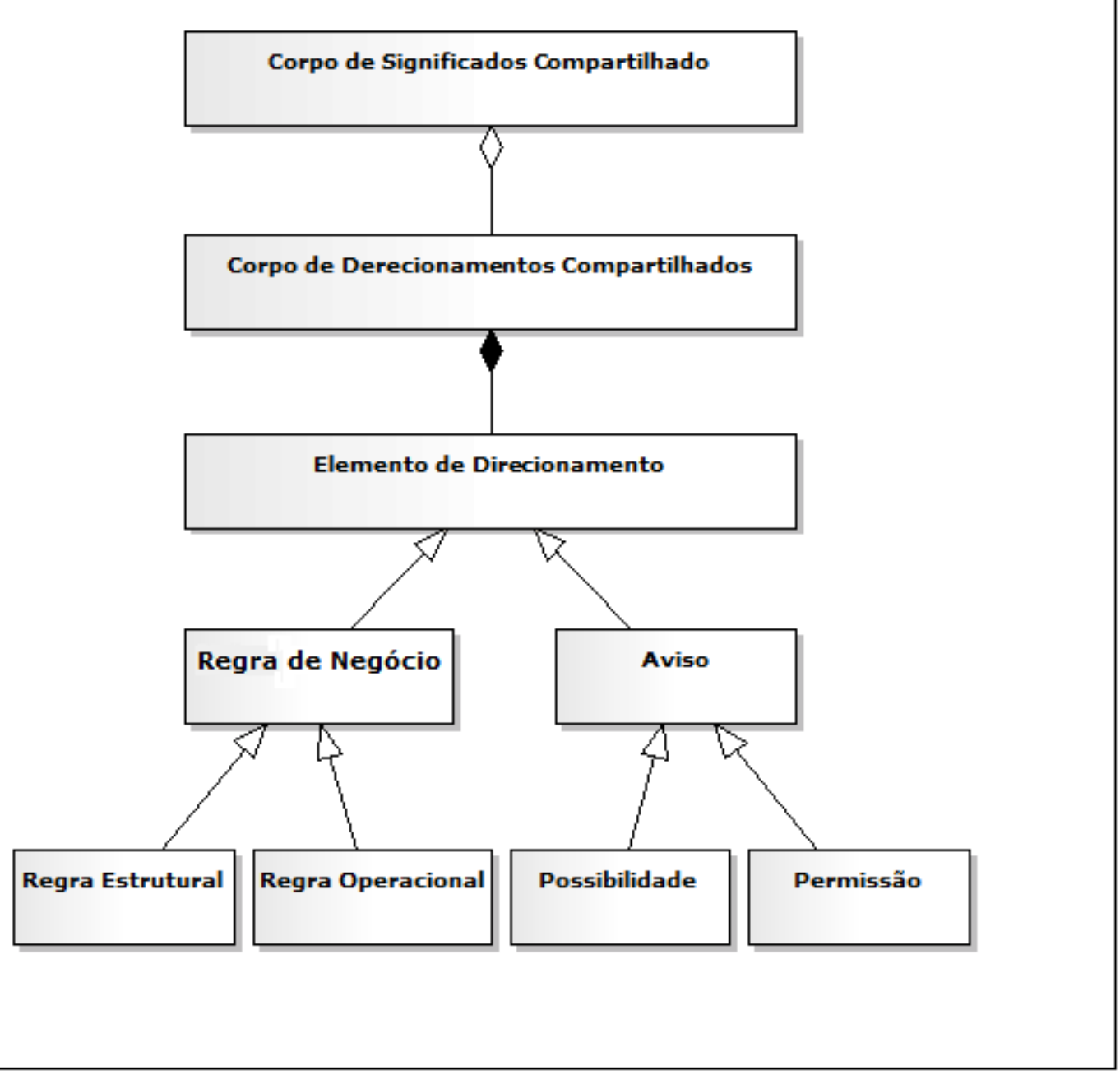

Figura 3.2: Os elementos de direcionamento formam o corpo de elementos de direcionamentos compartilhados que por sua vez faz parte do corpo de significados compartilhados de uma organização. Esses elementos são utilizados para representar as regras e os avisos de uma comunidade semântica. Adaptado de [Tea06].

proibido que um contrato de aluguel tenha vigência superior a 10 anos". A última regra, e sua forma negativa, atestam que a comunidade na qual elas foram definidas não permite um contrato de aluguel com vigência maior do que 10 anos, porém, elas assumem que isso é logicamente possível de acontecer. A diferença lógica entre regras operacionais e estruturais são explicitamente evidenciadas por meio da utilização dos elementos da SBVR obligation e necessity respectivamente. Quando uma regra for operacional deve ser utilizado o elemento obligatory e quando uma regra for estrutural deve ser utilizado o elemento necessary. Semelhantemente, são utilizados os elementos permitted e possible nas formas de negação.

Os avisos são utilizados para declarar que não existe uma regra que proíba algo ou 
que é possível que algo seja verdadeiro. Ou seja, eles são utilizados para deixar claro que não existe nenhuma regra que restrinja algo. Exemplos de avisos são "Um cliente não é proibido de possuir duas contas abertas em mais de uma filial" e "Não existe limite para a quantidade de empréstimos ativos para um cliente". Esses avisos dizem que dentro da comunidade semântica não existe nenhuma regra que restrinja de forma contrária esses dois aspectos.

\subsection{Formulação semântica das regras de negócio}

O padrão SBVR prove um conjunto de estruturas semânticas que são utilizadas para definir o significado das regras de negócio. A utilização dessas estruturas é feita por meio de uma formulação semântica que consiste em uma estruturação conceitual do significado de uma regra. Essa estruturação utiliza conceitos lógicos tais como quantificadores, variáveis, negações, implicações, conjunções e disjunções que são encontrados implicitamente na definição de regras de negócio e os define explicitamente. Isso permite que o significado da regra seja desacoplado de sua representação. Além disso, isso viabiliza o intercambio do significado dessas regras entre ferramentas ou grupos de pessoas que utilizam diferentes formas de representação.

As formulações semânticas em SBVR são divididas em dois tipos de estruturas: as formulações lógicas e as projeções. As formulações lógicas definem proposições. Essas proposições podem ser atômicas, de instanciação, modais, operações lógicas, quantificações dentre outras. As projeções são formulações que definem variáveis que satisfazem conjuntos de condições. Cada uma dessas estruturas possui um significado preciso definido na especificação SBVR. Além disso, são definidas as necessidades, características e inter-relacionamentos de cada uma delas.

O significado de uma regra de negócio é definido em SBVR por meio das estruturas de formulação semântica. Essas formulações podem ser recursivas, ou seja, uma formulação pode ser formada fazendo uso de outra formulação. Por exemplo, para formular a semântica da regra "Um cliente ativo é um cliente que não está bloqueado e já tenha efetuado compras" seria utilizada uma formulação de obrigação juntamente com uma formulação lógica para 


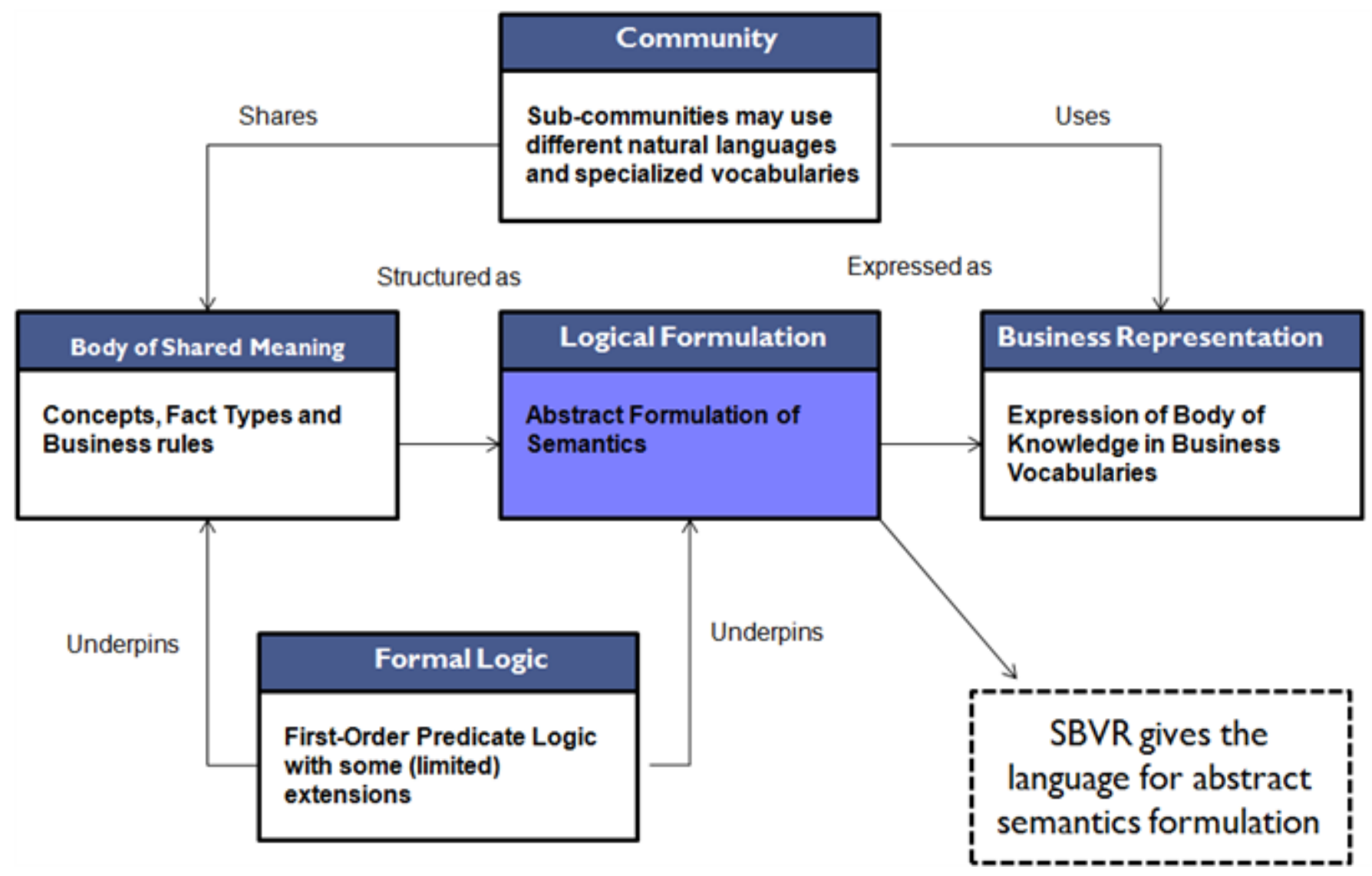

Figura 3.3: A formulação lógica, viabilizada pela SBVR, permite que as organizações definam formalmente o significado das expressões que elas utilizam. Adaptado de [Tea06].

representar a conjunção presente na regra. As principais estruturas semânticas fornecidas pelo SBVR estão ilustradas na figura 3.4.

\subsubsection{Exemplos de formulação semântica}

Abaixo estão ilustrados alguns exemplos de formulação semântica de regras de negócio. Esses exemplos foram construídos utilizando o padrão para descrição de formulação semântica encontrado na especificação da SBVR[Tea06]. Trata-se de uma descrição textual e estruturada sobre a semântica de uma regra em termos das estruturas da SBVR. 


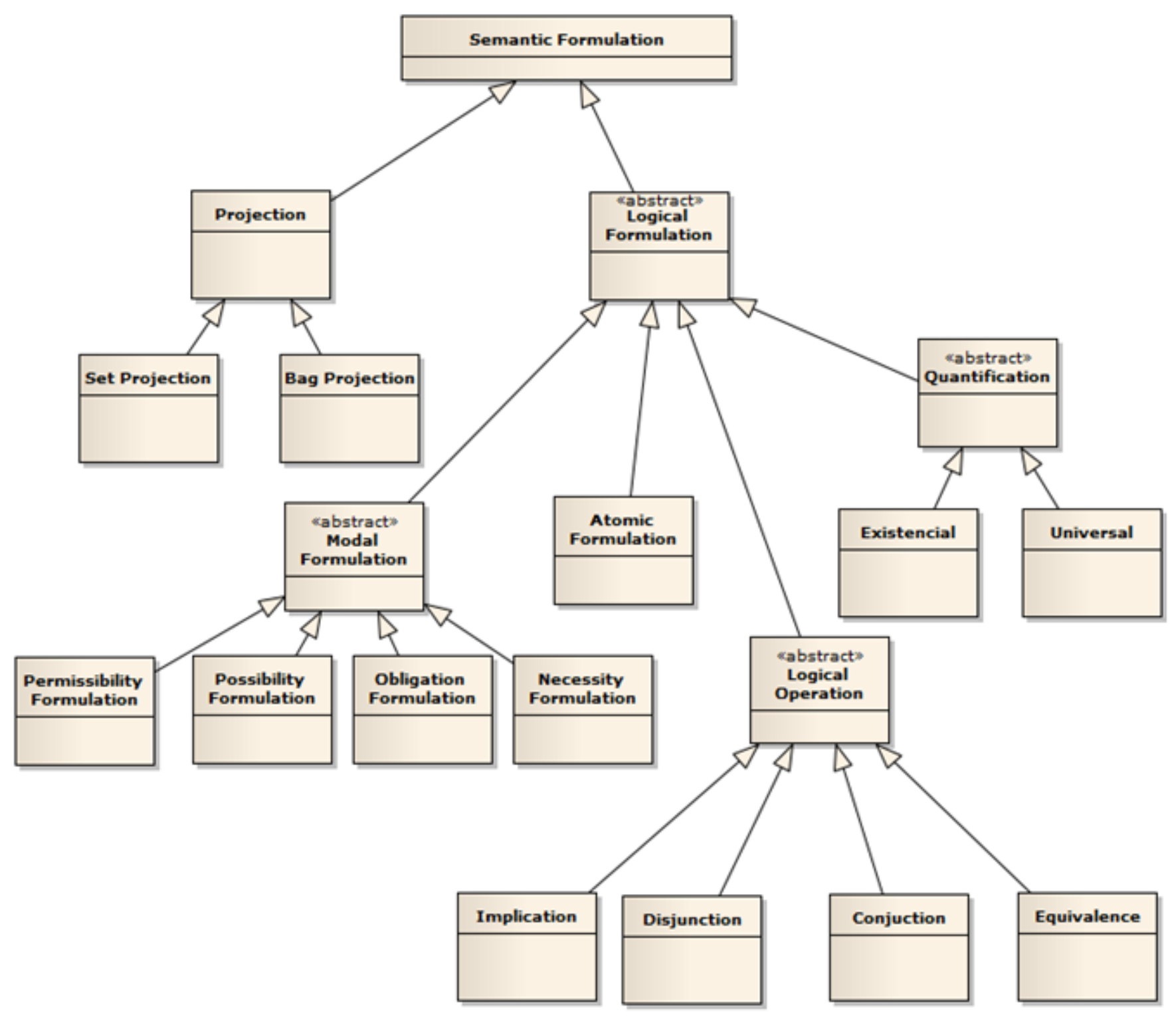

Figura 3.4: Os principais elementos do padrão SBVR para a formulação semântica.

\section{Exemplo 1}

"Its Obligatory that an account must have exactly one holder"

(1) The rule is a proposition meant by an obligation formulation.

(2) That obligation formulation embeds a universal quantification.

(3) The universal quantification introduces a first variable. 
(4) The first variable ranges over the concept 'Account'.

(5) The universal quantification scopes over an exactly-one quantification

(6) The exactly-one quantification introduces a second variable.

(7) The second variable ranges over the concept 'holder'.

(8) The exactly-one quantification scopes over an atomic formulation.

(9) The atomic formulation is based on the fact type 'Account has holder'.

(10) The atomic formulation has a role binding.

(11) The role binding is of the role 'account' of the fact type.

(12) The role binding binds to the first variable.

(13) The atomic formulation has a second role binding.

(14) The second role binding is of the role 'holder' of the fact type.

Na linha (1) é indicado que a regra de negócio se trata de uma obrigação. Isso indica que a comunidade que a definiu determinou que ela deve ser seguida mas, assume que é possível que isso não aconteça. Ou seja, que podem existir cenários onde essa regra esteja violada.

A linha (2) indica que a regra é definida por uma quantificação universal. Essa quantificação introduz uma variável na linha (3) e conforme a linha (4) essa variável referencia instâncias do conceito Account .

A linha (5) diz que as instâncias que referenciam a variável introduzida na linha (3) devem obedecer as restrições impostas por uma quantificação do tipo exactly-one. Essa quantificação introduz uma nova variável do conceito holder conforme as linhas (6) e (7).

A linha (8) determina que as instâncias que referenciam a segunda variável que foi introduzida na linha (6) devem estar de acordo com as restrições impostas por uma formulação atômica baseada no fato Account has holder conforme a linha (9).

O fato Account has holder possui os papéis account e holder que são atribuídos respectivamente a primeira e segunda variável conforme as linhas (10), (11), (12), (13) e (14).

\section{Exemplo 2}

"each product belongs to exactly 1 family"

(1) The rule is a proposition meant by a necessity formulation.

(2) The necessity formulation embeds a universal quantification. 
(3) The universal quantification introduces a first variable.

(4) The first variable ranges over the concept 'product'.

(5) The universal quantification scopes over an exactly one quantification

(6) The exactly one quantification introduces a second variable.

(7) The second variable ranges over the concept 'family'.

(8) The exactly one quantification scopes over an atomic formulation.

(9) The atomic formulation is based on the fact type 'product belongs to family'.

(10) The atomic formulation has the first role binding.

(11) The first role binding is of the role 'product'.

(12) The first role binding binds to the first variable.

(13) The atomic formulation has the second role binding.

(14) The second role binding is of the role 'family'.

(15) The second role binding binds to the second variable.

A linha (1) indica que esta regra de negócio especifica uma necessidade. Isso significa que em todos os "mundos" possíveis [Gir00], essa restrição deve ser respeitada.

Na linha (2) é indicado que esta necessidade é caracterizada por uma quantificação universal. Isso quer dizer que a verdade declarada pela regra deve se aplicar a todas as instancias dos conceitos sendo restringidos.

As linhas (3) e (4) explicitam que a quantificação universal criada na linha (2) introduz uma nova variável na formulação. Essa variável tem como domínio todos as instancias do conceito produto.

Na linha (5) é utilizada a estrutura Quantification escopes over Logical formulation. Isso indica que todas as referencias da variável introduzida pela quantificação satisfazem as condições impostas pela formulação lógica. Isso significa que a formulação lógica sempre será verdade para todas as instancias da variável sendo quantificada. No caso deste exemplo, a formulação lógica que restringe a quantificação é outra quantificação. Porém, essa quantificação é existencial.

As linhas (6) e (7) explicitam que a quantificação existencial criada na linha (6) introduz uma nova variável na formulação. Essa variável tem como domínio todos as instancias do conceito "family". 
A linha (8) indica que a quantificação existencial criada na linha (6) é restringida por uma formulação atômica.

Na linha (9) a formulação atômica citada na linha (8) é baseada no fact type "product belongs to family".

Nas linhas (10), (11) e (12) é indicado que o papel "product" do fact type "product belongs to family' é a atribuído a primeira variável que foi introduzida na linha (3).

As linhas (13), (14) e (15) indicam que o papel "family" do fact type "product belongs to family" é a atribuído a segunda variável que foi introduzida na linha (6). 


\section{Capítulo 4}

\section{Transformação de regras em SBVR para}

\section{$\pi$-calculus}

Neste capítulo serão apresentados os processos para a transformação de regras de negócio, especificadas em SBVR, em modelos baseados em eventos definidos formalmente em $\pi$-calculus. Essa transformação se faz necessária já que com o SBVR é possível apenas definir formalmente o significado de uma regra de negócio diminuindo assim a ambiguidade no entendimento. Entretanto, os procedimentos necessários para que essas regras sejam efetivamente consideradas em uma aplicação real estão fora do escopo da SBVR.

Um dos aspectos iniciais que deve ser considerado para que essas regras sejam implementadas é o da identificação da existência de condições que justifiquem a necessidade de verificação da conformidade do estado atual do sistema em relação às regras de negócio definidas. É preciso identificar os momentos em que essa conformidade precisa ser verificada. Em um cenário ideal, a verificação de uma regra deve ser realizada apenas quando existe a possibilidade da regra ter sido transgredida ou estiver prestes a ser transgredida. Como uma organização pode possuir uma quantidade expressiva de regras, torna-se inviável verificar todas elas dentro de um intervalo regular de tempo ao invés de ser utilizada uma técnica que utilize menos recursos de processamento. Não faz sentido verificar o cumprimento de uma regra definida que envolva algum elemento que não tenha sido criado, modificado ou excluído desde a última verificação realizada. Ou seja, se em um determinado momento não houve alteração no conjunto de instâncias dos conceitos relacionados às regras desde a última 
verificação, não faz sentido avaliar se as mesmas foram ou não violadas.

Uma forma de identificar os momentos onde uma verificação de conformidade se faz necessária é utilizando eventos que sinalizem quando houve a criação, modificação ou exclusão de um elemento que esteja relacionado a uma das regras de negócio definidas. Com base nessa notificação, deve ser avaliado se houve ou não violação das regras em questão.

A verificação de conformidade de uma regra de negócio não é uma atividade trivial. É necessária a utilização de algoritmos sofisticados como o RETE [For82] que são implementados em motores de regras como o Drools [Bro09] e Jess $\left[\mathrm{FH}^{+} 05\right]$. Tendo em vista isso, é razoável que esses motores sejam um elementos individual dentro de uma arquitetura de software ao invés de serem implementados como parte de algum outro componente. Isso permite que diferentes motores de regra sejam utilizados de acordo com a necessidade da aplicação. Além disso, essa separação permite que os motores possam evoluir independentes dos outros elementos da arquitetura.

Seguindo esse pensamento de manter separada a verificação de conformidade do sistema em relação às regras de negócio dos outros elementos da arquitetura é necessário que a comunicação desses motores de regras com esses outros elementos seja viabilizada. Neste trabalho vamos considerar o problema de comunicação entre os motores de regras e o restante dos elementos da arquitetura de software de um sistema de informação. Uma das vantagens diretamente obtidas dessa separação é a de que as regras de negócio não ficarão espalhadas dentro dos elementos da arquitetura. Ao invés disso, elas serão explicitamente definidas nos motores de regras e poderão ser alteradas independentemente.

Neste capítulo será apresentado um protocolo abstrato de comunicação entre os motores de regras e o restante da arquitetura de um sistema de informação. Será apresentado um método para a instanciação desse protocolo abstrato à partir da formulação semântica em SBVR das regras de negócio. Esse protocolo e esse método foram desenvolvidos seguindo os seguintes passos:

1. Foi percebida uma relação entre as variáveis das formulações semânticas em SBVR e os eventos que podem levar o sistema a um estado de não conformidade em relação a alguma regra de negócio. 
2. Esses eventos foram utilizados como base para a modelagem em $\pi$-calculus de um protocolo de comunicação formal e abstrato. Esse protocolo descreve a comunicação entre os motores de regras de negócio e o restante dos elementos em uma arquitetura de software.

3. Comunidade define regras de negócio utilizando algum modelo que seja adequado as suas necessidades. Existe uma grande quantidade de opções para essa escolha. Desde modelos criados exclusivamente para representação de regras de negócio até modelos mais gerais tais como UML e linguagem natural. São criadas em SBVR formulações semânticas destas regras utilizando alguma metodologia que está fora do escopo deste trabalho como também do escopo da SBVR. Alguns exemplos de abordagem são [BLB11], [CPR10], [PC08] e [PCR09].

4. É utilizado um método para a instanciação do protocolo de comunicação à partir de cada uma das formulações semânticas das regras de negócio. É gerada uma instância do protocolo de comunicação sugerido neste trabalho para cada uma das regras de negócio. Esse protocolo é modelado em $\pi$-calculus e destaca os eventos que devem ocorrer para que seja necessário verificar a conformidade do sistema em relação às regras de negócios e como a ocorrência desses eventos deve ser comunicada para os motores de regras.

5. Esses modelos em $\pi$-calculus são utilizados em alguma arquitetura específica para a implementação da comunicação entre os elementos desta arquitetura e os motores de regras de negócio.

Iremos agora descrever com detalhes os passos 1,2 e 4 que estão dentro do escopo deste trabalho. O passo 5 será explicado no Capítulo 5 onde é apresentado um sistema exemplo baseado nas propostas sugeridas neste trabalho. 


\subsubsection{As variáveis da formulação semântica SBVR e os eventos de violação.}

As variáveis nas formulações semânticas em SBVR são elementos que indicam quais são os conceitos envolvidos com a regra de negócio sendo descrita. Essas váriáveis são definidas por meio de quantificações que são um tipo de formulação semântica. Sabendo que nossa proposta para o protocolo de comunicação é baseada nas inserções de variáveis feitas pelas quantificações, vamos detalhar melhor esse elemento da formulação semântica da SBVR. Uma descrição a respeito das formulações semânticas em SBVR pode ser encontrada na seção 3.3 do Capítulo 3 ou na especificação completa do padrão [Tea06].

Em uma formulação semântica uma variável representa a referência para um conjunto, possivelmente vazio, de instâncias. Todas as instâncias de uma variável devem ser de no máximo um conceito. Ou seja, uma variável não pode referenciar instâncias de conceitos diferentes. As referências de uma determinada variável são definidas pela quantificação que a introduziu como também pela formulação semântica que restringe a variável.

Conforme dito anteriormente, o papel de uma quantificação é introduzir uma variável em uma formulação semântica e explicitar as restrições aplicadas a esta variável. Essas restrições podem ser de dois tipos. O primeiro é relacionado à quantidade de elementos que referenciam aquela variável. Ou seja, esse primeiro tipo de restrição define que uma quantidade determinada ou indeterminada de elementos daquela variável deve existir. As restrições indeterminadas são do tipo que dizem que o número de elementos deve ser no mínimo $x$, no máximo $x$, entre $x$ e $y$ ou todos os existentes. As restrições determinadas são as que indicam o número exato de elementos que devem existir.

O segundo tipo de restrição é feito por meio de uma formulação de escopo. Essa formulação define quais propriedades uma referência da variável deve possuir para ser considerada na formulação semântica. Essa formulação de escopo nada mais é do que outra formulação semântica que pode ser atômica, lógica ou até mesmo outra quantificação.

Na regra de negócio "É necessário que uma nota fiscal tenha pelo menos um modelo" encontramos duas variáveis. A primeira é a variável nota fiscal introduzida por uma quantificação universal. A segunda é a variável modelo introduzida por uma quantificação existencial. 
O conjunto de instâncias da primeira variável é restringido pela necessidade de que essa nota fiscal tenha um ou mais modelos. Enquanto isso, o conjunto de instâncias da segunda variável é restringindo pela necessidade de que o modelo esteja associado a uma nota fiscal referenciada na primeira variável.

Todos os tipos de quantificações presentes na SBVR estão ilustrados na figura 4.1.

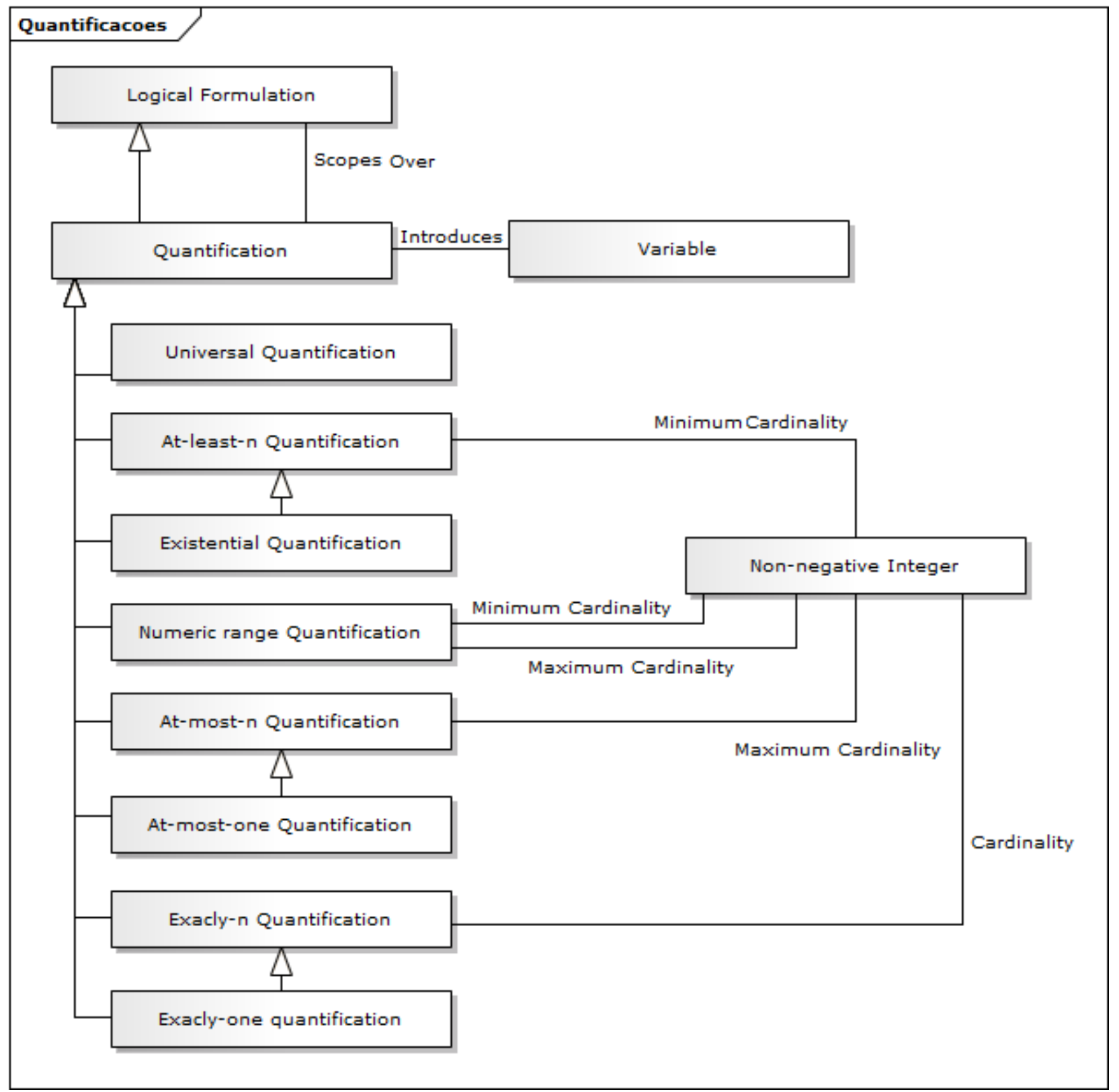

Figura 4.1: Estrutura das quantificaçôes em SBVR. Imagem adaptada de [Tea06].

No exemplo a seguir é fornecida uma formulação semântica envolvendo quantificações. O objetivo darmos desse exemplo é descrever com mais detalhes a função das quantificações e a relação delas com os demais elementos da formulação semântica. 


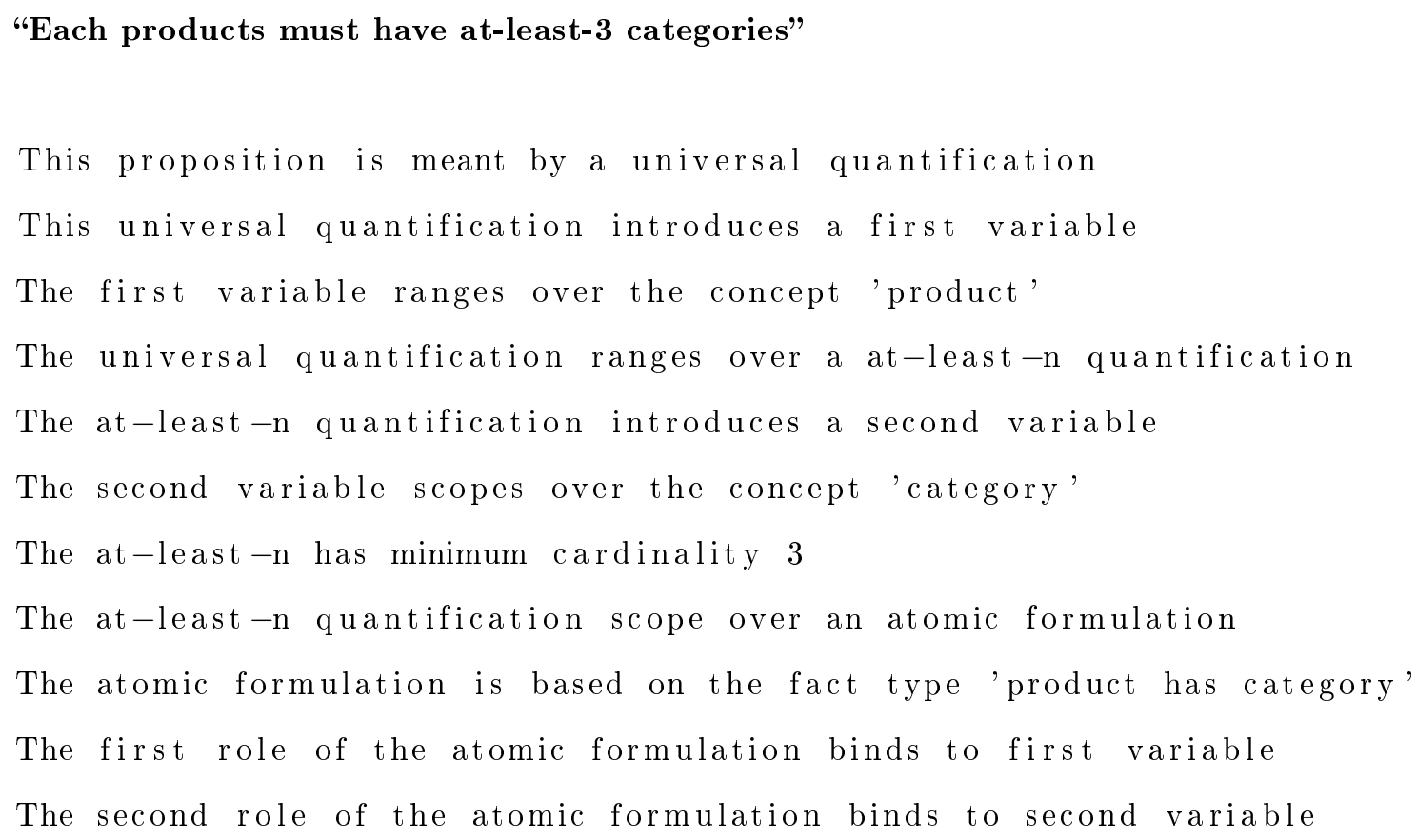

Neste exemplo podemos visualizar a ocorrência de duas quantificações. A primeira quantificação introduz a variável product. Essa quantificação é do tipo universal e isso significa que as restrições impostas as instâncias referentes a essa variável se aplicam a todas essas referências. Ou seja, todas as referências devem estar de acordo com as restrições. A segunda quantificação introduz a variável category. Essa quantificação é do tipo no mínimo $n$ e possui cardinalidade igual a três. Isso quer dizer que as restrições impostas as instâncias que referenciam essa variável devem ser verdadeiras pelo menos para três dessas instâncias ao invés de todas como vemos na primeira quantificação. Deve se notar que a segunda quantificação possui dois tipos de restrição. A primeira é a própria cardinalidade da quantificação "no mínimo $n$ " e a segunda é definida por uma formulação atômica que limita as instâncias referentes à essa variável naquelas que fazem parte de uma instância de um fato do tipo product has category onde o produto seja um dos produtos que são referentes a primeira variável.

As variáveis introduzidas pelas quantificações indicam quais conceitos estão relacionados à regra de negócio sendo descrita. Esse fato é importante, pois, indica que as instâncias desses conceitos devem ser de alguma forma monitoradas já que mudanças na população dessas instâncias podem levar a alguma violação da regra de negócio. No exemplo "Each products must have at-least-3 categories" sempre que uma categoria ou produto forem alterados é 
necessário que a regra seja verificada.

\subsection{Protocolo de comunicação}

Para definir como deve ser feita a comunicação entre os motores de regra e o restante da arquitetura de um sistema de informação será definido um protocolo padrão de comunicação. Esse protocolo será utilizado para que as regras de negócio sejam implementadas de uma forma onde as mesmas possam ser gerenciadas separadamente do restante da arquitetura ao invés de estarem implicitamente definidas dentro de outros elementos. Esse protocolo é necessário já que essa comunicação não é trivial e não é desejável que para cada situação onde essa separação seja necessária, seja construída uma solução particular. Ao invés disso, estamos fornecendo uma proposta de uma solução abstrata que pode ser adaptada para situações diversas. Esse protocolo foi definido formalmente por meio da álgebra de processo $\pi$-calculus . A seguir serão dadas algumas informações a respeito desse formalismo e como ele pode ser utilizado para a representação de protocolos de comunicação baseados em eventos.

\subsubsection{Representação de eventos em $\pi$-calculus}

Nossa proposta tem como objetivo tornar as regras de negócio e o restante da arquitetura de um sistema de informação dois elementos separados que executam paralelamente. Com isso, deve existir comunicação entre esses elementos. Uma das formas de analisar essa comunicação é por meio de uma álgebra de processos. Essa abordagem permite que resultados da comunidade de modelagem formal de sistemas concorrentes sejam utilizados.

O $\pi$-calculus é um modelo criado por Robin Milner [Mi199] que faz parte do conjunto de técnicas de descrição formal para a modelagem de sistemas concorrentes chamadas de álgebras de processos [BPS01]. Por meio desse modelo, podemos descrever formalmente o comportamento e a comunicação de processos concorrentes. Com base nessa descrição algébrica, é possível extrair propriedades como a não existência da possibilidade de deadlock ou a prova de que um determinado estado do sistema nunca será alcançado. Outra possibilidade trazida por esse arcabouço, é a de verificar a equivalência entre dois ou mais processos por meio do conceito de bissimulação [Mil99]. Todos esses benefícios podem ser obtidos utili- 


\begin{tabular}{|l|l|}
\hline Operador & Descrição \\
\hline$P=Z \mid Q$ & Processos Z e Q executando em paralelo \\
\hline$P=a \cdot Q$ & Processo executa a ação "a" e depois se comporta como Q \\
\hline$P=(a+b) \cdot Q$ & Processo que se comporta como "a" ou como "b" e depois como Q \\
\hline$P=a(x) \cdot Q$ & Processo que espera receber um valor "x" do canal "a" e depois se comporta como Q \\
\hline$P=\bar{a}\langle x\rangle \cdot \mathrm{Q}$ & Processo que espera enviar um valor "x" pelo canal "a" e depois se comporta como Q \\
\hline
\end{tabular}

Tabela 4.1: Principais construções sintáticas do $\pi$-calculus

zando resultados já provados e consolidados pela comunidade de pesquisa envolvida com o $\pi$-calculus. A sintaxe básica do $\pi$-calculus é apresentada na Tabela 4.1.

Uma das características que diferenciam o $\pi$-calculus das outras álgebras de processo é o conceito de mobilidade. Esse conceito é fundamentado na possibilidade dos canais de comunicação entre dois processos podem mudar com o tempo. Isso quer dizer que dois processos que não se comunicavam no início podem vir a se comunicar no decorrer da execução do sistema. Semelhantemente, é possível que dois processos que se comunicavam em um determinado instante possam deixar de se comunicar. Isso é viabilizado em $\pi$-calculus pela possibilidade de enviar canais de comunicação por meio de canais de comunicação.

Abaixo está a descrição de um exemplo de um processo concorrente modelado em $\pi$ calculus.

$$
\begin{aligned}
& \mathrm{P} 1=\mathrm{a}(\mathrm{x}) \cdot \tau \cdot \mathrm{x}(\mathrm{y}) \cdot \mathrm{P} 1 \\
& \mathrm{P} 2=(c(z) \cdot \bar{a}\langle z\rangle+d(w) \cdot \bar{a}\langle w\rangle) \cdot \mathrm{P} 2 \\
& \mathrm{~S}=\mathrm{P} 1 \quad \mathrm{P} 2
\end{aligned}
$$

Neste exemplo temos dois processos concorrentes P1 e P2. O processo P2 se comunica com o processo P1 sempre por meio do canal "a". Entretanto, a comunicação do processo P1 com o processo P2 pode ser feita pelo canal "z" caso seja transmitida alguma comunicação por meio do canal "a" ou pelo canal w caso seja transmitida alguma comunicação por meio do canal "d". Essa variação da comunicação do processo P1 com o processo P2 é um exemplo da aplicação do conceito de mobilidade já que os canais de comunicação utilizados pelos processos mudam ao decorrer do tempo. 


\subsubsection{O protocolo de comunicação}

Para cada regra de negócio definida deverá haver um modelo em $\pi$-calculus que indicará como deve ser feita a comunicação com os motores de regra a fim de que essa regra possa ser verificada. Esses modelos serão instâncias de um protocolo de comunicação abstrato que é descrito da seguinte forma:

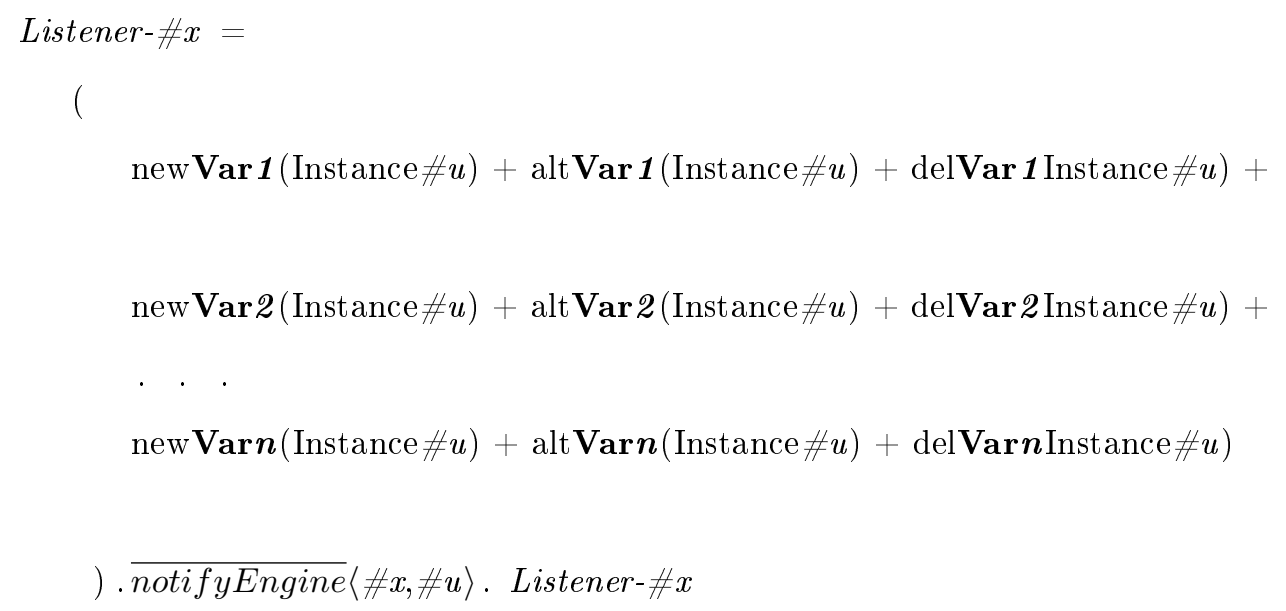

Essa descrição é formada por três processos:

- O processo Listener-\#x tem o objetivo de monitorar os eventos que ao ocorrerem indicam a necessidade de verificação da regra de negócio \#x. Esse processo é formado pela soma dos eventos de alteração, remoção e criação de todas as variáveis dos conceitos relacionados a regra de negócio. Ou seja, para cada variável inserida por uma quantificação na formulação semântica há um conjunto de três ações dentro do processo Listener. Na ocorrência de qualquer um desses eventos é acionada a ação notifyEngine do processo Notifier. Essa ação é acionada com a passagem de dois parâmetros \#x e $\# u$. O parâmetro $\# x$ é o número da regra de negócio enquanto que o parâmetro \#u representa uma identificação da instância que foi alterada, removida ou criada. Após o acionamento da ação notifyEngine o processo Listener-\#x é acionado novamente e volta a monitorar os eventos relacionados a regra de negócio $\# x$. 
- O processo Notifier-\#x é o responsável por receber a indicação da ocorrência de algum evento que possa levar o sistema a um estado de não conformidade em relação a regra de negócio \#x e notificar os motores de regras para que os mesmos verifiquem efetivamente se a regra foi ou não violada. Essa notificação é representada pela ação silenciosa $\tau$.

- Por último temos o processo Integrator-\#x que realiza uma composição paralela entre os processos Notifier-\#x e Listener-\#x. Essa composição é necessária já que esses elementos devem ser executados em paralelo para que o comportamento total do protocolo seja obtido.

É importante dizer que os modelos em $\pi$-calculus gerados por meio desse método não contém toda a informação existentes originalmente na formulação semântica em SBVR. Os modelos gerados só possuem as informações necessárias para a identificação do momento na qual uma verificação de conformidade é necessária. Isso implica que não é possível realizar uma transformação no sentido modelo $\pi$-calculus para SBVR. Isto é, não é possível derivar a formulação semântica de uma regra de negócio com base apenas no modelo em $\pi$-calculus.

\subsection{Transformação de regras em SBVR para o protocolo de comunicação em $\pi$-calculus}

Apesar do structured english [Tea06] ser utilizado para definir os elementos da SBVR, ele é apenas um exemplo de linguagem que uma comunidade pode utilizar para descrever seus elementos de negócio e dessa forma não faz parte do meta-modelo SBVR. Por isso, as transformações apresentadas neste trabalho são feitas a partir da formulação semântica das regras de negócio em SBVR. Com base no significado das regras de negócio, definidas por meio das estruturas de formulação semântica da SBVR, vamos gerar uma representação em $\pi-$ calculus de processos que conseguem identificar o momento em que a conformidade do sistema em relação a essas regras precisa ser verificado.

O momento onde uma regra precisa ser verificada sempre estará associado a alguma alteração no conjunto das instâncias dos conceitos que estejam relacionados à regra. Isto é, devemos verificar se o estado atual do sistema está de acordo com uma regra apenas quando 
houver a inclusão, remoção ou alteração de uma instância de algum conceito que esteja relacionado a regra. Logo, os modelos gerados neste trabalho têm como objetivo capturar o momento em que ocorre alguma alteração na população de instâncias dos conceitos que estão relacionados a cada regra de negócio sendo considerada e notificar os motores de regras para que os mesmos possam verificar a conformidade do sistema.

Conforme dito anteriormente, a base para a criação dos modelos em $\pi$-calculus será a formulação semântica da regra de negócio em SBVR. Essa formulação deve ser obtida da representação utilizada pela comunidade semântica utilizando alguma metodologia que está fora do escopo deste trabalho. Uma abordagem para a obtenção de modelos baseados em SBVR com base em linguagem natural está descrita em [BLB11].

\subsubsection{Método de Transformação de SBVR para $\pi$-calculus}

A extração dos modelos em $\pi$-calculus das formulações semânticas em SBVR será feita por meio de um método de transformação. Por meio desse método será definido quais e como os elementos das formulações semânticas em SBVR serão mapeados para os elementos dos modelos em $\pi$-calculus. Conforme dito anteriormente, a base para essa transformação serão as variáveis introduzidas pela formulação semântica. Logo, os passos desse método indicarão identificar essas variáveis na formulação semântica das regras de negócio em SBVR e indicar como elas devem ser representadas no modelo em $\pi$-calculus.

A base para esse método de transformação será a formulação semântica da regra de negócio definida em SBVR. A saída será o modelo em $\pi$-calculus equivalente. A seguir cada um dos passos desse método será apresentado.

\section{Para cada formulação semântica de regra de negócio \#x em SBVR}

Deve ser criado um processo chamado Listener-\#x. Esse processo será responsável por identificar os eventos relacionados às alterações nas instâncias dos conceitos envolvidos com a regra de negócio e enviar as informações sobre a ocorrência desses eventos para o processo Notifier-\#x. As informações enviadas devem ser a identificação da regra de negócio que possivelmente pode ter sido violada após a ocorrência do evento e a identificação da instância na qual houve a alteração que gerou o evento. 


\section{Para cada formulação semântica de regra de negócio $\# x$ em SBVR}

Deve ser criado um processo chamado Notifier-\#x. Esse processo será responsável por reunir as informações a respeito do evento coletadas pelo processo Listener e enviar essas informações para os motores de regras a fim de que a conformidade do sistema, em relação à regra em questão, seja verificada. O envio das informações a respeito do evento detectado é representado no modelo como uma ação silenciosa $\tau$.

\section{Para cada formulação semântica de regra de negócio \#x em SBVR}

Deve ser criado um processo chamado integrator-\#x e irá conter uma composição paralela entre o processo Listener-\#x e o processo notifier-\#x.

4. Para cada variável introduzida por uma quantificação na formulação da regra de negócio \#x em SBVR

Deve ser criada uma ação dentro do processo Listener-\#x para cada evento relacionado às instâncias referentes a esta variável. Esses eventos representarão as possíveis alterações que podem ser realizadas em um instância e que justifiquem uma nova verificação de conformidade da regra de negócio \#x. Esses eventos são a exclusão de uma instância, a alteração de uma instância e a inclusão de uma nova instância. Cada um desses eventos é representado no processo Listener-\#x respectivamente por meio das ações del, alt e new. Caso uma formulação semântica possua quantificações que introduzam variáveis de um mesmo conceito, só deverá ser incluída no modelo a primeira inserção. Essas ações recebem como parâmetro a identificação da instância que sofreu alteração. Essa identificação é representada pelo texto Instance \# $u$. As ações relacionadas a uma variável devem ser organizadas dentro do processo como um somatório de alternativas. Assim, o processo listener-\#n só poderá captar um evento de cada vez.

\subsection{Exemplos de transformação}

Em seguida neste texto serão dados exemplos de transformações de SBVR para $\pi$ calculus. Esses exemplos trazem uma regra de negócio e sua respectiva formulação semântica e em seguida a representação do modelo em $\pi$-calculus que explicita quais eventos devem ser 
observados a fim de identificar o momento onde a verificação de conformidade da regra precisa ser realizada. As linhas onde as variáveis das regras são introduzidas foram destacadas a fim de explicitar quais as linhas da formulação semântica foram utilizadas como base para a geração do modelo em $\pi$-calculus. As formulações semânticas utilizadas nesses exemplos foram adaptadas de [Tea06].

\subsubsection{Exemplo 1}

No primeiro exemplo utilizaremos a regra de negócio "Its necessary that a order must have one or more item". Esta regra indica que em todas as circunstâncias uma ordem precisa ter um ou mais itens. Neste exemplo temos uma regra de negócio com duas variáveis, order e item, introduzidas por uma quantificação universal e uma quantificação no mínimo n. Seguindo as regras para a transformação, os primeiros passos são criar os processos Listener1, Notifier-1 e Integrator-1. O segundo passo consiste em definir que o processo Listener-1 será uma soma das ações newOrder, altOrder, delOrder, newItem, altItem e delItem. Essa soma será seguida pela ação de saída $\overline{\text { notifyEngine }}\langle \# 1$, \#u $\rangle$ onde o número um é referente ao número da regra de negócio e \#u é referente à identificação da instância na qual houve a alteração que gerou o evento. A seguir será apresentada a formulação semântica desta regra de negócio e logo em seguida o modelo em $\pi$-calculus gerado.

Formulação semântica da Regra de Negócio 1

"Its necessary that a order must have one or more item"

This rule is meant by a obligatory claim

The obligatory claim is embebed by a universal quantification

The universal quantification introduces a first variable

The first variable ranges over the concept " order, ,

The universal quantification scopes over an at-least-n quantification

The at-least $-n$ quantification has the minimum cardinality 1

The at-least-n quantification introduces a second variable

The second variable ranges over the concept " item, ,

The at-least-n quantification scopes over an atomic formulation

The atomic formulation is based on the fact type "order has item, , 
The atomic formulation has a first role binding

The first role binding is of the role "'order, of the fact type

The first role binding bins to the first variable

The atomic formulation has a second role binding

The second role binding is of role "item", of the fact type

The second role binding binds to the second variable

\title{
Modelo em $p i$-calculus referente à regra de negócio 1
}

\author{
Listener-\#1 = \\ $\operatorname{new} \operatorname{Order}(\# u)+\operatorname{alt} \operatorname{Order}(\# u)+\operatorname{delOrder} \# u)+$ \\ $\operatorname{new} \operatorname{Item}(\# u)+\operatorname{altItem}(\# u)+\operatorname{del} \operatorname{Item} \# u)$ \\ ). $\overline{\text { notifyEngine }}\langle \# 1, \# u\rangle$. Listener-\#x \\ Notifier-\#1 = notifyEngine $(\# x, \# u) \cdot \tau$. Notifier-\#1 \\ Integrator-\#1 = Listener-\#1 | Notifier-\#1
}

\subsubsection{Exemplo 2}

Neste segundo exemplo utilizaremos a regra de negócio "It is prohibited that a rental is open if an estimated rental charge is not provisionally charged for the rental". Essa regra determina que um aluguel não pode estar com o status aberto se uma estimativa de custo não foi definida para o mesmo. Esta regra de negócio também possui duas variáveis, rental e estimated rental charge. A primeira é introduzida por uma quantificação universal enquanto que a segunda é introduzida por uma quantificação existencial. Aplicando-se os passos definidos para a obtenção do modelo em $\pi$-calculus devem ser criados os processos Listener-2, Notifier-2 e Integrator-2. As ações contidas no processo Listener-2 serão newRental, altRental, delRental, newEstRentRange, altEstRentRange e delEstRentRange. A execução de alguma dessas ações será precedida pela ação $\overline{\text { notifyEngine }}\langle \# \mathscr{Q}$, \#u $\rangle$ que irá ativar o processo Notifier-2 para que o mesmo notifique os motores de regras de negócio da 
existência da possibilidade de violação da regra de negócio dois em consequência de alguma alteração na instância \#u que pode ser uma instância do da variável rental como também da variável estimated rental charge. A seguir será apresentada a formulação semântica desta regra de negócio e logo em seguida o modelo em $\pi$-calculus gerado. 


\section{Formulação semântica da Regra de Negócio 2}

"It is prohibited that a rental is open if an estimated rental charge is not provisionally charged for the rental".

The rule is a proposition meant by an obligation formulation.

The obligation formulation embeds a logical negation

The logical operand of the logical negation is a universal quantification.

The universal quantification introduces a first variable.

The first variable ranges over the concept "rental',

The universal quantification scopes over an implication.

The consequent of the implication is an atomic formulation.

The atomic formulation is based on the fact type "rental is open',

The "rental", role is bound to the first variable.

The antecedent of the implication is an existential quantification.

The existential quantification introduces a second variable.

The second variable ranges over the concept " estimated rental charge",

The existential quantification scopes over a logical negation.

The logical operand of the logical negation is an atomic formulation.

The atomic formulation is based on the fact type "estimated rental charge is provisionally charged for rental',

The "estimated rental charge', role is bound to the second variable.

The "rental", role is bound to the first variable.

\section{Modelo em $p i$-calculus referente à regra de negócio 2}

Listener-\#2 =

(

$$
\begin{aligned}
& \operatorname{new} \operatorname{Rental}(\# u)+\operatorname{altRental}(\# u)+\operatorname{delRental} \# u)+ \\
& \operatorname{newEstRentRange}(\# u)+\operatorname{altEstRentRange}(\# u)+\operatorname{delEstRentRange} \# u)
\end{aligned}
$$

). $\overline{\text { notifyEngine }}\langle \# 2, \# u\rangle$. Listener-\#x

Notifier-\#2 = notifyEngine $(\# x, \# u) \cdot \tau$. Notifier-\#2

Integrator-\#2 = Listener-\#2 | Notifier-\#2 


\section{Capítulo 5}

\section{Sistema exemplo}

Para ilustrarmos a utilização do modelo de implementação e do método de transformação propostos neste trabalho iremos fornecer um sistema exemplo. Nesse exemplo utilizaremos o método para a transformação, das regras de negócio expressas em SBVR, em uma representação formal baseada em $\pi$-calculus. Essa representação formal será utilizada como base para a implementação das regras. Para isso, revisitaremos o problema exemplo apresentado no capítulo de introdução que descreve os requisitos de negócio de uma aplicação de gerenciamento de comércio eletrônico. As características dessa aplicação foram concebidas com o intuito de criar um cenário onde a utilização de uma solução que considere explicitamente as regras de negócio como um elemento individual dentro da arquitetura se mostre adequada. Para isso foi definido um vocabulário e um conjunto de regras de negócio que influenciam significativamente o modo no qual essa aplicação irá funcionar. Portanto, é desejável que essas regras possam ser alteradas com facilidade pelos envolvidos com o negócio. Com base no vocabulário definida e nas regras de negócio, serão derivados os modelos em $\pi$-calculus correspondentes. Esses modelos serão utilizados na arquitetura da aplicação para viabilizar a verificação explícita das regras de negócio. O objetivo é permitir flexibilidade na alteração das regras de negócio dessa aplicação ao permitir uma individualização das regras de negócio dentro da arquitetura. 


\subsection{Vocabulário de Negócio}

Antes de fornecermos as formulações semânticas das regras de negócio do exemplo e, posteriormente, os modelos em $\pi$-calculus, é necessário definirmos alguns conceito e tipos de fatos relacionados ao domínio da aplicação. Na Figura 5.1 é apresentado um diagrama conceitual com os elementos do domínio da aplicação que utilizaremos no sistema exemplo.

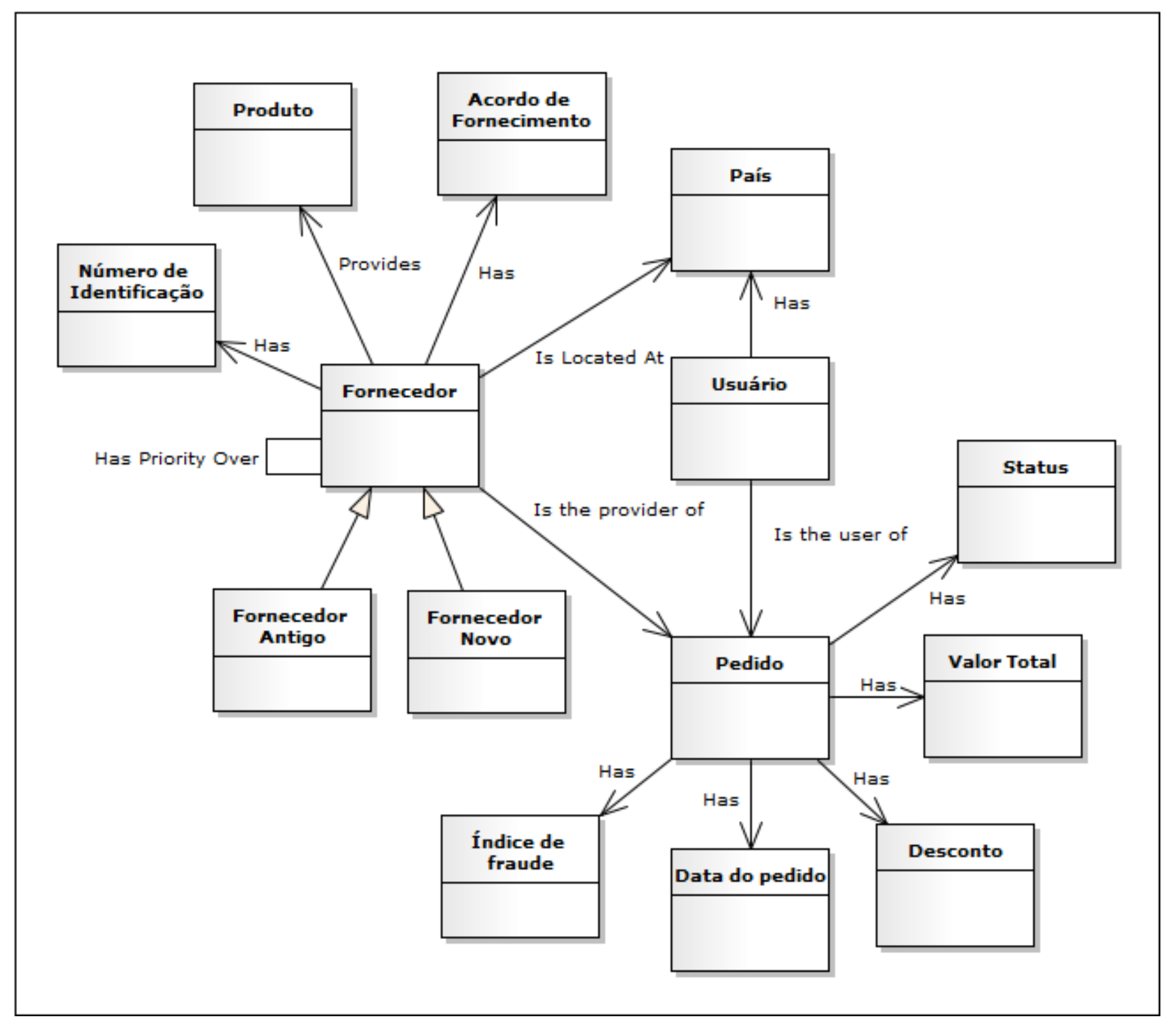

Figura 5.1: Diagrama conceitual dos elementos da aplicação utilizados no sistema exemplo.

\subsubsection{Conceitos}

A seguir serão listados os principais conceitos relacionados ao domínio da aplicação fictícia de comércio eletrônica. Juntamente com a definição desses elementos são indicadas 
também as necessidades relacionadas a cada um deles. Lembrando que necessidades dentro do contexto da SBVR são restrições intrinsicamente impostas a conceitos. Isso significa que uma instância de um conceito de um determinado tipo só será realmente tal se ele respeitar todas as necessidades impostas a aquele tipo. A definição desses conceitos é feita utilizando a linguagem $S B V R$ Structured English descrita em [Tea06]. Nesta linguagem cada cor representa um item semântico na definição das regras de negócio.

\section{Fornecedor}

Definição: A empresa that may fornecer produto para a loja eletrônica

Necessidade: Each fornecedor está localizado em exacly one país .

Necessidade: Each fornecedor has exacly one número de identificação .

\section{Usuário}

Definição: A pessoa or empresa cadastrada na loja and may realizar pedidos Necessidade: Each usuário has exacly one país .

\section{Pedido}

Definição: A solicitação of any produto por um usuário .

Necessidade: Each pedido has exacly one fornecedor .

Necessidade: Each pedido has exacly one status .

Necessidade: Each pedido at most one Desconto .

Necessidade: Each pedido has exacly one Data.

Necessidade: Each pedido has exacly one Índice de fraude

\section{Fornecedor Antigo}

Definição: A Fornecedor cadastrado a mais de 5 anos Fornecedor Novo

Definição: A Fornecedor cadastrado a menos de 5 anos

\subsubsection{Tipos de Fatos}

A seguir serão fornecidos os tipos de fatos relacionados ao domínio da aplicação.

Fornecedor fornece produto

$\underline{\text { Fornecedor }}_{\text {A tem }}$ prioridade sobre Fornecedor $B$ 
Definição: Significa que o fornecedor ${ }_{A}$ será escolhido ao invés do fornecedor ${ }_{B}$ durante o processo de escolha do fornecedor para um determinado pedido.

Fornecedor está localizado em país

Definição: O fornecedor está fisicamente localizado no país.

Fornecedor possui acordo

Definição: Fornecedor possui um acordo de fornecimento de produtos.

Usuário está localizado em país

Definição: O usuário está fisicamente localizado no país.

Fornecedor é identificado por número de identificação

Pedido possui valor total

Pedido possui desconto

Pedido possui data

Data está dentro de mês

$\underline{\text { Pedido possui indice de fraude }}$

Pedido possui status

Fornecedor está localizado no mesmo pais que usuário Definição: O fornecedor está fisicamente localizado no mesmo país que o usuário.

\subsection{Regras de negócio e a formulação semântica}

Abaixo segue uma lista com algumas das regras de negócio definidas no capítulo de introdução juntamente com a formulação semântica definida em SBVR. Também serão fornecidos os modelos em $\pi$-calculus dessas regras de negócio. Esses modelos foram obtidos por meio do método de transformação apresentado neste trabalho e descrito na seção 4.2.1.

Formulação semântica da Regra de negócio 1.

"RN 1 - Todos os fornecedores antigos devem ter prioridade sobre os fornecedores novos."

This proposition is meant by a universal quantification

The universal quantification introduces a first variable

The first variable ranges over the concept fornecedor antigo 
The universal quantification scopes over a existential quantification

The existential quantification introduces a second variable

The second variable ranges over the concept fornecedor novo

The existential quantification scopes over a implication formulation

The consequent of the implication formulation is a atomic formulation

The atomic formulation is based on the fact type fornecedor tem prioridade sobre fornecedor

The first role is bounded to the first variable

The second role is bounded to the second variable

\section{Modelo em $\pi$-calculus da Regra de negócio 1.}

Listener-\#1 =

( newFornecedorAntigo $(\# u)+\operatorname{altFornecedorAntigo}(\# u)+\operatorname{delFornecedorAntigo}(\# u)$ newFornecedorNovo $(\# u)+\operatorname{altFornecedorNovo}(\# u)+\operatorname{delFornecedorNovo}(\# u)$

). $\overline{\text { notifyEngine }}\langle \# 1, \# u\rangle$. Listener-\#1

Notifier-\#1 = notifyEngine $(\# x, \# u) \cdot \tau$. Notifier-\#1

Integrator-\#1 = Listener-\#1 | Notifier-\#1 
Formulação semântica da Regra de negócio 2.

"RN 2 - Todos os fornecedores com acordo de fornecimento devem ter prioridade sobre fornecedores sem acordo de fornecimento"

This proposition is meant by a universal quantification

The universal quantification introduces a first variable

The first variable ranges over the concept fornecedor

The universal quantification scopes over a implication formulation

The antecedent of the implication is a conjunction formulation

The disjunction's operand 1 is a existential formulation

The existential formulation introduces a second variable

The second variables ranges over the concept acordo de fornecimento

The existential formulation scopes over a atomic formulation

The atomic formulation is based on the fact type fornecedor possui acordo

The first role of atomic formulation bounds to the first variable

The second role of atomic formulation bounds to the second variable

The disjunction's operand 2 is a existential formulation

The existential formulation introduces a third variable

The third variables ranges over the concept fornecedor

The existential formulation scopes over a negation formulation

The negations's operand is a existential formulation

The existential formulation introduces a fourth variable

The fourth variable ranges over the concept acordo de fornecimento

The existential formulation scopes over a atomic formulation

The atomic formulation is based on the fact type fornecedor possui acordo

The first role of the atomic formulation bound to the third variable

The second role of the atomic formulation bounds to the fourth variable

The consequent of the implication formulation is a atomic formulation

The atomic formulation is based on the fact type fornecedor tem prioridade sobre fornecedor

The first role is bounded to the first variable

The second role is bounded to the third variable

Modelo em $\pi$-calculus da Regra de negócio 2. 
(

newFornecedor $(\# u)+\operatorname{altFornecedor}(\# u)+\operatorname{delFornecedor}(\# u)+$

newAcordoFornecimento $(\# u)+\operatorname{altAcordoFornecimento}(\# u)+$ delAcordoFornecimento $(\# u)$

). $\overline{\text { notifyEngine }}\langle \# 2, \# u\rangle$. Listener-\#2

Notifier-\#2 = notifyEngine $(\# x, \# u) \cdot \tau$. Notifier-\#2

Integrator-\#2 = Listener-\#2 | Notifier-\#2

Formulação semântica da Regra de negócio 3 .

"RN 3 - Pedidos com valor total maior do que R\$5000,00 devem ter desconto de 10\%."

This proposition is meant by a universal quantification

The universal quantification introduces a first variable

The first variable ranges over the concept Pedido

The universal quantification scopes over a implication formulation

The antecedent of the implication formulations is a conjunction

formulation

The conjunction's operand 1 is a existential formulation

The existential formulation introduces a second variable

The second variable ranges over the concept Valor Total

The existential formulation scopes over a atomic formulation

The atomic formulation is based on the fact type Pedido possui Valor Total

The first role of the atomic formulation bounds to the first variable

The second role of the atomic formulation bounds to the second variable

The conjunction's operand 2 is a atomic formulation

The atomic formulation is based on the fact type number is greater than or equal to number

The first role of the atomic formulation bounds to the second variable

The second role of the atomic formulation bounds to "5000"

The consequent of the implication formulation is a atomic formulation

The atomic formulation is based on the fact type Pedido possui Desconto

The first role is bounded to the first variable 
The second role is bounded to ' $10 \backslash \%$ '

\section{Modelo em $\pi$-calculus da Regra de negócio 3.}

Listener-\#3=

$$
\begin{aligned}
& \operatorname{newPedido}(\# u)+\operatorname{altPedido}(\# u)+\operatorname{delPedido}(\# u)+ \\
& \operatorname{new} \operatorname{ValorTotal}(\# u)+\operatorname{alt} \operatorname{ValorTotal}(\# u)+\operatorname{del} \operatorname{ValorTotal}(\# u) \\
& ) . \overline{\text { notifyEngine }}\langle \# 3, \# u\rangle . \text { Listener-\#3 }
\end{aligned}
$$

Notifier-\#3 = notifyEngine $(\# x, \# u) \cdot \tau$. Notifier-\#3

Integrator-\#3 = Listener-\#3| Notifier-\#3

\section{Formulação semântica da Regra de negócio 4.}

"RN 4 - Pedidos com indice de fraude entre $30 \%$ e $50 \%$ devem ser encaminhados para aprovação manual."

This proposition is meant by a universal quantification

The universal quantification introduces a first variable

The first variable ranges over the concept Pedido

The universal quantification scopes over a implication formulation

The antecedent of the implication formulation is a conjunction

The conjunction's operand 1 is a existential quantification

The existential quantification introduces a second variable

The second variables ranges over the concept indice de fraude

The existential quantification scopes over a atomic formulation

The atomic formulation is based on the fact type Pedido possui indice de fraude

The first role of the atomic formulation bounds to the first variable

The second role of the atomic formulation bounds to the second variable

The conjunction's operand 2 is a conjunction formulation

The conjunction's operand 1 is a atomic formulation

The atomic formulation is based on the fact type number is greater than or equal number 
The first role of the atomic formulation bounds to the second variable

The second role of the atomic formulation bounds to ' $30 \backslash \%$ '

The conjunction's operand 2 is a atomic formulation

The atomic formulation is based on the fact type number is less than or equal number

The first role of the atomic formulation bounds to the second variable

The second role of the atomic formulation bounds to ' $50 \backslash \%$ '

The consequent of the implication formulation is a atomic formulation

The atomic formulation is based on the fact type Pedido possui Status

The first role of the atomic formulation bounds to the first variable

The second role of the atomic formulation bounds to "Aprovação manual"

\section{Modelo em $\pi$-calculus da Regra de negócio 4.}

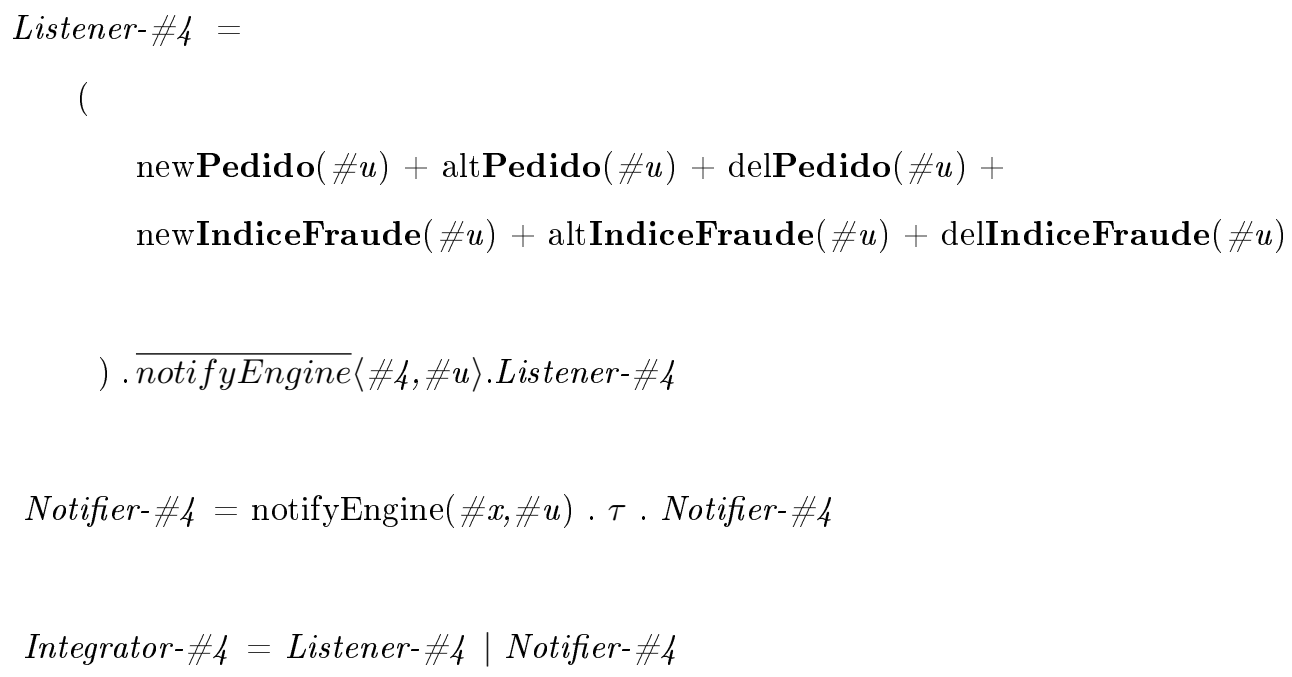

Formulação semântica da Regra de negócio 5 .

"RN 5 - Pedidos com índice de fraude maior do que 50\% devem ser automaticamente cancelados."

This proposition is meant by a universal quantification

The universal quantification introduces a first variable

The first variable ranges over the concept Pedido

The universal quantification scopes over a implication formulation

The antecedent of the implication formulation is a conjunction

The conjunction's operand 1 is a existential quantification

The existential quantification introduces a second variable 
The second variables ranges over the concept índice de fraude

The existential quantification scopes over a atomic formulation

The atomic formulation is based on the fact type Pedido possui indice de fraude

The first role of the atomic formulation bounds to the first variable

The second role of the atomic formulation bounds to the second variable

The conjunction's operand 2 is a atomic formulation

The atomic formulation is based on the fact type number is greater than or equal number

The first role of the atomic formulation bounds to the second variable

The second role of the atomic formulation bounds to ' $50 \backslash \%$ '

The consequent of the implication formulation is a atomic formulation

The atomic formulation is based on the fact type Pedido possui Status

The first role of the atomic formulation bounds to the first variable

The second role of the atomic formulation bounds to "Cancelado"

\section{Modelo em $\pi$-calculus da Regra de negócio 1.}

Listener-\#5=

(

$\operatorname{newPedido}(\# u)+\operatorname{altPedido}(\# u)+\operatorname{delPedido}(\# u)+$

new IndiceFraude $(\# u)+\operatorname{altIndiceFraude}(\# u)+\operatorname{delIndiceFraude}(\# u)$

). $\overline{\text { notifyEngine }}\langle \#$ $\$$, $u\rangle$. Listener- $\# 5$

Notifier-\#5 = notifyEngine $(\# x, \# u) \cdot \tau$. Notifier-\#5

Integrator-\#5 = Listener-\#5 | Notifier-\#5

\subsubsection{Arquiteturas sugeridas}

Uma alternativa de arquitetura para esse sistema é a baseada em repositórios de dados. Nesse modelo haveria um banco de dados central com as informações de todos os produtos, usuários e fornecedores. Todas as regras poderiam ser implementadas em um módulo escrito em alguma linguagem de programação convencional e os valores numéricos relacionados às 
regras poderiam ser armazenados como dados a serem consultados por esses módulos. Além disso, poderia ser criada uma interface onde os administradores desse sistema pudessem alterar esses valores de acordo com as necessidades do negócio.

Existem algumas desvantagens nesta abordagem. A primeira delas é que apenas as regras previamente identificadas durante a construção desse software poderiam ser alteradas por meio dessa interface [BKR00]. Não seria possível acrescentar novas regras ou remover as já existentes. Outra desvantagem é que apenas alguns tipos de regras poderiam ser gerenciados sem a necessidade de envolvimento de programadores. Como exemplo podemos citar a dificuldade na alteração da regra RN2 para que sejam priorizados os fornecedores mais novos ao invés dos mais antigos.

O estilo arquitetural baseado em camadas consiste na organização do sistema em níveis definidos por meio de interfaces sendo que cada nível utiliza o nível anterior como base para oferecer funcionalidades para o próximo nível [SMAdAB03]. Com base nesse modelo arquitetural poderia ser definida uma camada onde todas as regras de negócio fossem implementadas. Assim, a alteração dessas regras ficaria mais simples já que todas elas estariam em uma mesma localização no sistema. A principal desvantagem dessa abordagem é a total dependência de algum processo de desenvolvimento para a adição, remoção e alteração das regras existentes.

Outra possível abordagem para a solução desse problema é a utilização de uma arquitetura baseada em serviços juntamente com regras de negócio.

No contexto de sistemas distribuídos foram desenvolvidos diversos modelos de arquitetura de software com o objetivo de viabilizar a interação entre sistemas baseados em tecnologias heterogêneas. Uma dessas iniciativas que vem ganhando importância na comunidade é a arquitetura de software baseada em serviços - SOA [Erl08] que permite a organização e disponibilização de capacidades. Essas capacidade, ou funcionalidades, podem estar sob controle da própria entidade como também podem ser oferecidas por outra entidade. Elas são oferecidas e consumidas por meio de unidades chamadas de serviços. Um serviço é o mecanismo que permite que as necessidades de uma entidade ou grupo de entidades consumidoras sejam reunidas com as capacidades oferecidas por outra entidade ou grupo[ $\left[\mathrm{M}^{+} 06\right]$. Essas capacidades podem ser implementadas utilizando tecnologias diversas, porém, a interação e 
descrição das mesmas são feitas por meio de protocolos padrão com uma semântica e sintaxe bem definida e conhecida pelos envolvidos. Para que os consumidores possam utilizar esses serviços, não deve ser necessária alguma atividade intermediária como algum tipo de implantação, compilação ou instanciação $\left[\mathrm{M}^{+} 06\right]$. Depois de serem disponibilizados os serviços estão prontos para serem utilizados. Essa é uma característica que diferencia o paradigma orientado a serviços de outros paradigmas como o da orientação a objetos e arquitetura baseada em componentes. Isso permite que a integração entre sistemas seja feita de uma forma mais simples e passível de evolução já que as camadas de tecnologia e infraestrutura, que são utilizadas para implementar esses serviços, podem ser alteradas sem a necessidade de alteração por parte dos sistemas que fazem uso desses serviços.

\subsection{Arquitetura sugerida para a solução do problema exemplo}

Para iniciarmos a definição da arquitetura sugerida o problema exemplo, vamos analisar onde começa e onde termina o papel dos modelos em $\pi$-calculus gerados à partir das regras de negócio. Conforme dito anteriormente, esses modelos têm como principal objetivo explicitar quais eventos são necessários para identificar o momento em que a verificação da conformidade atual do sistema, em relação a cada uma das regras de negócio definidas, deve ser feita. Essa informação então será utilizada para notificar os motores de regras de negócio quando algum desses eventos ocorre. Resta agora identificar outros papeis que não são desempenhados pelos modelos em $\pi$-calculus mas, que são necessários para que a implementação das regras de negócio em SOA seja feita.

O primeiro deles é a emissão ou indicação efetivamente de que um evento ocorreu. Normalmente, o comportamento interno dos serviços é algo que não é divulgado para o restante da arquitetura. Ao invés disso, temos apenas a definição do que o serviço espera receber como parâmetro de entrada e a definição do que o serviço irá retornar como resultado do processamento. Mas, os passos internos que o serviço executa bem como os resultados intermediários desses passos não são visíveis para o restante da aplicação. Nossa proposta não elimina totalmente essa característica mas, ela traz a necessidade de que algumas informa- 
ções a respeito dos eventos que ocorrem internamente nos serviços sejam divulgadas para o restante da aplicação a fim de que esses eventos possam ser capturados pelos modelos em $\pi$-calculus e os que estiverem relacionados à alguma regra de negócio sejam enviados para os motores de regra. O padrão WS-Notification [GHM06] será utilizado para que os serviços possam enviar essas notificações para os outros elementos da arquitetura. O objetivo desse padrão é estabelecer diretrizes para a divulgação de eventos entre serviços web. Essa padronização é baseada no princípio arquitetural de sistemas conhecido como publish/subscribe [EFGK03]. Neste princípio arquitetural, a notificação da ocorrência de eventos é realizada entre os componentes por meio de dois tipos de elementos. Os Notification Producers e os Notification Consumers. Esses eventos são criados por componentes chamados de publishers e enviados por meio dos Notification Producers para posteriormente serem recebidos assincronamente pelos Notification Producers. Esses eventos além da informação específica da aplicação contém um conjunto de metadados que indicam qual o assunto da informação. Esses metadados são definidos com utilizando como base o padrão WS-Topics. Isso permite que clientes possam se cadastrar para receber apenas os eventos que são do seu interesse. Esse princípio possibilita uma comunicação fracamente acoplada entre esses elementos já que as informações são consumidas e produzidas sem que os envolvidos saibam necessariamente da existência de um do outro.

Na Figura 5.2 são apresentados os detalhes dos elementos da arquitetura e como os modelos em $\pi$-calculus são utilizados para que as regras de negócio possam ser verificadas. Podemos dividir essa arquitetura em três camadas. A primeira com os motores de regras, a segunda com o núcleo da aplicação e a terceira com os webservices que realizam interface com a loja.

A primeira camada, considerando-se de cima para baixo, é constituída pelos motores de regras. Esses motores são os responsáveis por efetivamente verificar as regras de negócio com o objetivo de identificar alguma violação. Para isso, eles utilizam o banco de dados corporativo da organização. Esse banco de dados deverá conter todas as regras de negócio definidas e os dados relacionados à essas regras. Como é possível perceber no diagrama, escolhemos utilizar apenas um motor de regra para essa aplicação. Foi escolhido o Drools Engine pelo fato do mesmo ser compatível com todos as regras de negócio definidas no 


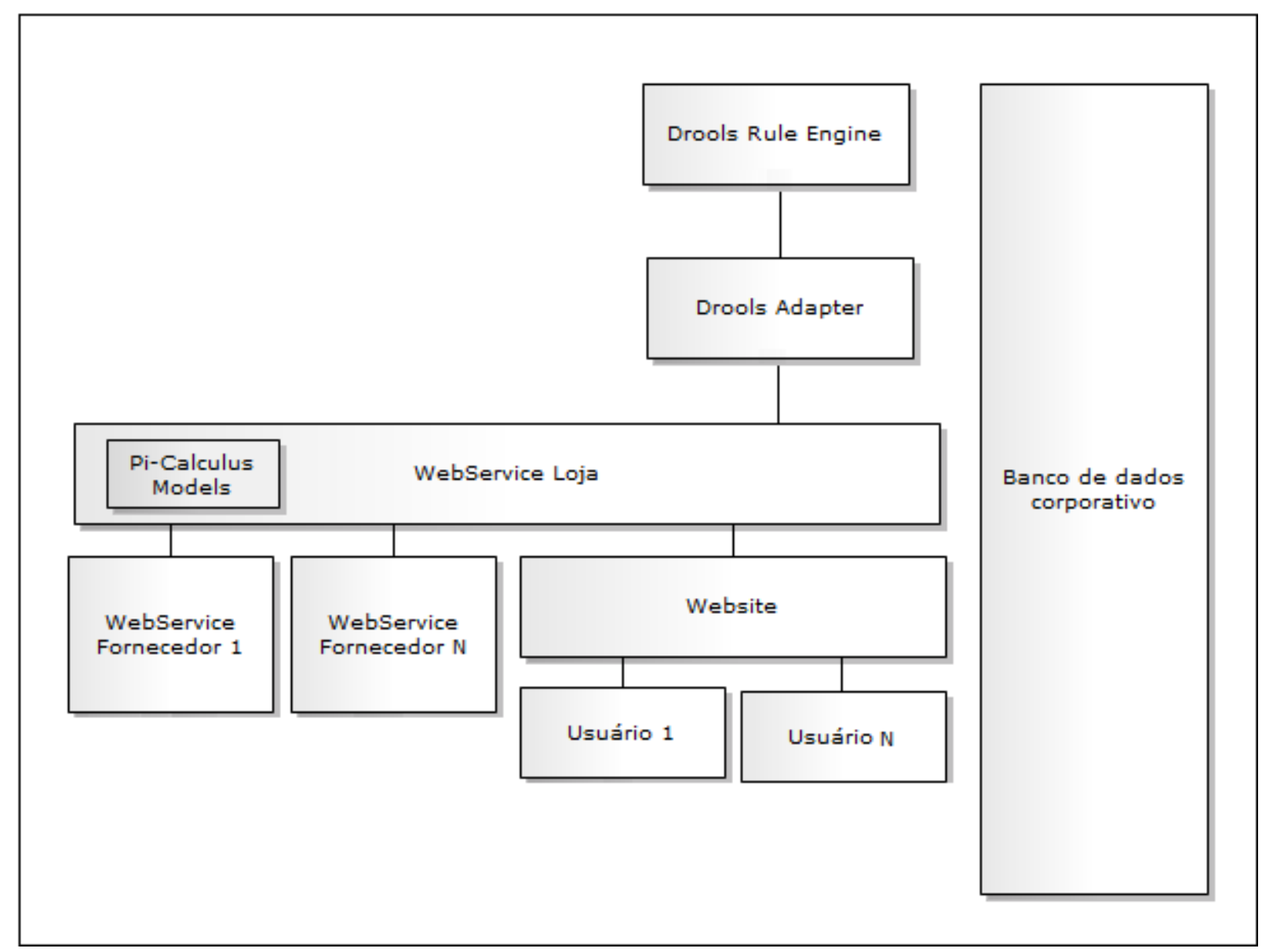

Figura 5.2: Arquitetura da proposta.

sistema exemplo, por ser um software livre e por possui uma comunidade ativa que fornece documentação e suporte aos usuários. Isso será importante caso venhamos a desenvolver algum protótipo no futuro. No caso do Drools Engine, o adaptador a ser desenvolvido é baseado na linguagem Java. Ele deverá receber as notificações de eventos do webservice loja e solicitar ao Drools, via integração java, que verifique as regras de negócio que possivelmente podem ter sido violadas.

A segunda camada consiste nos elementos que realizarão uma adaptação entre a interface fornecida por cada um dos motores de regras e o restante da arquitetura. Os motores de regras existentes atualmente apresentam muitas diferenças entre si. Uma das diferenças encontradas está relacionada as interfaces de comunicação que eles oferecem. Cada um dos motores de regras fornece um conjunto diferente de formas pelo qual outros elementos da arquitetura podem se comunicar com eles. O motor de regra Drools Expert, por exemplo, permite que as aplicação acessem seus recursos por meio de uma interface baseada no padrão java JSR94[Mah05]. O motor ILOG JRules[JRu05] da IBM disponibiliza interfaces baseadas 


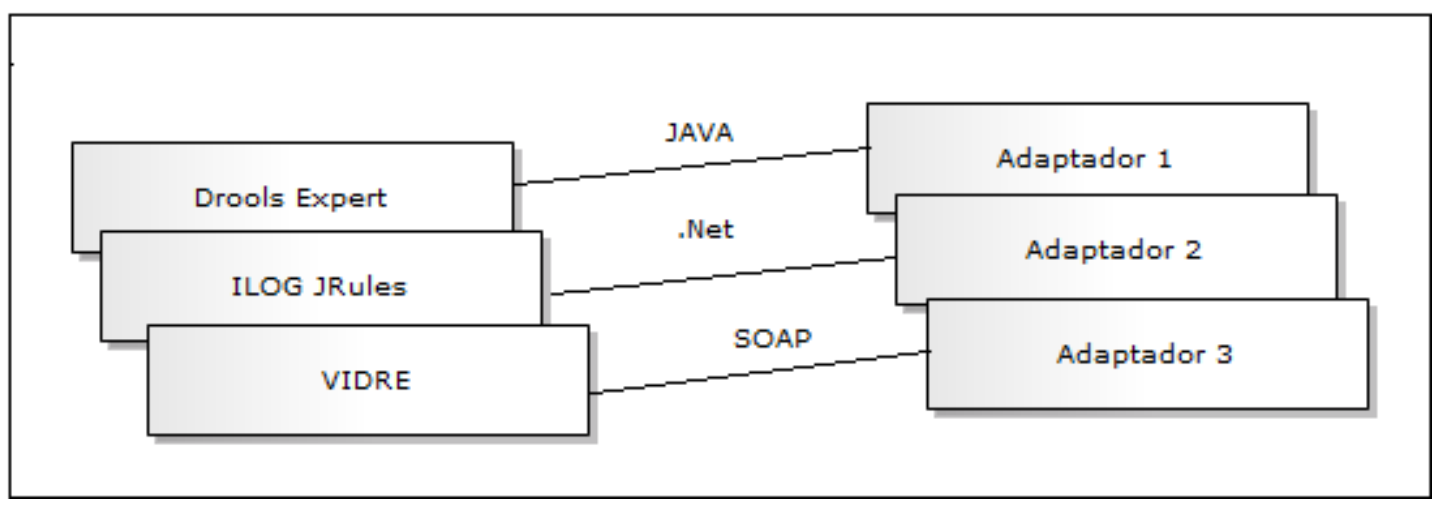

Figura 5.3: Cada motor de regra utilizado nas aplicações que seguirem essa arquitetura de referência deverão ter um elemento que faça a adaptação entre a interface desse motor e o restante da arquitetura. Esse elemento será chamado de adaptador.

na plataforma .Net[Pla02]. Enquanto isso, o motor VIDRE[NRD06] disponibiliza interfaces baseadas em serviços web. Além da linguagem ou tecnologia utilizadas nas interfaces, cada uma delas possuem outras características específicas relacionadas às funcionalidades expostas dos motores de regra. Essa relação entre os motores de regras e os adaptadores são apresentados na figura 5.3. Tendo em vista essa diversidade de motores de regras e suas interfaces é necessário que exista um conjunto de elementos dentro da nossa arquitetura de referência que seja responsável por realizar uma adaptação entre a interface de cada um dos motores que será utilizado e o elemento que realizará as notificações da necessidade de verificação de conformidade das regras de negócio. Esses elementos serão chamados de adaptadores e deverá existir um para cada motor de regra utilizado na arquitetura. Cada um desses adaptadores terá de receber as notificações do Notification Producer e devidamente converte-las para o formato da interface do motor de regra correspondente. Isso permitirá que as notificações possam fluir pela arquitetura de forma uniforme e serem convertidas para um formato específico apenas quando ela for enviada para o motor de regra. Esses adaptadores são equivalentes aos Notification Consumers do padrão WS-Notification[HWJ+05] já que são eles que recebem as notificações do Notification Producer que no caso, é o webservice loja.

A terceira camada contém o elemento mais importante da arquitetura que é o WebService Loja. O Webservice Loja consiste no elemento principal da arquitetura. Ele é o responsável por receber as solicitações dos usuários realizadas por meio do website como também realizar a comunicação com os webservices dos fornecedores. Esse elemento é corresponde ao Notifi- 
cation Producer do padrão WS-Notification e é responsável por manter uma lista de todos os interessados em receber notificações a respeito das regras de negócio e efetivamente enviar as notificações para esses interessados. É o elemento que utiliza os modelos em $\pi$-calculus para identificar o momento na qual ocorre algum evento que pode ter levado o sistema a um estado de inconformidade em relação a alguma das regras de negócio. Ao identificar isso, esse elemento envia uma mensagem para o adaptador do motor de regra indicando qual a regra de negócio que pode ter sido violada e qual a instância do conceito que foi alterada e que pode ter levado a isso. Uma das vantagens deste modelo é viabilizar o cumprimento do objetivo de separar os motores de regras e serviços. O Webservice Loja permite que não exista uma comunicação direta entre os motores de regras e seus adaptadores e os serviços.

A quarta camada é composta pelos serviços que comporão a aplicação. No contexto da arquitetura, esses serviços terão o papel de enviar notificações para o WebService Loja sempre que realizarem a alteração, exclusão ou remoção de algum fato ou conceito presente no repositório. Esse repositório pode ser um banco de dados relacional convencional ou qualquer outro repositório de informações a respeito das atividades sendo realizadas pela organização. É importante que exista um compartilhamento desse repositório entre os serviços e os motores de regras. Isso é necessário já que as regras de negócio serão verificadas pelos motores e essa verificação é justamente verificar a população de conceitos e fatos a fim de encontrar algum informação que esteja em desacordo com alguma regra de negócio.

\subsubsection{Papel dos modelos em $\pi$-calculus na Arquitetura da solução}

Os modelos em $\pi$-calculus das regras de negócio obtidos da formulação semântica em SBVR tem como principal objetivo explicitar o momento na qual é necessário verificar se uma regra de negócio foi violada. Dentro da arquitetura proposta, esse momento é capturado pelo WebService Loja que por sua vez envia uma mensagem para cada um dos motores de regras. O papel dos modelos é auxiliar o WebService Loja a realizar essa tarefa ao explicitar quais eventos o mesmo deve monitorar e repassar para os adaptadores.

Para ilustrar o papel dos modelos iremos revisitar o exemplo a seguir. Trata-se do modelo em $\pi$-calculus da regra de negócio "It is prohibited that a rental is open if an estimated rental charge is not provisionally charged for the rental". 


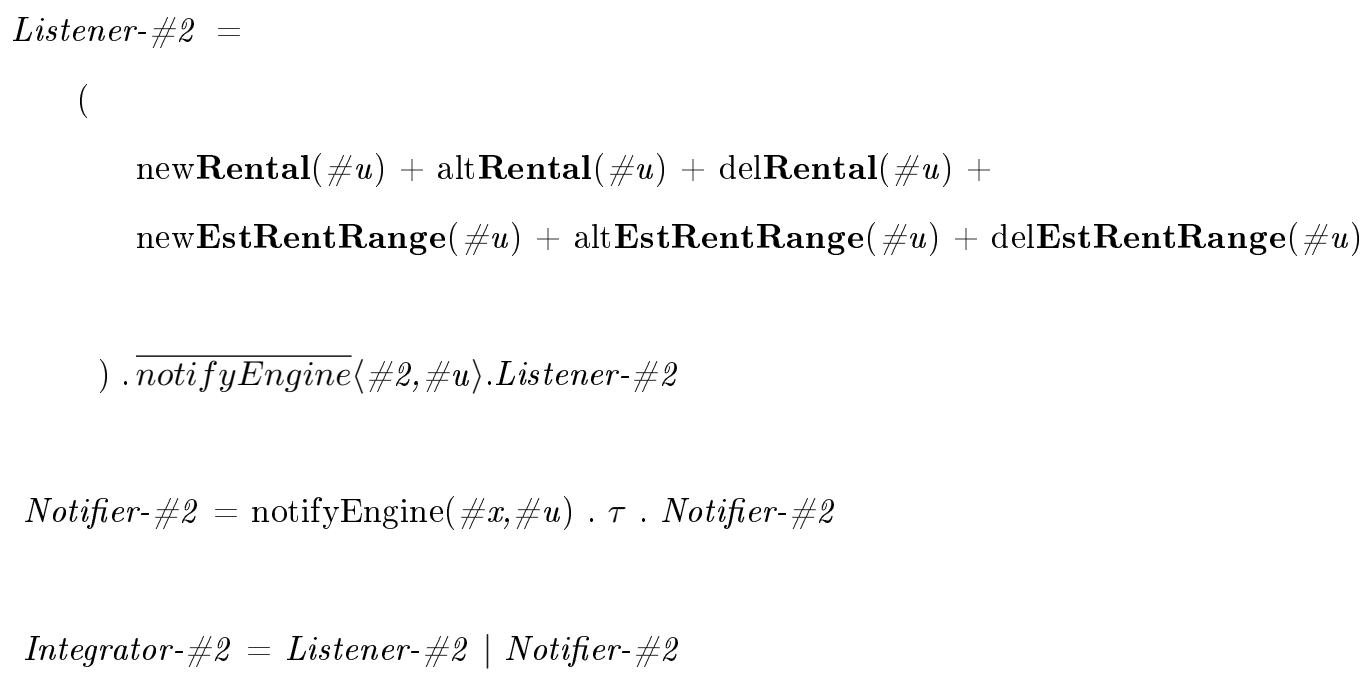

A identificação da necessidade de verificação de uma regra de negócio é representada nos modelos em $\pi$-calculus como canais. Como no exemplo acima, deve existir um canal para cada evento que seja uma justificativa para que a conformidade do sistema em relação a regra de negócio em questão seja realizada. Quando um desses canais é acionado, deve ser emitida uma notificação para todos os motores de regras de negócio. Essa notificação é acompanhada de duas informações. A identificação da regra de negócio que deve ser verificada e a identificação das instância do conceito que sofreu a alteração na qual resultou a necessidade de verificação de conformidade do sistema.

O WebService Loja deve implementar o comportamento descrito nos modelos em $\pi$ calculus e assegurar que todos os motores de regras sejam notificados quando um dos eventos previstos nos modelos em $\pi$-calculus ocorrer. Essa notificação será realizada por meio do envio de mensagens com informações sobre o evento ocorrido. Essas mensagens serão iguais para todos os adaptadores já que os mesmo que serão responsáveis por traduzi-las para o motor de regra específico. De acordo com o modelo em $\pi$-calculus elas devem conter a identificação da regra de negócio possivelmente violada e a identificação da instância alterada que gerou essa possibilidade. No caso do exemplo acima, quando ocorrer algum dos eventos de alteração, remoção e inclusão de um Rental ou Estimated Rental Range, o Webservice Loja deverá criar uma mensagem para cada um dos adaptadores informando qual a regra que deve ser verificada e uma identificação do elemento que foi alterado e que fez com que essa verificação fosse necessária. Como exemplo podemos citar a alteração no Rental de número 
310. Essa alteração deverá gerar uma mensagem de evento para cada adaptador informando que a regra número 2 precisa ser verificada devido a uma alteração no Rental 310 . 


\section{Capítulo 6}

\section{Conclusão}

Neste trabalho foi apresentado um método para a transformação das regras de negócio especificadas em SBVR para um protocolo de comunicação entre regras de negócio e aplicações especificado formalmente em $\pi$-calculus. Esse modelo foi definido com o objetivo de facilitar a implementação das regras de negócio ao indicar explicitamente o momento na qual é possível que uma regra tenha sido violada. A necessidade deste modelo foi percebida ao observar que as diversas abordagem existentes para a representação de regras de negócio por um lado são apropriadas para comunicá-las entretanto, por outro lado, não fornecem meios para que essas regras possam ser efetivamente implementadas em um sistema computacional. Dentro deste contexto, foi escolhido o meta-modelo SBVR que consiste em uma linguagem para a descrição da semântica de regras e vocabulários de negócio que possui a característica de não ser restrita a alguma tecnologia ou forma de representação específica permitindo um alto grau de interoperabilidade e abstração. Ainda dentro do ecossistema de técnicas relacionadas a regras de negócio, foram descritas as principais tecnologias para implementação das mesmas em sistemas de informação. Foi mostrado, por meio da revisão da literatura, que apesar de existirem várias formas de implementação, os motores de regra se mostram uma alternativa vantajosa por apresentarem características que facilitam a efetivação do business rule approach que indica que as regras de negócio devem ser organizadas de tal forma que sejam um elemento independente dentro de uma arquitetura de software. Nosso método de transformação extrai da representação em SBVR da regra de negócio os eventos que devem ser monitorados, pois, a ocorrência de algum deles pode gerar uma violação. Quando um 
desses eventos ocorre, é enviada uma notificação para os motores de regras indicando que deve ser realizada uma verificação na regra de negócio. Como exemplo, foi escolhida uma arquitetura baseada no modelo SOA onde essa abordagem se mostrou adequada como uma opção para a implementação das regras de negócio.

\subsection{Contribuições}

A realização deste trabalhou trouxe algumas contribuições para a área de implementação de regras de negócio. A seguir é apresentada uma lista com um resumo das principais contribuições.

\subsubsection{Protocolo de comunicação}

Foi proposto um modelo de implementação de regras de negócio baseado em eventos. Esse modelo é baseado em um protocolo de comunicação definido em pi-calculus e descreve os elementos necessários e o comportamento desses elementos a fim de que as regras de negócio sejam efetivamente implementadas em um sistema computacional. Nesse protocolo, a verificação das regras de negócio e o restante do comportamento do sistema são vistos como dois elementos separados que executam paralelamente. Assim, é necessário que haja uma comunicação entre esses dois elementos a fim de que o comportamento total do sistema seja composto. Esse protocolo é composto por três elementos. O primeiro elemento consiste em um ouvinte que tem como responsabilidade identificar quando é necessário realizar uma verificação de conformidade em relação a uma regra de negócio. Essa verificação de conformidade consiste em analisar a população de fatos e conceitos e identificar se existem elementos nessas população que violam a regra de negócio. Ao identificar o momento na qual é necessário realizar essa checagem, é acionado um outro elemento chamado notificador. Esse elemento tem a responsabilidade de acionar os motores de regras que irão efetivamente identificar se a regra foi ou não violada. 


\subsubsection{Método de transformação}

A principal contribuição deste trabalho é a proposta de um método para a transformação das regras de negócio na qual a semântica esteja definida em SBVR para um modelo formal onde a implementação é facilitada. Foi observado que as quantificações presentes nas formulações semânticas das regras de negócio em SBVR indicam quais são os elementos relacionadas à regra que precisam ser observados a fim de identificar quando faz sentido realizar uma verificação de conformidade.

\subsection{Relação da proposta com a literatura}

Durante a realização deste trabalho foram encontradas na literatura propostas semelhantes, porém, que apresentam diferenças significativas. Em [DRV10] Roover e Vanthienen propõem um conjunto de templates para a transformação das regras de negócio especificadas por meio do inglês estruturado fornecido pela especificação SBVR para uma linguagem baseada em eventos. As limitações desse trabalho estão na utilização de uma linguagem informal para descrever os eventos relacionados à regra de negócio. Além disso, o trabalho não explica como essa regras podem ser efetivamente implementadas. Outra proposta relacionada é a de [RD05] Rosenberg e Dustdar que propõem uma arquitetura para sistemas baseados em serviços onde as regras de negócio são implementadas por meio dos motores de regras que por sua vez são acionados como serviços. Uma desvantagem dessa proposta é a de exigir uma representação semântica de todo o banco de dados de regras de negócio a fim de que seja gerado um WSDL[CLS $\left.{ }^{+} 05\right]$ para que essa comunicação com os motores de regras possa ser estabelecida. Dessa forma, cada vez que uma nova regra de negócio seja criada é necessária a intervenção humana para a atualização dessa descrição semântica. Essa dificuldade não existe em nosso trabalho já que nós apresentamos um método de transformação automático de SBVR para um modelo de eventos que pode ser utilizado diretamente pelos elementos da arquitetura. 


\subsection{Limitações}

Existem algumas limitações relacionada às propostas apresentadas neste trabalho. A primeira delas é que no modelo de implementação sugerido a notificação de violação de uma regra é feita apenas depois da regra ter sido violada. Isso seguramente não será apropriada para determinados contextos onde não seja aceitável que a violação ocorra e só então sejam tomadas as medidas necessárias. É possível que sejam feitos trabalhos futuros onde essa limitação seja eliminada. Uma das possíveis abordagens seria alterar os elementos que enviam a notificação de possibilidade de violação para realizarem esse envio antes de alterarem algum dos elementos relacionados à regra. A dificuldade estará em enviar, juntamente com essa notificação, os dados necessários para que os motores de regras possam verificar se a alteração irá ou não gerar uma violação. Outra limitação da nossa abordagem está relacionada à possíveis otimizações no modelo de implementação e no método de transformação. Na abordagem sugerida, as quantificações são analisadas para identificar os elementos que devem ser monitorados e com isso são criados três eventos que ao ocorrem indicam a possibilidade de violação da regra de negócio. A limitação está no fato de que nem todos esses eventos podem levar a um estado de não conformidade. Um exemplo pode ser uma regra que determine que só podem haver dez processos sendo ativamente conduzidos em um escritório de advocacia. Nesse caso, a remoção ou alteração de um contrato da população de contratos não poderá levar a uma violação da regra de negócio. Com isso, só deveria haver um evento associado a essa regra de negócio. Esse evento seria o de adição de um novo contrato.

\subsection{Trabalhos futuros}

Durante o desenvolvimento desta pesquisa foi possível encontrar oportunidades para novos trabalhos relacionados ao tema de implementação de regras de negócio. A primeira oportunidade está relacionada a dificuldade que foi encontrada para traduzir as regras de negócio especificadas em linguagem natural para as formulação semânticas em SBVR. Não foram encontrados trabalhos para essa tradução tendo como ponto de partida as regras de negócio especificadas em português. Outra possibilidade de trabalho futuro está relacionada à limitação deste trabalho em apenas indicar a violação da regra de negócio após ela ter 
sido violada. Poderia ser analisada a possibilidade de alterações no modelo proposto neste trabalho para que essa notificação seja feita antes da regra ter sido possivelmente violada. Por fim, o formalismo trazido pela utilização do $p i$-calculus poderá ser mais aproveitado em novos trabalhos. É possível que sejam feitas análises em ferramentas de simulação a fim de identificar possíveis melhorias. 


\section{Referências Bibliográficas}

[Bal09] Michal Bali. Drools JBoss Rules 5.0: Developer's Guide. Packt Publishing, 2009. xi, 30

[Ber86] JA Bergstra. Process algebra: specification and verification in bisimulation semantics. CWI monographs, 4:61-94, 1986. 10

[BJW93] J.A. Bubenko Jr e B. Wangler. Objectives driven capture of business rules and of information systems requirements. Em Systems, Man and Cybernetics, 1993.'Systems Engineering in the Service of Humans', Conference Proceedings., International Conference on, páginas 670-677. IEEE, 1993. 4

[BK09] A. Buchmann e B. Koldehofe. Complex event processing. it-Information Technology, 51(5):241-242, 2009. 22

[BKR00] M. Bajec, M. Krisper e R. Rupnik. Using business rules technologies to bridge the gap between business and business applications. Em Proceedings of the IFIP 16th World Computer Congress, páginas 77-85, 2000. 5, 17, 24, 25, 26, 73

[BLB11] I.S. Bajwa, M.G. Lee e B. Bordbar. Sbvr business rules generation from natural language specification. Em AAAI Spring Symposium, páginas 2-8, 2011. 49,57

[Bol08] P. Bollen. Sbvr: A fact-oriented omg standard. Em On the Move to Meaningful Internet Systems: OTM 2008 Workshops, páginas 718-727. Springer, 2008. 35

[BPS01] J.A. Bergstra, A. Ponse e S.A. Smolka. Handbook of process algebra. Elsevier Science, 2001. 53

[Bro09] P. Browne. Jboss drools business rules. Birmingham, UK: Packt Publishing, 2009. 21, 48

[BTW01] H. Boley, S. Tabet e G. Wagner. Design rationale of ruleml: A markup language for semantic web rules. Em International Semantic Web Working Symposium (SWWS), páginas 381-402. Citeseer, 2001. 21, 22

[CGT89] S. Ceri, G. Gottlob e L. Tanca. What you always wanted to know about datalog (and never dared to ask). Knowledge and Data Engineering, IEEE Transactions on, 1(1):146-166, 1989. 22

[Cha08] D. Chapin. Sbvr: What is now possible and why. Business Rules Journal, 9(3), 2008. 7, 9 
$\left[\mathrm{CLS}^{+}\right.$05] Francisco Curbera, Frank Leymann, Tony Storey, Donald Ferguson e Sanjiva Weerawarana. Web services platform architecture: SOAP, WSDL, WS-policy, WS-addressing, WS-BPEL, WS-reliable messaging and more. Prentice Hall PTR Englewood Cliffs, 2005. 11, 83

[CPR10] J. Cabot, R. Pau e R. Raventós. From uml/ocl to sbvr specifications: A challenging transformation. Information systems, 35(4):417-440, 2010. 49

[CPS93] R. Cleaveland, J. Parrow e B. Steffen. The concurrency workbench: A semantics-based tool for the verification of concurrent systems. ACM Transactions on Programming Languages and Systems (TOPLAS), $15(\overline{1): 36-}$ 72, 1993. 11

[DRV10] W. De Roover e J. Vanthienen. Unified patterns to transform business rules into an event coordination mechanism. Em Proceedings of the 4th International Workshop on Event-Driven Business Process Management (edBPM'10), páginas 61-73, 2010. 12, 83

[DTC06] M. De Tommasi e A. Corallo. Sbeaver: a tool for modeling business vocabularies and business rules. Em Knowledge-Based Intelligent Information and Engineering Systems, páginas 1083-1091. Springer, 2006. 12

[EFGK03] P.T. Eugster, P.A. Felber, R. Guerraoui e A.M. Kermarrec. The many faces of publish/subscribe. ACM Computing Surveys (CSUR), 35(2):114-131, 2003. 75

[Erl08] Thomas Erl. Soa: principles of service design, volume 1. Prentice Hall Upper Saddle River, 2008. 73

$\left[\mathrm{FH}^{+} 05\right]$ E. Friedman-Hill et al. Jess, the rule engine for the java platform. Sandia National Laboratories, 2005. 21, 48

[For82] C.L. Forgy. Rete: A fast algorithm for the many pattern/many object pattern match problem* 1. Artificial intelligence, 19(1):17-37, 1982. 29, 48

[FUR02] R. FURUYA. How appearance of the'information technology'in new generation affects to enterprise information systems!? 99. under slackening in growth on it market, hp inc. intends to survive by takeover of compack inc. Comput Rep, 42(8):52-58, 2002. 2

[FW04] D.C. Fallside e P. Walmsley. Xml schema part 0: primer second edition. W3C recommendation, 2004. 22

[GHM06] S. Graham, D. Hull e B. Murray. Web services base notification 1.3. OASIS Standard. October, 2006. 75

[GHV07] S. Goedertier, R. Haesen e J. Vanthienen. Em-bra2ce v0. 1: A vocabulary and execution model for declarative business process modeling. FETEW Research Report KBI, 728, 2007. 12

[Gir00] R. Girle. Modal logics and Philosophy. McGill-Queen's University Press, 2000. 44 
[GR87] J.H. Gallier e S. Raatz. Hornlog: A graph-based interpreter for general horn clauses. The Journal of Logic Programming, 4(2):119-155, 1987. 22

[HH00] D. Hay e K.A. Healy. Defining business rules-what are they really. Final Report, 2000. 1, 16, 19

[HKMS94] Holger Herbst, Gerhard Knolmayer, Thomas Myrach e Markus Schlesinger. The specification of business rules: A comparison of selected methodologies. Em Methods and associated tools for the information systems life cycle, páginas 29-46. Citeseer, 1994. 20

$\left[\mathrm{HWJ}^{+} 05\right]$ Marty Humphrey, Glenn Wasson, Keith Jackson, Joshua Boverhof, Matt Rodriguez, Jarek Gawor, Joe Bester, Sam Lang, Ian Foster, Sam Meder et al. State and events for web services: a comparison of five ws-resource framework and ws-notification implementations. Em High Performance Distributed Computing, 2005. HPDC-14. Proceedings. 14 th IEEE International Symposium on, páginas 3-13. IEEE, 2005. 77

$\left[\mathrm{JEA}^{+} 07\right]$ D. Jordan, J. Evdemon, A. Alves, A. Arkin, S. Askary, C. Barreto, B. Bloch, F. Curbera, M. Ford, Y. Goland et al. Web services business process execution language version 2.0. OASIS Standard, 11, 2007. 12

[JJ13] Philip C Jackson Jr. Introduction to artificial intelligence. DoverPublications. com, 2013. 29

[JRu05] ILOG JRules. Leading the way in business rule management systems. ILOG, Mar, 2005. 76

[KB03] T. Koppelaars e C. Boekhuis. Business rules: Theory \& implementation. 2003. 16

[KHS94] G. Knolmayer, H. Herbst e M. Schlesinger. Enforcing business rules by the application of trigger concepts. Em Proceedings Priority Programme Informatics Research, Information Conference Module, volume 1, páginas 24-30, 1994. 26

[Kif08] M. Kifer. Rule interchange format: The framework. Web Reasoning and Rule Systems, páginas 1-11, 2008. 21

[KWB03] A.G. Kleppe, J. Warmer e W. Bast. MDA explained: the model driven architecture: practice and promise. Addison-Wesley Longman Publishing Co., Inc., 2003. 24, 36

[Lar04] M. Lara. Linguagem documentária e terminologia. Transinformação, 16(3), 2004. 8

[LP04] M. Levy e P. Powell. Strategies for growth in SMEs: The role of information and information systems. Butterworth-Heinemann, 2004. 1, 2

[LRP06] S. Lovrenčić, K. Rabuzin e R. Picek. Formal modelling of business rules: what kind of tool to use? Journal of Information and Organizational Sciences, 30(2), 2006. 20

$\left[\mathrm{M}^{+} 06\right]$ C.M. MacKenzie et al. Reference model for service oriented architecture. Public Review Draft 2, 2006. 73, 74 
[Mah05] Qusay H Mahmoud. Getting started with the java rule engine api (jsr 94): Toward rule-based applications. SUN Developer Network (SDN), 2005. 28, 76

[Mil99] R. Milner. Communicating and mobile systems: the [symbol for pi]-calculus. Cambridge Univ Pr, 1999. 11, 53

[Mor02] T. Morgan. Business rules and information systems: aligning IT with business goals. Addison-Wesley Professional, 2002. 17, 20

$\left[\mathrm{N}^{+} 10\right]$ OMG Number et al. Business motivation model. Business, (May), 2010. 2

[NRD06] C. Nagl, F. Rosenberg e S. Dustdar. Vidre-a distributed service-oriented business rule engine based on ruleml. 2006. 21, 77

[PC08] R. Pau e J. Cabot. Paraphrasing ocl expressions with sbvr. Natural Language and Information Systems, páginas 311-316, 2008. 49

[PCR09] R. Pau, J. Cabot e R. Raventós. Umltosbvr: An sbvr-based tool to validate uml conceptual schemas. Revista de Informática Teórica e Aplicada, 16(2):105108, 2009. 49

[Pla02] David S Platt. Introducing Microsoft. Net. Microsoft Press, 2002. 77

[PNLF08] M. Proctor, M. Neale, P. Lin e M. Frandsen. Drools documentation. JBoss, 5(05):2008, 2008. 29

[RD05] F. Rosenberg e S. Dustdar. Business rules integration in bpel-a serviceoriented approach. Em E-Commerce Technology, 2005. CEC 2005. Seventh IEEE International Conference on, páginas 476-479. IEEE, 2005. 11, 83

[Ros03a] RG Ross. The business rules manifesto. Business Rules Group. Version, 2, 2003. 16

[Ros03b] R.G. Ross. Principles of the business rule approach. Addison-Wesley Professional, 2003. 5, 16

$\left[\mathrm{S}^{+} 00\right]$ R. Soley et al. Model driven architecture. OMG white paper, 308:308, 2000. 36

[SE96] Harry M. Sneed e Katalin Erdos. Extracting business rules from source code. Em Proceedings of the 4th International Workshop on Program Comprehension (WPC '96), páginas 240-, Washington, DC, USA, 1996. IEEE Computer Society. 20

[SMAdAB03] I. Sommerville, S.S.S. Melnikoff, R. Arakaki e E. de Andrade Barbosa. Engenharia de software. Pearson Addison-Wesley, 2003. 73

[Smu95] R.M. Smullyan. First-order logic. Dover Publications, 1995. 22

[Tea06] S. Team. Semantics of business vocabulary and rules (sbvr). Relatório técnico, Technical Report dtc/06-03-02, 2006. xi, 7, 9, 12, 19, 24, 37, 39, 41, 50, 51, $56,59,65$ 
[TNCK91] A.K. Tanaka, S.B. Navathe, S. Chakravarthy e K. Karlapalem. Er-r: An enhanced er model with situation-action rules to capture application semantics. Em Proceedings of the 10th International Conference on the Entity Relationship Approach, E/R Institute, San Mateo, páginas 59-75, 1991. 20

[VDKV00] A. Van Deursen, P. Klint e J. Visser. Domain-specific languages: An annotated bibliography. ACM Sigplan Notices, 35(6):26-36, 2000. 32

[VHR02] B. Von Halle e R.G. Ross. Business rules applied: business better systems using the business rules approach. J. Wiley, 2002. 4, 25

[Wal91] R. Wallsgrove. The inexpert history of expert systems. Critical Public Health, 2(3):37-41, 1991. 19

[Whi04] S.A. White. Introduction to bpmn. IBM Cooperation, páginas 2008-029, 2004. 13

[WKL04] W.M.N. Wan-Kadir e P. Loucopoulos. Relating evolving business rules to software design. Journal of Systems architecture, 50(7):367-382, 2004. 4

[WvdHH08] H. Weigand, W.J. van den Heuvel e M. Hiel. Rule-based service composition and service-oriented business rule management. Em Proceedings of the International Workshop on Regulations Modelling and Deployment (ReMoD'08), páginas 1-12. Citeseer, 2008. 11 